
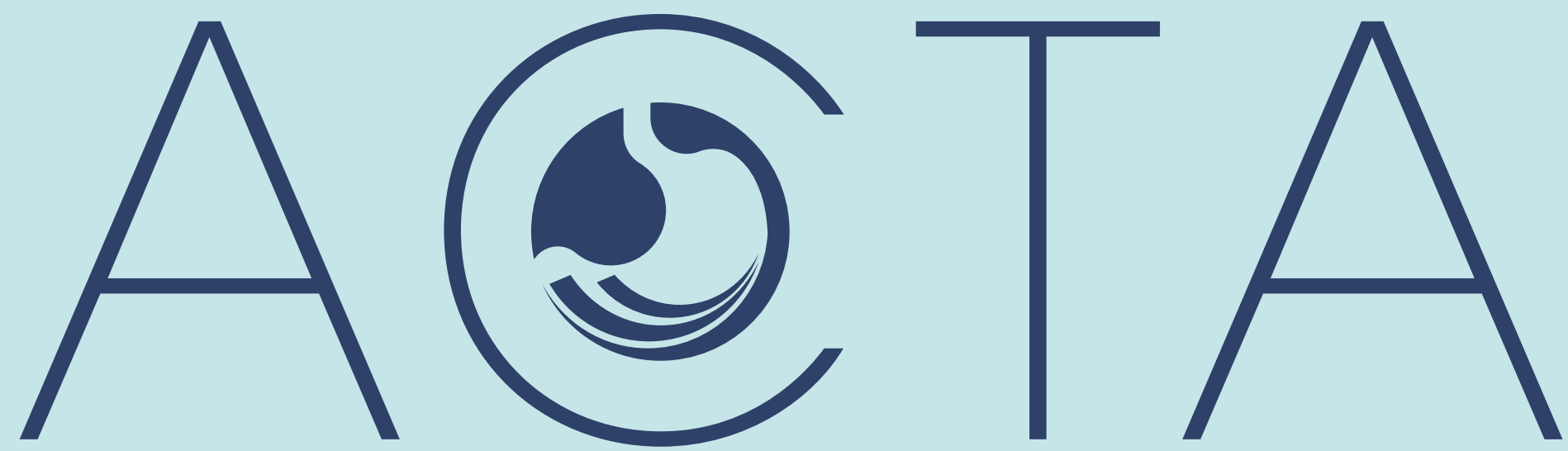

Vol 50 Supl. N² año 2020

ISSN: 2469-1119

SUPLEMENTO

\title{
Recomendaciones para el diagnóstico y tratamiento del Adenocarcinoma Ductal de Páncreas
}

\section{Club del Páncreas de la República Argentina}

\author{
Directores: Gustavo Kohan, Mariano Moro \\ Coordinadores por Especialidad \\ Gastroenterología: Dra. Analía Pasqua \\ Diagnóstico por imágenes: Dr. Mariano Volpacchio \\ Endoscopía: Dr. Federico Marcaccio \\ Anatomía patológica: Dra. Mirta Kujaruk \\ Oncología: Dra. Marcela Carballido \\ Cirugía: Dr. Oscar María Mazza \\ Nutrición: Lic. Marisa Canicoba
}

Participantes

Analía Pasqua, Mariano Moro, Lisandro Alle, Sandra Basso, Marisa Canicoba, Pablo Capitanich, Marcela Carballido, Federico Cayol, Javier Crisci, Diego Fernández, 10 Lucas Granero, Silvia Gutiérrez, Eduardo Javier Houghton, Hui Jer Hwang, Zohar Jastreblansky, Mirta Kujaruk, Tomás Lancelotti, Federico Marcaccio, José Mella, Eduardo Mullen, Nicolás Muñoz, Jorge Nefa, Luciana Olivero, Elisa Panelli, Sebastián

Piaggio, Juan Carlos Spina, Graciela Uranga, Lucio Uranga, María Laura Vergara, Anabel Villagra, Mariano Volpacchio, Natalia 


\section{A(c)TA

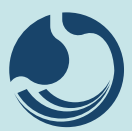

Órgano oficial
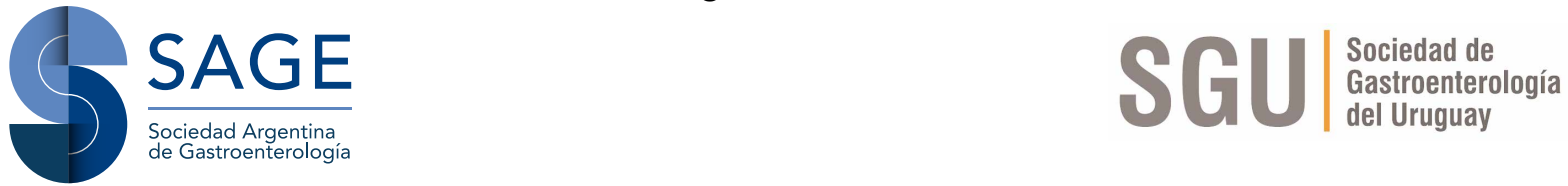

Gastroenterología

del Uruguay

Edita: Sociedad Argentina de Gastroenterología, Ciudad Autónoma de Buenos Aires. Argentina.

ISSN 2469-1119

\section{EDITOR EN JEFE}

\section{Jorge A. Olmos}

Hospital de Clínicas General San Martín, Universidad de Buenos Aires, CABA.

\section{COMITÉ EDITORIAL}

Julieta Argüero

Hospital Italiano de Buenos Aires. CABA.

\section{María Marta Piskorz}

Hospital de Clínicas General San Martín, Universidad de Buenos Aires, CABA.

Juan Pablo Stefanolo

Hospital de Gastroenterología

Dr. Carlos Bonorino Udaondo, CABA.

\section{SECCIÓN HUMANIDADES}

Coordinador: Carlos Guido Musso

\section{SECCIÓN EVIDENCIAS}

Coordinador: Rodolfo Pizarro

\section{SECCIÓN PASE DE GUARDIA}

Coordinadora: María Cecilia Carraro

\section{REVISOR IMÁGENES DEL NÚMERO}

Manuel Alejandro Mahler Spinelli

\section{SECRETARIA}

Mariela García Muñoz

PRODUCCIÓN Y EDICIÓN

Raúl Groizard

\section{DISEÑO Y ARMADO DIGITAL}

Alejandro Javier Sfich

\section{CORRECTOR}

María Nochteff Avendaño

\section{PUblicidad}

Establecer contacto con: Secretaría Revista Acta: actasage@gmail.com o Sociedad Argentina de Gastroenterología: sagesecretaria@gmail.com Tel.: 4816-9396/9391

\section{REVISORES NACIONALES}

\section{Ana Adet}

Valentina Araya

Fernando Barreyro

Sandra Basso

Maricel Bellicoso

Claudia Bestani

Román Bigliardi

Jorge Bosh

Maximiliano Bun

Fernando Cairo

Federico Cassella

Juan Pablo Campana

María Cristina Cañero Velasco

Marcela Carballido

Cecilia Carraro

Mariano Cartier

Karina Collia

Luis Colombato

Mónica Contreras

Florencia Costa

Andrea Curia

Cecilia Curvale

Jorge Daruich

Juan Andrés De Paula

Judith Doweck

Lucila Facio

José L. Fernández

Andrea González

Nicolás González

Ramiro González Sueyro
Estanislao Gómez

Verónica Gorodner Ubaldo Gualdrini

Martín Guidi

Silvia Gutiérrez

Mauricio Guzmán

Hui Jer Hwang

Nadia Kujta

Matías Lafage

Juan Lasa

Oscar Laudanno

Mariano Loureiro

Carlos Miguel Lumi

Mercedes Manresa

Eduardo Mauriño

Ezequiel Matías Mauro

Dolores Matoso

Lucas McCormack

Guillermo Mendez

Daniela Milito

Alejandro Moreira

María Laura Moreno

Fabio Nachman

Adrián Narvaez

Alejandro Nieponice

Juan Manuel O'connor

Juan Ignacio Olmos

Agostina Pascual Russo

Analía Verónica Pasqua

Margarita Ramonet

\section{Ana Rocca}

Andrés Ruf

Judith Cohen Sabban

José María Sanguinetti

Fran Schlottmann

Alberto Seehaus

Edgardo Smecuol

Luis Soifer

Laura Sole

Silvia Susana Soler

Eduardo Sosa

Juan Spina

Leandro Steinberg

Hugo Tanno

Pablo Tirado

María del Carmen Toca

Lucio Uranga

Carlos Vaccaro

María Inés Vaccaro

Amanda Varela

Mariano Villaroel

Mariano Volpacchio

Marta Wagener

Daniel Wainstein

Florencia Yamasato

David Zagalsky

Hugo Zandalazini

\section{REVISORES INTERNACIONALES}

Herbert Burgos

Henry Cohen

Angel Lanas

Xavier Llor

Natalie Nabon

\section{Carolina Olano}

Julio Carlos Pereira Lima Mario Reis Alvares da Silva

José M. Remes-Troche

Carlos Robles Medrana
Roque Saenz

Asadur Jorge Tchekmedyian Marcelo Vela

Elena Verdú 


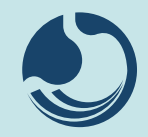

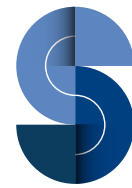

\section{COMISIÓN DIRECTIVA \\ SAGE - PERÍODO 2020}

\section{PRESIDENTE}

Edgardo Smecuol

VICEPRESIDENTE

Fabio Nachman

\section{SECRETARIO}

Juan Manuel Romeo

\section{PROSECRETARIA}

María Dolores Matoso

TESORERA

Claudia Fuxman

PROTESORERA

Maricel Bellicoso

VOCALES TITULARES

Ramiro Calcagno

Federico Cassella

Juan Pablo Stefanolo

\section{VOCALES SUPLENTES}

María Eugenia Oregui

Josefina Etchevers

Claudia Bestani

\section{CONSULTOR EX-PRESIDENTE}

Jorge Olmos

\section{SGU Joserastis Gastroenterología del Uruguay}

COMISIÓN DIRECTIVA SGU - PERÍODO 2019 - 2020

\section{PRESIDENTE}

Susana Kohen

$1^{\text {er VICEPRESIDENTE }}$

Adriana Raggio

2 $^{\text {er VICEPRESIDENTE }}$

Andrés Taullard

\section{SECRETARIA}

Viviana Nachmann

TESORERO

Inés María Trucco

SECRETARIA DE ACTAS

Yéssica Pontet

ENCARGADO DE ASUNTOS INTERNACIONALES

Carolina Olano

ENCARGADO DE PROGRAMACIÓN NACIONAL

Virginia López

\section{VOCALES}

Claudia Méndez

Ximena Rodríguez

Suplentes preferenciales

María Di Pace

Juan José Arnejo

Pabla Ortega

\section{COMISIÓN FISCAL}

Miembros titulares

Cristina Dacoll

Beatriz Iade

Elena Trucco

Suplentes

Andrea Maucione

Patricia Gaggero

Ana Pose 


\title{
Recomendaciones para el diagnóstico y tratamiento del Adenocarcinoma Ductal de Páncreas
}

\section{Club del Páncreas de la República Argentina}

\author{
Directores: Gustavo Kohan, ${ }^{34}$ Mariano Moro ${ }^{2}$
}

\section{Coordinadores por Especialidad}

Gastroenterología: Dra. Analía Pasqua ${ }^{1}$

Diagnóstico por imágenes: Dr. Mariano Volpacchio ${ }^{31}$

Endoscopía: Dr. Federico Marcaccio ${ }^{18}$

Anatomía patológica: Dra. Mirta Kujaruk ${ }^{16}$

Oncología: Dra. Marcela Carballido

Cirugía: Dr. Oscar María Mazza ${ }^{33}$

Nutrición: Lic. Marisa Canicoba ${ }^{5}$

\section{Participantes}

Analía Pasqua, ${ }^{1}$ Mariano Moro, ${ }^{2}$ Lisandro Alle, ${ }^{3}$ Sandra Basso, ${ }^{4}$ Marisa Canicoba, ${ }^{5}$ Pablo Capitanich,${ }^{6}$ Marcela Carballido, ${ }^{7}$ Federico Cayol, ${ }^{8}$ Javier Crisci, ${ }^{9}$ Diego Fernández, ${ }^{10}$ Lucas Granero, ${ }^{11}$ Silvia Gutiérrez, ${ }^{12}$ Eduardo Javier Houghton, ${ }^{13}$ Hui Jer Hwang, ${ }^{14}$ Zohar Jastreblansky, ${ }^{15}$ Mirta Kujaruk, ${ }^{16}$ Tomás Lancelotti, ${ }^{17}$ Federico Marcaccio, ${ }^{18}$ José Mella, ${ }^{19}$ Eduardo Mullen, ${ }^{20}$ Nicolás Muñoz, ${ }^{21}$ Jorge Nefa, ${ }^{22}$ Luciana Olivero, ${ }^{23}$ Elisa Panelli, ${ }^{24}$ Sebastián Piaggio, ${ }^{25}$ Juan Carlos Spina, ${ }^{26}$ Graciela Uranga,${ }^{27}$ Lucio Uranga, ${ }^{28}$ María Laura Vergara, ${ }^{29}$ Anabel Villagra, ${ }^{30}$ Mariano Volpacchio, ${ }^{31}$ Natalia Zavaroni, ${ }^{32}$ Oscar María Mazza, ${ }^{33}$ Gustavo Kohan ${ }^{34}$

\footnotetext{
${ }^{1}$ Gastroenterología. Hospital Italiano de Buenos Aires y CEMIC.

${ }^{2}$ Cirugia. Hospital Italiano de Bahía Blanca.

${ }^{3}$ Cirugía. Hospital de Clinicas José de San Martín.

${ }^{4}$ Gastroenterología. Hospital Dr. Bonorino Udaondo.

${ }^{5}$ Nutrición. Hospital Nacional Profesor Alejandro Posadas.

${ }^{6}$ Cirugía. Hospital Alemán de Buenos Aires.

${ }^{7}$ Oncología. Hospital Dr. Bonorino Udaondo.

${ }^{8}$ Oncología. Hospital Italiano de Buenos Aires.

${ }^{9}$ Cirugía. Sanatorio Parque de Rosario.

${ }^{10}$ Cirugía. Clinica Pueyrredón de Mar del Plata.

${ }^{11}$ Cirugía. Hospital San Roque y Sanatorio Allende de Córdoba.

${ }^{12}$ Gastroenterología. Hospital Británico de Buenos Aires.

${ }^{13}$ Cirugia Mini-invasiva. Hospital Bernardino Rivadavia y Fundación DAICIM.

${ }^{14}$ Endoscopia. Hospital de Alta Complejidad El Cruce y Fundación Favaloro.

${ }^{15}$ Nutrición. Policlínico Bancario.

${ }^{16}$ Anatomía Patológica. Hospital Dr. Bonorino Udaondo.

${ }^{17}$ Cirugía. CEMIC.

${ }^{18}$ Endoscopia. Sanatorio Las Lomas.
} 
${ }^{19}$ Endoscopía. Hospital Alemán y Hospital Británico de Buenos Aires.

${ }^{20}$ Anatomía Patológica. Hospital Italiano de Buenos Aires.

${ }^{21}$ Diagnóstico por Imágenes. Centro INOVA de Bahía Blanca.

${ }^{22}$ Cirugía. Hospital Italiano de Mendoza.

${ }^{23}$ Nutrición. Hospital Dr. Bonorino Udaondo.

${ }^{24}$ Anatomía Patológica. Hospital Dr. José Penna y Laboratorio Maturi de Bahía Blanca.

${ }^{25}$ Radioterapia. Instituto CREO de Bahía Blanca.

${ }^{26}$ Diagnóstico por Imágenes. Hospital Italiano de Buenos Aires.

27 Oncología. Sanatorio Parque de Rosario.

${ }^{28}$ Cirugía. Hospital Dr. Bonorino Udaondo.

${ }^{29}$ Nutrición. Hospital Italiano de Buenos Aires.

${ }^{30}$ Nutrición. Hospital de Alta Complejidad El Cruce.

${ }^{31}$ Diagnóstico por Imágenes. Hospital de Clinicas y Centro Dr. Rossi.

${ }^{32}$ Nutrición. Hospital Español de Mendoza.

${ }^{33}$ Cirugía. Hospital Italiano de Buenos Aires.

${ }^{34}$ Cirugía. Sanatorio Mitre y Hospital Dr. Cosme Argerich.

\section{Acta Gastroenterol Latinoam 2020;50:1-43}

\section{Puntos claves}

- El Adenocarcinoma Ductal de Páncreas (ADCP) es una de las neoplasias malignas más letales; el 80-85\% de los pacientes presenta una enfermedad avanzada al momento del diagnóstico y la tasa de sobrevida a 5 años es del $9 \%$.

- Si bien no está recomendado realizar pesquisa de cáncer de páncreas en la población general, es mandatorio identificar a los individuos con predisposición heredada y/o factores de riesgo tóxicos y metabólicos.

- Las lesiones consideradas precursoras del ACDP son la Neoplasia Intraepitelial Pancreática (PanIN), la Neoplasia Mucinosa Papilar Intraductal (IPMN) y la Neoplasia Quística Mucinosa (NQM), cuyo manejo apropiado es fundamental.

- Para la estadificación del ACDP, la interpretación sistemática y ordenada de las imágenes es clave $y$ el informe debe incluir en forma mandatoria una serie de ítems, teniendo en cuenta que las imágenes son uno de los pilares en los que se basarán las decisiones terapéuticas.

- La ecoendoscopía es una herramienta útil para el diagnóstico, la estadificación y el manejo de algunos síntomas o complicaciones del ACDP.

- El estudio citológico y de la pieza quirúrgica deben seguir estrictos protocolos para ga- rantizar diagnósticos confiables. De la misma forma, la nomenclatura de los informes citológicos y anatomo-patológicos debe ser estandarizada para asegurar interpretaciones homogéneas y universales.

- La resecabilidad del ACDP se define teniendo en cuenta la combinación de tres factores: las características locales del tumor con respecto al contacto con las estructuras vasculares, factores biológicos evaluados por biomarcadores como el CA 19-9 y el performance status del paciente.

- El cambio de paradigma terapéutico en curso se relaciona con los aportes de la genómica y la medicina traslacional así como con el rol de la neoadyuvancia para determinados estadios de la enfermedad.

- La pérdida de peso es frecuente y multifactorial, y el síndrome anorexia-caquexia y la insuficiencia pancreática exocrina deben ser considerados. El diagnóstico nutricional y su manejo deben realizarse en todos los casos desde el momento de la sospecha diagnóstica y en todos los estadios de la enfermedad.

- El manejo del paciente con ACDP debe ser personalizado, individualizando las conductas y desde una mirada multidisciplinaria en todos los casos. 


\section{Índice}

1. Fundamentos y objetivo del Consenso $\quad 5$

2. Manifestaciones clínicas y factores de riesgo 6

$\begin{array}{lr}\text { 3. Pesquisa } & 8\end{array}$

4. Diagnóstico y estadificación 99

4.1 Laboratorio.

4.2 Rol de las imágenes en el diagnóstico y la estadificación.

4.3 Rol de la ecoendoscopía en el diagnóstico y la estadificación. 11

4.4 Diagnóstico citopatológico. $\quad 12$

5. Consideraciones terapéuticas 13

5.1 Tumor potencialmente resecable.

5.2 Tumor borderline. $\quad 16$

$\begin{array}{llr}5.3 & \text { Tumor irresecable localmente avanzado. } & 17\end{array}$

$\begin{array}{ll}5.4 & \text { Tumor metastásico. }\end{array}$

6. Rol de la cirugía y estándares quirúrgicos 19

7. Estudio de la pieza quirúrgica e informe histopatológico 21

8. Manejo endoscópico de las complicaciones 23

8.1 Tratamiento del dolor.

8.2 Manejo endoscópico de la obstrucción gastroduodenal.

8.3 Manejo endoscópico de la obstrucción biliar. $\quad 24$

9. Rol del drenaje biliar percutáneo $\quad 24$

10. Seguimiento 26

11. Aspectos nutricionales 26

11.1 Evaluación y requerimientos nutricionales.

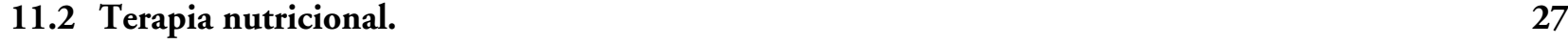

$\begin{array}{ll}11.3 & \text { Insuficiencia pancreática exocrina. } \\ \end{array}$

$\begin{array}{ll}\text { Referencias } & 32\end{array}$

$\begin{array}{lr}\text { Anexo A y B } & 41\end{array}$

$\begin{array}{lr}\text { Anexo C y D } & 42\end{array}$

\begin{tabular}{lr} 
Anexo E & 43 \\
\hline
\end{tabular}

\section{Fundamentos y objetivo del Consenso}

El Adenocarcinoma Ductal de Páncreas (ACDP) es una de las neoplasias malignas más letales, causa de 432.242 muertes en $2018 . .^{1-3}$ El 80-85\% de los pacientes presenta una enfermedad avanzada al momento del diagnóstico. La tasa de sobrevida a 5 años es del 9\%, a pesar de algunos avances en la detección "temprana" y en el cambio de paradigma terapéutico en curso que considera que se trata de una enfermedad sistémica, genéticamente compleja, con un comportamiento biológico extremadamente particular, distintas variantes histológicas y un estroma que tiene un rol activo en la diseminación de la enfermedad y en la respuesta al tratamiento.

Numerosas y diferentes líneas de investigación dirigidas a la prevención, diagnóstico y medicina de precisión para esta patología están en constante desarrollo. 
De acuerdo con lo pronosticado, tanto la incidencia como la mortalidad del ACDP aumentarán durante la próxima década y será la segunda causa de muerte por cáncer en el año 2030, superada únicamente por el cáncer broncopulmonar. ${ }^{3}$ Las causas del aumento de la incidencia son motivo de estudio y debate y podría explicarse, al menos parcialmente, por el aumento de la prevalencia de algunos de los factores de riesgo como la obesidad, la diabetes y el consumo de tabaco en algunas regiones del mundo, especialmente en mujeres, entre otros motivos. ${ }^{4}$

El manejo de estos pacientes por equipos multidisciplinarios en centros de alto volumen de casos favorece una evaluación rápida y precisa y la planificación de una estrategia diagnóstica y terapéutica adecuada para cada individuo.

El presente documento está dirigido a clínicos, gastroenterólogos, endoscopistas digestivos, especialistas en diagnóstico por imágenes, cirujanos, oncólogos, anatomopatólogos, nutricionistas, endocrinólogos, especialistas en cuidados paliativos y en salud mental y a todo el personal involucrado en la atención de los pacientes con cáncer de páncreas.

Estas recomendaciones consensuadas surgen del análisis de la evidencia y de la experiencia derivada de la práctica de los autores y el objetivo es ofrecer una herramienta que facilite la identificación de individuos en riesgo y las oportunidades de prevención, el diagnóstico temprano y las decisiones terapéuticas más apropiadas.

\section{Manifestaciones clínicas y factores de riesgo - ¿Cuáles son los signos y síntomas de presentación} del ACDP?

Las manifestaciones clínicas incluyen numerosos y variables signos y síntomas, en ocasiones inespecíficos. ${ }^{5-7}$ La mayoría de estas manifestaciones depende de la localización y de la extensión de la enfermedad. Los pacientes con tumores localizados en el área cefálica (70-80\%) suelen presentar síntomas más tempranamente que aquellos con tumores corporocaudales. No es infrecuente que los pacientes permanezcan asintomáticos y se presenten con una enfermedad en estadio avanzado. Existe un grupo de individuos cuyo diagnóstico surge del estudio de lesiones focales detectadas incidentalmente en estudios por imágenes cuyas indicaciones no estaban relacionadas con la evaluación pancreática.

\section{Manifestaciones clínicas: \\ Astenia (86\%) \\ Pérdida de peso involuntaria $(85 \%)$ \\ Anorexia (83\%)}

\author{
Dolor abdominal (79\%) \\ Dolor epigástrico (71\%) \\ Coluria $(59 \%)$ \\ Ictericia $(56 \%)$ \\ Náuseas (51\%) \\ Dorsalgia (49\%) \\ Diarrea $(44 \%)$
}

Otras manifestaciones son hepatomegalia (39\%), vómitos (33\%), esteatorrea (25\%), masa palpable en cuadrante superior derecho (15\%), caquexia (13\%), signo de Courvoisier (13\%), masa palpable epigástrica ( $\% \%)$, ascitis (5\%) y trombosis (3\%).

Es importante destacar que se recomienda considerar el diagnóstico de ACDP en una serie de situaciones clínicas que incluyen:

- Pancreatitis aguda o recurrente de causa no definida. Ha sido reportado el diagnóstico de cáncer hasta dos años después de un evento de pancreatitis aguda de etiología no definida. ${ }^{8,9}$ Se sugiere considerar esta posibilidad especialmente en pacientes de 40 años o mayores e investigar exhaustivamente la causa de su pancreatitis.

- Diabetes de reciente comienzo, especialmente en pacientes sin otras condiciones relacionadas con el síndrome metabólico (obesidad, hipertrigliceridemia, esteatosis hepática, etc.) o diabetes conocida en un paciente que modificó su patrón de respuesta al tratamiento.

- Enfermedad tromboembólica, especialmente en pacientes $\sin$ otros factores de riesgo. ${ }^{10,11}$

- Síndrome depresivo de reciente presentación. ${ }^{12,13}$

Otras manifestaciones menos frecuentes son los fenómenos paraneoplásicos cutáneos, como el penfigoide cicatrizal o bulloso y la paniculitis pancreática, la cual también puede observarse en carcinomas acinares, neoplasias mucinosas papilares intraductales, tumores neuroendocrinos y pancreatitis.

\section{- ¿Cuáles son los factores de riesgo tóxico-metabó- licos para el ACDP?}

¿Cuáles son los factores modificables?

Los factores de riesgo tóxico-metabólicos incluyen el consumo de tabaco, alcohol, la obesidad y la diabetes.

El tabaquismo es el factor ambiental independiente más importante para el ACDP en el mundo. ${ }^{14,15} \mathrm{De}$ acuerdo con algunos estudios, el riesgo aumenta con la duración del hábito y con la cantidad de cigarrillos diarios. ${ }^{16} \mathrm{El}$ riesgo es casi dos veces mayor en fumadores en comparación con los no fumadores. De acuerdo con los resultados de un metaanálisis de 82 estudios, el riesgo re- 
lativo es 1,74 (95\% IC 1,61-1,87) para los fumadores y 1,2 (95\% IC 1,11-1,29) para los exfumadores, y el riesgo puede persistir por, al menos, 10 años después del cese del hábito. Es importante señalar que el tabaquismo pasivo puede aumentar el riesgo de cáncer de páncreas. ${ }^{17}$

El consumo de alcohol mayor de 60 gramos/día también es considerado factor de riesgo (consultar cálculo del consumo de alcohol en Anexo A).

La obesidad se reconoce como un estado proinflamatorio sistémico asociado al aumento del riesgo de presentar tumores en múltiples órganos, incluido el páncreas. ${ }^{18}$

La relación entre la diabetes y el ACDP es compleja; la diabetes puede ser un factor de riesgo para el cáncer de páncreas y también puede ser una manifestación temprana de este. ${ }^{19,20}$

Existe evidencia creciente de que el ACDP frecuentemente causa diabetes; aproximadamente el $85 \%$ de los pacientes con esta neoplasia presenta diabetes o hiperglucemia, que se manifiesta a menudo en el lapso de los 2-3 años previos a la detección del tumor. Los pacientes con diabetes de reciente diagnóstico tienen un aumento del riesgo de detección de un ACDP de 5-8 veces en el lapso de 1 a 3 años posteriores. La pesquisa de todos los pacientes con diabetes de reciente diagnóstico no es factible actualmente ya que aproximadamente solo el $1 \%$ de estos individuos mayores de 50 años presentará un ACDP en los siguientes 2-3 años. ${ }^{21}$ Sin embargo, cuando la diabetes se diagnostica en pacientes añosos o con bajo peso, debería considerarse esta posibilidad. La relación entre la diabetes y el ACDP continúa en estudio. ${ }^{18,22-24}$
Los factores relacionados con el estilo de vida, como el consumo de tabaco y de alcohol y los hábitos vinculados con la obesidad, son modificables y su cese debe ser fuertemente recomendado.

- ¿Es la pancreatitis crónica (PC) un factor de riesgo para el ACDP?

La PC de larga evolución es un factor de riesgo para presentar un ACDP. ${ }^{25} \mathrm{El} 1,8 \%$ de los pacientes con PC desarrollará el tumor dentro de los 10 años del diagnóstico y el $4 \%$ después de 20 años. ${ }^{17}$

Es fundamental el cese de los factores de susceptibilidad y de progresión, como el tabaquismo, en cualquier momento de la evolución.

Si bien no existe una recomendación para la pesquisa sistemática de ACDP en enfermos con PC, se sugiere atención a situaciones específicas como la reaparición de dolor pancreático o la pérdida de peso inexplicada en pacientes con PC. ${ }^{26}$

El riesgo de ACDP en la pancreatitis hereditaria (relacionada con mutaciones en el gen PRSS1) es especialmente elevado.

- ¿Cuáles son las entidades con predisposición heredada para presentar ACDP?

El 90\% de los ACDP es esporádico, mientras que el $10 \%$ restante se relaciona con condiciones con predisposición heredada para presentar esta neoplasia. ${ }^{27,28}$

En la Tabla 1 a continuación se detallan algunos de los síndromes genéticos caracterizados por presentar un aumento del riesgo para el desarrollo de ACDP además de neoplasias en otros órganos: ${ }^{29-36}$

Tabla 1.

Gen/Genes

STK11

CDKN2A

BRCA2

MLH1, MSH2, MSH6, PMS2, EPCAM

PALB2

APC

ATM

BRCA1
Síndrome

Peutz-Jeghers

Mola / Melanoma múltiple atípico familiar

Cáncer de mama / ovario hereditario

Lynch

$-$

Poliposis adenomatosa familiar

Ataxia / Telangiectasia

Cáncer de mama / ovario hereditario

Li Fraumeni
Riesgo de cáncer de páncreas (\%) 10-30 10-30 5-10 $5-10$ $5-10$ $1-5$ $1-5$ 2 No definido 
El Cáncer de Páncreas Familiar (Ca. Pa. Fa.) se define por la presencia de un par de familiares de primer grado con cáncer de páncreas (padre o madre e hijo / par de hermanos) sin reunir criterios para ninguno de los síndromes genéticos mencionados previamente. ${ }^{37}$ En el Ca. Pa. Fa. el riesgo de presentar cáncer de páncreas aumenta con la cantidad de familiares de primer grado afectados $(6,4$ veces cuando los familiares afectados son dos y 32 veces cuando son tres).

Las mutaciones del gen CFTR (relacionado con la fibrosis quística) y del gen PRSS1 (gen del tripsinógeno catiónico relacionado con la pancreatitis hereditaria) aumentan el riesgo de desarrollar cáncer de páncreas, especialmente en el caso del PRSS $1 .{ }^{38}$

- ¿En cuáles situaciones está recomendada la consulta con Genética Clínica?

Actualmente se recomienda en individuos con:

- $\geq 2$ familiares con cáncer de páncreas.

- Familiar con una mutación identificada.

- Sospecha de un síndrome específico (múltiples cánceres, particularmente diagnosticados a edades tempranas).

- Cáncer de páncreas.

\section{Pesquisa}

- ¿Cuál es el objetivo de la pesquisa de cáncer de páncreas?

Las lesiones consideradas precursoras del ACDP son la Neoplasia Intraepitelial Pancreática (PanIN) y las neoplasias quísticas mucinosas: Neoplasia Mucinosa Papilar Intraductal (IPMN) y la Neoplasia Quística Mucinosa (NQM). ${ }^{39}$ El objetivo es detectar lesiones precursoras con displasia de alto grado y tumores pequeños y resecables.

- ¿Está recomendada la pesquisa de cáncer de páncreas en la población general?

No está recomendado realizar pesquisa de cáncer de páncreas en la población general. ${ }^{29}$

\footnotetext{
- ¿A qué grupos de alto riesgo habría que realizarles pesquisa?

El Consorcio Internacional de Pesquisa de Cáncer de Páncreas ${ }^{40}$ definió, en 2013, los grupos de alto riesgo por predisposición heredada en los cuales estaría recomendada la pesquisa:

- Familiar de primer grado de paciente con Ca. Pa. Fa.

- Síndrome de Peutz-Jeghers.

- Síndrome de cáncer de mama-ovario hereditario (por-
}

tador de mutación del gen BRCA2) con familiares de primer o segundo grado con cáncer de páncreas.

- Síndrome de Melanoma Múltiple Atípico Familiar (portador de mutación del gen CDKN2A) con familiares de primer grado con cáncer de páncreas.

- Síndrome de Lynch (portador de mutación de los genes MLH1, MSH2, MSH6 o PMS2) con familiares de primer grado con cáncer de páncreas.

- Pancreatitis hereditaria.

\section{- ¿A qué edad debería comenzar la pesquisa?}

La edad a la que debería iniciarse la pesquisa no ha sido consensuada ampliamente.

Se recomienda:

- Síndrome de Peutz-Jeghers: a partir de 25 años.

- Pancreatitis hereditaria: a partir de 40 años.

- Los demás grupos: a partir de 50 años o 10 años antes del caso más joven de la familia. ${ }^{33}$

\section{- ¿Con cuál/es método/s debería realizarse la pes- quisa?}

Es muy importante la anamnesis orientada a obtener información sobre historia familiar de cáncer de páncreas y de otros órganos y sobre antecedentes personales de hábitos tóxicos o pancreatitis recurrente / crónica.

La Ecoendoscopía (USE) y la Resonancia Magnética (RM) abdominal con contraste endovenoso (EV) y Colangiopancreatoresonancia Magnética (CPRM) son los métodos recomendados para realizar la pesquisa de cáncer de páncreas. Ambos estudios son complementarios y se recomienda intercalarlos anualmente. ${ }^{40}$

La ecografía abdominal es poco sensible y la Tomografía Computada (TC) no se recomienda debido a la exposición a la radiación.

Los marcadores tumorales, Antígeno CA 19-9 y Antígeno Carcinoembrionario (CEA) no son sensibles ni específicos para ser utilizados en la pesquisa.

- ¿Cuál es la conducta recomendada ante el hallazgo de lesiones pancreáticas en el contexto de la pesquisa?

Ante el hallazgo de una lesión sólida o quística debe evaluarse la punción guiada por ecoendoscopía o seguimiento, según sus características.

En los estudios de pesquisa, una alta proporción de las lesiones halladas son benignas con bajo o sin potencial de malignización y debe evitarse el sobretratamiento.

La pancreatectomía profiláctica no está recomendada.

Sugerimos que el programa de pesquisa sea realizado en forma multidisciplinaria por especialistas experimentados en patología pancreática. 


\section{Diagnóstico y estadificación}

\subsection{Laboratorio}

- ¿Cuáles son los estudios de laboratorio recomendados inicialmente ante la sospecha de ACDP?

Hemograma.

Glucemia y hemoglobina glicosilada.

Urea y creatinina / Ionograma.

Hepatograma / Perfil lipídico / Coagulograma / Proteinograma.

Marcadores tumorales: CEA y CA 19-9.

Con respecto al CA 19-9, se sugiere tener presente la posibilidad de resultados falsos negativos en individuos con fenotipo de Lewis negativo (5 a 10\% de la población general) y falsos positivos en pacientes con colestasis, pancreatitis crónica, diabetes y otras entidades, por lo cual los resultados deben interpretarse cautelosamente junto con la clínica y las imágenes.

Es importante señalar que la determinación de amilasa y lipasa NO tiene utilidad en este escenario.

\subsection{Rol de las imágenes en el diagnóstico y la estadi- ficación}

- ¿Cuál es el método de imágenes de elección para evaluar a un paciente con sospecha clínica de cáncer de páncreas?*

El método de elección es la tomografía computada multicorte (TCMC) de abdomen y pelvis con contraste endovenoso $(\mathrm{EV})$ con protocolo dedicado al páncreas con triple fase: sin contraste $\mathrm{EV}$, fase poscontraste pancreática $(40 s)$ y fase poscontraste portal $(60-70 s) .{ }^{41}$ En caso de dudas, puede agregarse una fase tardía $(3 \mathrm{~min}$ ) para valorar el realce progresivo de la lesión en tumores con componente desmoplásico.

Se recomienda administración previa del contraste neutro por vía oral (agua).

Se debe utilizar tomógrafo computado multicorte con al menos 16 detectores.

Se recomienda utilizar contraste EV yodado no iónico. El empleo de bomba inyectora es mandatorio (flujo de inyección no menor a 2,5 ml/seg). En caso de efectuar reprocesos, estos deben ser menores de $2 \mathrm{~mm}$ de espesor en los planos axial y coronal. . $^{41,42}$

En caso de TCMC no concluyente o en pacientes con antecedentes de alergia al yodo, deterioro de la función renal u otra contraindicación, como por ejemplo embarazo, debe realizarse resonancia magnética (RM) con contraste $\mathrm{EV}$, adicionando en todos los casos colangiopancreatorresonancia (CPRM).

La RM de abdomen con CPRM tiene similar sensibi- lidad y especificidad que la TCMC para el diagnóstico. ${ }^{43}$, ${ }_{44}$ Debe realizarse en un equipo de alto campo $(1,5 \mathrm{~T}$ o 3T) empleando bobina de torso. Deben incluirse las siguientes secuencias: T1 en fase / fuera de fase o variantes de DIXON, T2 con y sin supresión grasa en planos axial y coronal, secuencia de difusión (DWI) y secuencia T1 GRE 3D volumétrica con contraste EV en 4 fases (sin contraste, pancreática, portal y tardía) como especificado en la sección de TC. ${ }^{41,44}$ Secuencia de CPRM 2D y 3D.

En cualquiera de los dos casos (TCMC o RM) se recomienda enfáticamente la realización de estudio diagnóstico inicial previo a la colocación de un stent biliar.

Por otro lado, es recomendable que el tiempo transcurrido entre la cirugía y el estudio de imágenes sea menor a 4 semanas.

* Incluye hallazgos clínicos o serológicos o estudios de imágenes que revelan alteraciones en páncreas, incluidos ecografía, TC sin contraste o cualquier evaluación previa no diagnóstica.

- ¿Cómo se realiza el diagnóstico de cáncer de páncreas por $\mathrm{TC}$ ?

El ACDP se presenta como una lesión focal o, con menos frecuencia, difusa de carácter hipovascular con márgenes mal definidos, que se pone más de manifiesto con menor densidad que el parénquima circundante durante la fase pancreática. ${ }^{41,44}$

Típicamente produce amputación abrupta del conducto pancreático y/o del colédoco con dilatación retrógrada de ambos. ${ }^{41}$ Es frecuente la atrofia parenquimatosa asociada en la glándula distal al tumor. Un porcentaje menor de adenocarcinomas de páncreas (aproximadamente $11 \%$ ) puede ser isodenso con respecto al resto del parénquima y, por lo tanto, difícil de discriminar. ${ }^{45}$ No obstante, suelen demostrar signos indirectos, como dilatación ductal. En estos casos se recomienda proseguir el estudio mediante RM.

- Ante un hallazgo equívoco o indeterminado o ante una TC normal en un paciente con alta sospecha clínica, ¿Qué estudio debería solicitarse en el algoritmo diagnóstico?

En caso de un hallazgo equívoco o indeterminado o ante una alta sospecha clínica con un estudio de TC inicial no diagnóstico, se recomienda solicitar RM de abdomen con contraste EV y CPRM. ${ }^{43}, 46$

Si el paciente tuviese una contraindicación para realizar RM o el resultado de la misma fue no concluyente, se sugiere completar con ecoendoscopía o PET TC con FDG (tomografía por emisión de positrones / tomografía computada con fluorodesoxiglucosa) y contraste EV. ${ }^{47,48}$ 


\section{- ¿Cómo se diagnostica el cáncer de páncreas por RM?}

En RM, el ACDP presenta un aspecto morfológico similar a la TC; habitualmente se trata de una lesión focal o menos frecuentemente difusa, con márgenes mal definidos que genera dilatación retrógrada del conducto pancreático con atrofia parenquimatosa asociada. ${ }^{43}, 44,46 \mathrm{En}$ secuencia $\mathrm{T} 1$ es típicamente hipointensa, y en secuencia T2 es variable pero suele ser levemente hiperintensa. En secuencia de DWI suele haber restricción, pero esto es variable. Luego de la administración del contraste EV se presenta como una lesión hipovascular en fases tempranas con realce tardío en aquellos tumores con mayor componente desmoplásico. ${ }^{44,46}$

\section{PET?}

- ¿Cómo se diagnostica el cáncer de páncreas por

En PET-TC con FDG la mayoría de los adenocarcinomas se manifiestan como áreas de hipermetabolismo focal. ${ }^{47-49}$ No obstante, algunos tumores pueden ser hipometabólicos con captación similar o menor al resto del parénquima pancreático. ${ }^{47,49}$ Los tumores pequeños (menores de $10 \mathrm{~mm}$ ) están por debajo del límite de resolución del PET. El componente TC del PET TC debe efectuarse con contraste EV para lograr un mejor rendimiento diagnóstico. ${ }^{47}$

- ¿Qué información debe incluirse en la estadificación?

La interpretación sistemática y ordenada es clave; ${ }^{50,51}$ puede realizarse mediante un informe estructurado o bien con texto libre a discreción del intérprete, pero debe incluir en forma mandatoria los siguientes ítems:

- Localización.

- Tamaño tumoral, medido en plano axial, eligiendo el eje mayor.

- Dilatación del conducto pancreático: SÍ / NO.

- Dilatación de la vía biliar: Sí / NO.

- Grado de contacto del tumor con los siguientes vasos: vena porta, vena mesentérica superior, tronco de las primeras ramas yeyunales, tronco celíaco, arteria hepática, arteria mesentérica superior, arteria gastroduodenal. .4, $52,53^{2}$

- Si el porcentaje de contacto es igual o menor a $180^{\circ}$ se denomina abutment.

- Si el porcentaje de contacto es mayor a $180^{\circ}$ se denomina encasement.

Deben incluirse otros hallazgos claves para reconocer compromiso vascular, como la alteración de la forma y la disminución de la luz por compresión u obstrucción por estenosis o trombosis.
- Alteración de la densidad de la grasa circundante a los vasos y con particular interés la del surco entre vena y arteria mesentérica superior: Sí / NO.

- Variantes vasculares de relevancia para el acto quirúrgico (arteria hepática originada de la arteria mesentérica superior).

- Adenomegalias: si bien el desempeño diagnóstico de los diferentes métodos (TC, RM y PET) para el compromiso ganglionar es limitado, debe mencionarse la presencia de ganglios sospechosos locorregionales y a distancia. ${ }^{47}$

- Metástasis: un exhaustivo análisis del resto de abdomen y pelvis con especial énfasis en el hígado y el peritoneo es fundamental para detectar o excluir lesiones secundarias.

\section{- ¿Cómo se determina la resecabilidad por imágenes?}

La resecabilidad por imágenes se determina en base al compromiso vascular local y por la presencia de enfermedad a distancia.

- ¿Cómo se determina que un tumor es borderline?

Se subdivide según el compromiso sea venoso o arterial. $42-44$

En caso de compromiso únicamente venoso (vena porta / vena mesentérica superior) debe existir encasement, afinamiento bilateral u oclusión de dichos vasos, pero sin que tal compromiso supere el borde inferior del duodeno.

En caso de compromiso arterial debe existir abutment sin estenosis ni deformación de la arteria mesentérica superior o del tronco celíaco. En caso de que el tumor tome contacto con la arteria hepática común, no debe existir contacto con el tronco celíaco ni con la arteria hepática propia.

- ¿Cómo se determina que un tumor es irresecable?

Un tumor es irresecable en caso de existir enfermedad metastásica a distancia, incluyendo la presencia de adenomegalias lateroaórticas o extraabdominales. ${ }^{44,46}$

En caso de existir solo compromiso local, se considera irresecable si existe estenosis / oclusión de la vena mesentérica superior por debajo del borde inferior del duodeno, encasement de la arteria mesentérica superior, tronco celíaco o arteria hepática propia. ${ }^{44}$

La presencia de contacto de tumor con la aorta es también criterio de irresecabilidad.

- ¿Cómo debe realizarse la estadificación a distancia en un paciente con diagnóstico de ACDP?

Debe realizarse estadificación del tórax mediante TC sin contraste. 
En caso de hallazgos inespecíficos o indeterminados a nivel hepático en la TC diagnóstica inicial, debe realizarse una RM de abdomen con contraste EV y difusión para una mejor caracterización de las lesiones hepáticas.

Dada la mayor sensibilidad y especificidad de la RM con con contraste EV y difusión para la detección y caracterización de pequeñas lesiones hepáticas, se recomienda su empleo de rutina en la estadificación inicial de un paciente pasible de tratamiento quirúrgico. ${ }^{47,54}$

Queda a criterio del grupo tratante la realización de un PET-TC para descartar metástasis ocultas a distancia.

\section{- ¿Cuál es el rol del PET en el diagnóstico y esta- dificación del ACDP?}

El empleo del PET en un paciente con diagnóstico de ACDP queda sujeto a criterio oncológico en situaciones particulares como: detección de foco hipermetabólico en paciente con sospecha de cáncer de páncreas, pero con TC no concluyente y contraindicación para $\mathrm{RM}$, tumores grandes, adenopatías regionales o lesión borderline potencialmente resecable sin evidencia de secundarismo, pero valores altos de CA19-9. En caso de realizarse PET/TC se recomienda el empleo de estudio con contraste EV en el componente TC del estudio.

Debe tenerse en cuenta que factores como colangitis o stents biliares pueden ser causa de captación de naturaleza inflamatoria dando lugar a potenciales falsos positivos. ${ }^{47,49}$

\subsection{Rol de la USE en el diagnóstico y estadificación \\ - ¿Cuál es el rol de la USE en el diagnóstico del cáncer de páncreas?}

La evidencia acumulada ha demostrado el impacto clínico de la USE tanto en el diagnóstico como en la estadificación del cáncer de páncreas..$^{55}$ La USE brinda una evaluación dinámica del páncreas, con imágenes de alta resolución, y permite obtener material para estudio citológico y en ocasiones histológico con una alta eficacia $(90 \%)$ y baja tasa de complicaciones $(1-2,5 \%),{ }^{56}$ colaborando también en el avance del tratamiento oncológico dirigido (genómico).

En 22 estudios que incluyeron 1170 pacientes, la USE tuvo una sensibilidad media de 94\%. La USE demostró ser más sensible que la TC de alta resolución para la detección de lesiones sólidas pancreáticas pequeñas (menores de $20 \mathrm{~mm}) .{ }^{57}$

\section{- ¿Cuáles son las herramientas complementarias de la USE?}

Existen herramientas complementarias a la USE con- vencional (elastografía y agentes de contraste) que mejoran la precisión diagnóstica (biopsia dirigida a una región de especial interés) y optimizan la caracterización de las lesiones sólidas pancreáticas. Sin embargo, estas tecnologías complementarias no reemplazan a la USE-punción aspirativa con aguja fina (PAAF), según la evidencia disponible en la actualidad para esta patología.

\section{- ¿Cuál es el rol de la USE en la estadificación del cáncer de páncreas?}

La sensibilidad y especificidad de la USE en la estadificación de invasión vascular en cáncer de páncreas varía de 42 a $91 \%$ y de 89 a $100 \%$, respectivamente, similar a la TC y la RM, y la combinación de estos métodos mejora la precisión diagnóstica. ${ }^{55,58}$ La USE es menos precisa que la TC y la RM en el diagnóstico de metástasis hepáticas, debido a la imposibilidad de evaluar en todos los casos algunos segmentos del lóbulo hepático derecho; sin embargo, es capaz de detectar y tomar muestras de metástasis pequeñas o ascitis que no son reconocidas por los otros métodos. ${ }^{59}$ La USE presenta la limitación de ser operador-dependiente (variabilidad interobservador) y de no estar disponible en todos los centros asistenciales. En síntesis, recomendamos la realización de USE ante la sospecha o evaluación de una lesión sólida pancreática.

\section{- ¿Cuáles son los estándares de la USE en las lesio- nes sólidas de páncreas?}

La USE debe evaluar las características de la lesión (tamaño, localización, ecogenicidad, bordes), compromiso vascular (vasos mesentéricos superiores, tronco celíaco, arteria hepática, confluencia espleno-mesentérica y vena porta), compromiso biliar, adenopatías loco-regionales, parénquima hepático, presencia de ascitis. La evaluación también debe incluir la caracterización del resto del parénquima pancreático.

\section{- ¿Cuáles son las indicaciones de realizar USE-PA- AF en lesiones sólidas de páncreas?}

La decisión de realizar USE-PAAF en lesiones sólidas de páncreas deberá basarse en si la información obtenida tendrá el potencial de cambiar el manejo del paciente. ${ }^{60}$

Los diagnósticos diferenciales principales en las lesiones sólidas del páncreas son: adenocarcinoma, linfoma, tumor neuroendocrino, tumor sólido pseudopapilar, pancreatitis autoinmune y pancreatitis focal. Además, existen tumores primarios que pueden ocasionar metástasis en el páncreas: carcinoma renal, melanoma, tumores estromales, así como los cánceres de mama, ovario, tiroides, pulmón, próstata y colon. 
Se ha estimado que alrededor del 10\% de los pacientes que son sometidos a resecciones pancreáticas por lesiones sólidas tienen un proceso benigno o una histología atípica distinta a adenocarcinoma. ${ }^{61-63} \mathrm{La}$ USE-PAAF es una herramienta útil para minimizar el número de cirugías pancreáticas innecesarias. ${ }^{64,65}$

Una biopsia diagnóstica ante la sospecha de una neoplasia sólida de páncreas estaría indicada en las siguientes situaciones: enfermedad diseminada, enfermedad localmente avanzada y borderline, pacientes no candidatos a cirugía y ante la necesidad de excluir diagnósticos alternativos.

En las lesiones no resecables y en las lesiones borderli$n e$ se recomienda realizar USE-PAAF para tener un diagnóstico definitivo que permita asistir en la decisión de la conducta más apropiada para cada paciente (decidir un esquema de paliación o de neoadyuvancia, respectivamente). ${ }^{66}$

En las lesiones resecables, la decisión de realizar USEPAAF es un tema controversial y está definido por si el resultado de la punción afectará el manejo del paciente (exclusión de tumores infrecuentes que simulen un adenocarcinoma u obtención de información que asista en la decisión de realizar neoadyuvancia). ${ }^{66}$

En lesiones resecables que presentan adenopatías loco-regionales y/o en el tronco celíaco, está recomendado realizar USE-PAAF de los ganglios para confirmar o descartar metástasis ya que su confirmación modificaría el estadio.

- ¿Cuál es el rédito diagnóstico de la USE-PAAF en lesiones sólidas de páncreas?

La USE-PAAF es considerada una herramienta útil para el diagnóstico de las lesiones sólidas de páncreas. Si bien el rédito varía según los estudios reportados, se estima que una sensibilidad de 90,8\% (IC 95\% 89,4-92), especificidad de 96,5\% (IC 95\% 94,8-97,7) y precisión diagnóstica de $91 \% .{ }^{64,65}$

Según la Sociedad Americana de Gastroenterología (ASGE), un indicador de la calidad de la USE es tener un rédito diagnóstico de la $\mathrm{PAAF} \geq 85 \%$ en las lesiones sólidas de páncreas.

- ¿Qué tipo de agujas se recomiendan para la USEPAAF en lesiones sólidas de páncreas?

Aquellas agujas de punción con aguja fina diseñadas para obtener histología son más recomendables ya que permitirían un mayor rédito diagnóstico. Si bien el costo de estas agujas es superior al de las tradicionales, al incrementar el rédito en la adquisición de tejido (rédito de histología) en un $20 \%$, se reducirían los falsos negativos y aumentaría la posibilidad de realizar marcaciones moleculares si fuese necesario. ${ }^{67-69}$

- ¿Cuál sería la ventaja de la USE-PAAF en relación con la biopsia pancreática por vía percutánea?

Las biopsias de páncreas guiadas por ecoendoscopía han ganado terreno por su eficacia y seguridad (baja tasa de complicaciones). ${ }^{64,65}$ Las biopsias de páncreas guiadas por ecografía o tomografía son también un método válido de adquisición de muestras; sin embargo, se prefiere como primera línea a la USE-PAAF por considerarse un procedimiento ambulatorio, con menores complicaciones (especialmente riesgo de diseminación en el trayecto de la aguja) y similares tasas de diagnóstico. ${ }^{70,71}$

- ¿Cuál es la tasa de complicaciones de la USE-PAAF en lesiones sólidas de páncreas?

La USE-PAAF en lesiones sólidas del páncreas es considerada un procedimiento seguro con una tasa de complicaciones de $1 \%$ a $2,5 \%$. La tasa de complicaciones severas (sangrado, perforación o muerte) es extremadamente rara. $^{72}$

- ¿Cuáles son las complicaciones más frecuentes de la USE-PAAF en lesiones sólidas de páncreas?

Las complicaciones que más se han reportado son el dolor y la pancreatitis $(0,29-0,64 \%) .^{56,72,73}$

- ¿Existe riesgo de diseminación o siembra con células tumorales por el trayecto de la aguja tras la USEPAAF?

Si bien hay reportes de casos aislados, no hay evidencia concreta que demuestre que la USE-PAAF conlleve mayor riesgo de ocasionar siembra peritoneal o riesgo de recurrencia gástrica o peritoneal. ${ }^{74-76}$

- ¿La USE-PAAF preoperatoria afectaría adversamente los desenlaces de la cirugía pancreática?

La USE-PAAF preoperatoria es considerada un procedimiento que no se asocia con desenlaces adversos en el perioperatorio ni a largo plazo. ${ }^{77}$

\subsection{Diagnóstico citopatológico}

\section{Rapid on-site evaluation (ROSE)}

La confirmación diagnóstica del ACDP se obtiene únicamente mediante el estudio citológico o histológico de una muestra del tumor pancreático o de una metástasis. 
Existen varias modalidades para la obtención de muestras: PAAF o BAF/BAG (Biopsia con Aguja Fina / Biopsia con Aguja Gruesa) guiada por diferentes técnicas de imágenes (US, TC, USE). El rendimiento diagnóstico es variable ya que puede estar afectado por una serie de factores, desde el tipo de agujas, el número de pases, la característica de la lesión y la presencia de un citopatólogo en la sala del procedimiento para la evaluación rápida (ROSE), entre otros. La metodología de los procedimientos es variada y no existe un acuerdo en la literatura sobre cuál de los métodos es el gold standard; diferentes abordajes son utilizados en la práctica diaria con una gran variación entre las instituciones de alto y bajo volumen.

El procedimiento PAAF/ROSE requiere una estandarización debido a que ROSE es una técnica contextodependiente. En dicho escenario, la presencia del citopatólogo y la utilidad de ROSE tienen el potencial de mejorar la tasa de adecuación, el rendimiento y la precisión diagnóstica.

- ¿Es útil la evaluación citopatológica rápida durante el procedimiento de punción biopsia?

El control por parte del citopatólogo del material obtenido por PAAF/BAF-BAG puede no estar disponible de manera rutinaria y generalizada, pero la evaluación inmediata de la muestra in situ (ROSE) ha demostrado que puede mejorar las muestras adecuadas (10-15\%), el rendimiento (10-30\%) y la precisión diagnóstica de malignidad (88\%). ${ }^{78-83}$ Consideramos que incluir esta herramienta (ROSE) reduce el porcentaje de muestras insatisfactorias, mejora la sensibilidad, proporciona un diagnóstico rápido de neoplasia maligna y permite planear con antelación el manejo del material para estudios inmunohistoquímicos y pruebas moleculares. Esta estrategia permite la comunicación en tiempo real entre el citopatólogo y el intervencionista, proporcionando la más alta calidad en la interpretación de las muestras, lo que impacta positivamente en el manejo de los pacientes, ahorrando tiempo y reduciendo costos generados por la repetición de los procedimientos.

\footnotetext{
- El informe citopatológico. Propuesta de la Papanicolaou Society of Cytopathology

Los criterios de diagnóstico uniformes y la terminología forman la base de los informes estandarizados. Existe una gran heterogeneidad en los informes y actualmente no existe un documento de consenso para el reporte citológico de las punciones pancreáticas. En la práctica diaria, algunos citopatólogos utilizan categorías similares
}

a las del sistema Bethesda usadas para informar la citología cervical y tiroidea (insatisfactorio, benigno, atípico, sospechoso y positivo para células neoplásicas). Las categorías indeterminadas (atípico y sospechoso) siguen siendo, como en la mayoría de los órganos, las más difíciles de interpretar y manejar tanto para los patólogos como para los clínicos. La frecuencia de diagnósticos atípicos en páncreas oscila entre 1-14\% y el riesgo de malignidad asociado entre el 25-100\%, observándose una heterogeneidad significativa entre los estudios que informan diagnósticos atípicos. ${ }^{84}$

La Papanicolaou Society of Cytopathology ha propuesto un sistema de terminología estandarizado para informar la citología pancreatobiliar con seis categorías: no diagnóstico, negativo, atípico, neoplásico (benigno y otros), sospechoso y positivo / maligno. ${ }^{85}$ Los lineamientos de esta propuesta incluyen indicaciones, técnicas, terminología y nomenclatura, pruebas complementarias, manejo posterior al procedimiento y establecen criterios morfológicos para la identificación de las diferentes lesiones.

- ¿Son útiles la terminología y nomenclatura propuestas por la Papanicolaou Society of Cytopathology para el informe de los estudios citológicos?

Esta propuesta ha sido adoptada por diferentes grupos como un sistema relativamente simple que puede introducirse en los informes de citología de páncreas dado que conduce a varios potenciales beneficios. Algunos estudios señalan que la utilización de esta clasificación reduce el número de muestras reportadas como atípicas o sospechosas, ${ }^{86,87}$ y también confirma el riesgo creciente de malignidad asociado con las categorías de diagnóstico. ${ }^{88}$

Consideramos que ante la necesidad de estandarizar el informe, resulta útil el esquema de clasificación de la Papanicolaou Society of Cytopathology para describir y categorizar las muestras ya que proporciona una comunicación clara de los resultados y una buena estratificación del riesgo de malignidad, lo que permite el planteo de estrategias terapéuticas más personalizadas, además de una correcta comparación de los resultados con otros centros.

Consultar Clasificación de la Papanicolaou Society of Cytopathology para informar muestras pancreatobiliares en el Anexo B.

\section{Consideraciones terapéuticas}

El único tratamiento potencialmente curativo es la cirugía, pero solo el 15-20\% de los casos son potencialmente resecables. Aun en los pacientes ope- 
rados con márgenes negativos (R0), el pronóstico es pobre debido a la alta tasa de recurrencia local (> 20\%) y sistémica $(>80 \%) .{ }^{89}$

Consideramos que no debería tratarse a un paciente con sospecha o diagnóstico de ACDP fuera de un grupo multidisciplinario de especialistas ya que esto modifica la conducta terapéutica en un elevado número de casos. ${ }^{89}$

Un paciente con cáncer de páncreas puede encontrarse en una de las siguientes situaciones clínicas:

- Tumor potencialmente resecable.
- Tumor borderline para la resección.

- Tumor localmente avanzado inoperable.

- Enfermedad metastásica.

\subsection{Tumor potencialmente resecable}

- ¿Cómo se define resecabilidad?

La resecabilidad puede definirse por criterios anatómicos, pero también por criterios oncológicos más amplios que no solo tienen en cuenta las imágenes (Tablas 2 y 3$) .53$

Tabla 2.

Consenso internacional para la clasificación del ACDP (2017)

Basado en definiciones anatómicas / tomográficas

Resecable (R)

Borderline resecable (BR)
- VMS/NP: sin contacto o estrechamiento unilateral.

- AMS, AC, AHC: sin contacto.

- VMS/VP: tumor contacta $\geq 180^{\circ} 0$ afinamiento bilateral u oclusión.

- AMS, AC: tumor contacta $<180^{\circ}$ sin estenosis o deformidades.

- AHC: tumor contacta sin afectar AHP y/o AC.

Irresecable (IR)

Localmente avanzado

- VMS/NP: estrechamiento bilateral u oclusión que excede borde inferior del duodeno.

Metastásico

- AMS, AC: tumor contacta/invade $\geq 180^{\circ}$ sin estenosis o deformidades.

- AHC: tumor contacta / invade con compromiso AHP y/o AC.

- Tumor contacta / invade la AO.

- Enfermedad metastásica.

VMS: vena mesentérica superior; VP: vena porta; AMS: arteria mesentérica superior; AC: arteria celíaca; AHC: arteria hepática común; AHP: arteria hepática propia; A0: arteria aorta. 
Tabla 3.

Definición

Resecable (R)

Borderline resecable (BR)

Irresecable

Localmente avanzado (LA)
Anatómica

R-Tipo A

Sí: BR- Tipo B

BR-Tipo A

No: BR-Tipo A

Sí: BR-Tipo AB

No: LA-Tipo A

Sí: LA-Tipo AB

LA-Tipo A
Condicional relacionada con el paciente

No: R-Tipo A

No: BR-Tipo A

Sí: BR-Tipo AC

No: LA-Tipo A

Sí: LA-Tipo AC

Definiciones:

Biológica: CA 19-9 > $500 \mathrm{UI} / \mathrm{ml}$ y/o metástasis ganglionares regionales (biopsia o PET TC).

Condicional relacionada con el paciente: performance status disminuido $(\geq 2)$.

Consultar tabla de performance status (PS) en el Anexo C.

\section{- ¿Es adecuada la cirugía primaria?}

Consideramos que la cirugía es el tratamiento estándar para los pacientes resecables que no tienen contraindicaciones quirúrgicas..$^{52,90}$

En el caso de los pacientes con tumores potencialmente resecables, por criterios anatómicos, con hallazgos clínicos sospechosos de enfermedad a distancia, incluyendo niveles de CA 19-9 > $500 \mathrm{UI} / \mathrm{ml}$ o ganglios regionales metastásicos por biopsia o PET TC, sugerimos considerar tratamiento oncológico preoperatorio. 53 Algunos especialistas consideran que el tamaño debe ser otro factor a tener en cuenta para la decisión de realizar tratamiento preoperatorio, pero no hay consenso uniforme en este punto. $^{91,92}$

En el caso de pacientes con tumores inoperables por comorbilidades con:

- Performance status 0-2: recomendamos realizar tratamiento con quimioterapia y/o quimiorradioterapia.

- Performance status 3: se sugiere realizar interconsulta con equipo de cuidados paliativos y/o radioterapia paliativa.

Para aquellos pacientes que tienen tumores potencial- mente resecables y comorbilidades que pueden ser corregidas, se sugiere iniciar con quimioterapia neoadyuvante y realizar cirugía posteriormente. ${ }^{52,93}$

\section{- ¿Es necesario realizar quimioterapia adyuvante?}

Siempre debe reestadificarse al paciente luego de la cirugía del tumor primario con $\mathrm{TC}$ de tórax sin contraste y tomografía de abdomen y pelvis con contraste o resonancia de abdomen y pelvis con contraste y determinación de CA 19-9.

Debido a los pobres resultados de la cirugía como modalidad única, se aconseja realizar tratamiento de quimioterapia en todos los pacientes operados, incluidos aquellos con enfermedad T1N0M0.52, 94, 95 La radioterapia adyuvante quedaría a criterio del grupo de trabajo interdisciplinario.

Usualmente se recomienda iniciar dentro de las 8 semanas de la cirugía y realizar tratamiento por 6 meses; sin embargo, existe alguna información que indica que retrasar el inicio de la quimioterapia hasta la recuperación del paciente no comprometería su sobrevida. ${ }^{96,97}$ 
- ¿Cuál esquema de quimioterapia debería indicarse?

Consideramos que debe realizarse el mejor esquema de quimioterapia combinada que se pueda realizar en tiempo y forma, según las características de los pacientes y del centro tratante (Tabla 4).

En pacientes con buen performance status (0-1) se sugiere el esquema FOLFIRINOX, dados los resultados del trabajo PRODIGE 24..$^{98,99}$

En pacientes que no podrían tolerar el esquema anterior, se sugiere quimioterapia combinada con capecitabina-gemcitabina, teniendo en cuenta el trabajo ESPAC $4 .{ }^{100}$

En pacientes con regular estado general, que no toleren quimioterapia combinada, se sugiere gemcitabina. ${ }^{101,102}$

\section{Tabla 4. Esquemas de quimioterapia}

\section{FOLFIRINOX modificado}

- Oxaliplatino 85 mg/m² día 1.

- Irinotecan $150 \mathrm{mg} / \mathrm{m}^{2}$ día 1.

- Leucovorina 400 mg/m² día 1.

- Fluorouracilo 2400 mg/m² Infusión continua de 46 horas.

\section{Capecitabina-gemcitabina (ESPAC 4)}

- Capecitabina 1660 mg/m² día 1-21 cada 28 días.

- Gemcitabina 1000 mg/m² día 1, 8, 15 cada 28 días.

\section{Gemcitabina monodroga (CONKO 001)}

- Gemcitabina 1000 mg/m² día 1, 8, 15 cada 28 días.

\section{- ¿Existe indicación para realizar quimiorradiote- rapia adyuvante?}

Existen controversias sobre la utilización de quimiorradioterapia (QT/RT) adyuvante.

La mayoría de los expertos europeos considera que agregar radioterapia a la quimioterapia no es adecuado; esta postura está basada en el beneficio de la quimioterapia adyuvante demostrada en el estudio CONKO-001, ${ }^{164}$ incluso en los pacientes con resección $\mathrm{R} 1$, y en la ausencia de beneficio con la quimiorradioterapia, según los resultados del trial de la Organización Europea para la Investigación y Tratamiento del Cáncer (EORTC, por sus siglas en inglés) y su efecto deletéreo según el estudio ESPAC $1 .^{103}$
En las guías europeas sobre el tratamiento del cáncer de páncreas del año $2015^{52}$ se recomienda usar quimiorradioterapia adyuvante solo en contexto de estudios randomizados.

La escuela americana incluye el agregado de quimiorradioterapia a la quimioterapia adyuvante basándose en la elevada tasa de margen retroperitoneal positivo y el alto riesgo de recaída local.

La justificación del uso de quimiorradioterapia adyuvante estaría dada por el beneficio en la sobrevida global demostrado por el Gastrointestinal Tumors Study Group (GITSG) ${ }^{104}$ y la tendencia a este beneficio por la EORTC. ${ }^{105}$

La National Comprehensive Cancer Network (NCCN) mantiene la quimiorradioterapia basada en fluorouracilo más quimioterapia sistémica con gemcitabina como una alternativa aceptable, y las guías de la Sociedad Americana de Oncología Clínica (ASCO, por sus siglas en inglés) sugieren el agregado de quimiorradioterapia luego de 6 meses de quimioterapia adyuvante en pacientes con margen o ganglios positivos. ${ }^{95}$

La indicación del agregado de quimiorradioterapia a la adyuvancia con esquema FOLFIRINOX no está clara.

Según la evidencia actual, al momento de redactar este documento, este consenso no recomienda la quimiorradioterapia adyuvante como tratamiento estándar.

\section{- ¿Existe indicación para realizar quimioterapia neoadyuvante en tumores resecables? \\ Consideramos que realizar neoadyuvancia en pacien-} tes resecables no es el tratamiento estándar.

El rol de esta modalidad para enfermedad resecable se encuentra en evolución. Las guías de ASCO y NCCN sugieren no administrar quimioterapia neoadyuvante ni quimiorradioterapia neoadyuvante en pacientes potencialmente resecables. De considerar esta modalidad, se sugiere hacerlo dentro de un protocolo de investigación.

El mejor esquema de neoadyuvancia aún no está definido; sin embargo, se prefiere el esquema FOLFIRINOX teniendo en cuenta su tasa de respuesta y sobrevida alcanzada en pacientes metastásicos. ${ }^{98,99}$

\subsection{Tumor borderline}

El ACDP borderline constituye una entidad distintiva; se caracteriza por tener mayor riesgo de resecciones con márgenes quirúrgicos comprometidos, lo cual empeora el pronóstico.

Los criterios para su definición han ido variando en el tiempo. Este consenso adhiere a la definición del con- 
senso internacional de 2017, el cual definió los tumores borderline no solo desde un punto de vista anatómico sino también desde la biología tumoral y el estado general del paciente (Tablas 2 y 3 ).

\section{- ¿Es necesario el diagnóstico histológico en todos los casos?}

Sí. Consideramos indispensable la biopsia previa al tratamiento.

\section{- ¡Cuál es la estrategia terapéutica en tumores bor- derline?}

Se sugiere que, en la medida en que esté disponible en la institución, todo paciente con un tumor borderline se incluya en un protocolo de investigación. Esta sugerencia se basa en que utilizando los tratamientos que actualmente están disponibles, incluso los más intensivos, en pacientes seleccionados, la probabilidad de realizar una cirugía posterior es de aproximadamente $60 \%$ (el margen R0 se logrará en $60-80 \%$ de los casos). ${ }^{106}$

Teniendo en cuenta que los tumores de páncreas se caracterizan por su rápida diseminación sistémica, consideramos que la quimioterapia es el abordaje terapéutico inicial.

Por recomendación de expertos se sugiere completar 6 meses de tratamiento sistémico, incluyendo el tratamiento pre y/o posoperatorio.

Ante la imposibilidad de tratar al paciente dentro de un protocolo de investigación, el esquema de quimioterapia neoadyuvante recomendado por el panel es el FOLFIRINOX modificado en pacientes con buen performance status (0-1) y escasas comorbilidades.

En pacientes no candidatos al FOLFIRINOX se recomienda la quimioterapia combinada.

Luego de 4-6 meses de quimioterapia neoadyuvante puede realizarse radioterapia antes de la cirugía. De realizarse esta, se recomienda quimiorradioterapia con fluoropirimidinas o radioterapia estereotáxica (SBRT).

Está indicado reevaluar al paciente cada 8-12 semanas durante la neoadyuvancia y previo a cada cambio de estrategia terapéutica (radioterapia, cirugía).

\footnotetext{
- ¿Qué parámetros pronósticos luego del tratamiento neoadyuvante podemos utilizar?

La disminución del CA 19-9 luego de la quimioterapia neoadyuvante es utilizado como un factor pronóstico favorable. ${ }^{107}$

La respuesta completa o enfermedad residual mínima se considera como subrogante de mejor sobrevida global. ${ }^{108}$
}

\section{- ¿Cuál es la técnica de radioterapia adecuada para los tumores borderline?}

Por recomendación de expertos se sugiere alcanzar una dosis biológica efectiva (BED) mayor a 60 Gy. ${ }^{109}$

Se sugieren técnicas de SBRT o radioterapia de intensidad moderada (IMRT). ${ }^{10}$

En centros oncológicos sin posibilidad de realizar estas técnicas, podría utilizarse radioterapia 3D normofraccionada a una dosis total de 45-50,4 Gy.

- ¿Cómo se evalúa la respuesta al tratamiento en un paciente con ACDP borderline o inoperable en protocolo de rescate con quimioterapia y/o radioterapia?

Hasta la actualidad no existe un método de diagnóstico que permita evaluar con certeza el grado de respuesta en pacientes post neoadyuvancia. ${ }^{11}$

La TCMS permite constatar progresión de enfermedad en caso de aumento de tamaño o aparición de metástasis a distancia e inducir una probable respuesta favorable cuando se reconoce reducción del tamaño tumoral y menor compromiso de las estructuras vasculares. ${ }^{12}$

La RM con secuencias de difusión no ha demostrado mejores resultados que los hallazgos mencionados en TCMS. ${ }^{113}$

Algunos autores han demostrado el potencial valor del PET TC con FDG para evaluar objetivamente la respuesta a la quimiorradioterapia.

Debido a la falta de evidencia concluyente respecto de los méritos de las diferentes modalidades en cuanto a la evaluación cuali y cuantitativa de la respuesta al tratamiento, se recomienda el seguimiento con TC de tórax, abdomen y pelvis con contraste oral y EV o, en su defecto, el método utilizado de base. En contextos particulares seleccionados, el PET TC puede aportar información relativa a la respuesta al tratamiento relevante para la toma de decisiones.

\subsection{Tumor irresecable localmente avanzado}

Consideramos que este subgrupo de pacientes debe ser tratado de manera similar a los pacientes con tumores metastásicos.

Los casos de pacientes que no hayan progresado luego de un período de tratamiento de $\geq 6$ meses podrían ser discutidos en el contexto de un grupo interdisciplinario para evaluar el agregado de radioterapia.

Aquellos pacientes que han completado un tratamiento de, al menos, 6 meses con quimioterapia o quimioterapia seguida de radioterapia/quimiorradioterapia y han presentado signos de respuesta o ausencia de progresión deberían ser evaluados por el grupo interdisciplinario para determinar el rol de la cirugía. 


\subsection{Tumor metastásico}

$\mathrm{Al}$ menos el $50 \%$ de los pacientes con ACDP son diagnosticados con enfermedad metastásica y aproximadamente el $90 \%$ de aquellos que se diagnostican con enfermedad localizada desarrollará metástasis. La supervivencia a 5 años para todos los estadios es menor a $10 \%$ y para los pacientes metastásicos de inicio es de aproximadamente $3 \% .{ }^{90}$

- ¿Cuáles son las consideraciones a realizar en la evaluación inicial del paciente con ACDP metastásico / recaído (M/R)?

En la evaluación inicial de los pacientes $M / R$ se sugiere la participación temprana del equipo de cuidados paliativos.

No existe evidencia de beneficio del tratamiento quimioterápico en pacientes con PS 3-4.

En pacientes con PS 2-3 se recomienda gemcitabina monodroga. ${ }^{114}$

En pacientes con PS 0-2 se recomienda poliquimioterapia. La elección del esquema, FOLFIRINOX en PS 0-1, nab paclitaxel-gemcitabina u otro, deberá elegirse en función de las comorbilidades, toxicidades potenciales, accesibilidad y costos. ${ }^{98,115}$

En pacientes sin progresión luego de 4 meses de tratamiento con FOLFIRINOX puede considerarse el uso de fluoropirimidinas en administración continua. ${ }^{116}$

Consideramos que el esquema gemcitabina-erlotinib no es adecuado actualmente.

En el subgrupo de pacientes que presenta déficit de la recombinación homóloga, BRCA-ness, algunos autores recomiendan quimioterapia basada en platinos. En este subgrupo de pacientes, los inhibidores de poli ADP ribosa polimerasa (inhibidores PARP) han demostrado eficacia en el mantenimiento luego de estabilidad o respuesta a platinos, pero su utilización en nuestro país todavía no ha sido aprobada. ${ }^{117}$

En la actualidad, en pacientes con cáncer de páncreas metastásico en buena condición general (PS 0-1) se recomiendan esquemas de quimioterapia combinada, principalmente FOLFIRINOX o nab paclitaxel-gemcitabina, ya que ambos han demostrado mayor eficacia comparados con gemcitabina. ${ }^{98,115} \mathrm{Si}$ bien ambos esquemas no han sido comparados entre sí en un mismo ensayo clínico, los resultados relacionados con la eficacia y la toxicidad parecen superiores con el triplete.

Cabe recordar que el esquema de quimioterapia con nab paclitaxel-gemcitabina es válido incluso para pacientes con PS 2 dado que fueron incluidos en el estudio pivotal.
- ¿Existe evidencia sobre realizar tratamiento en segunda línea?

La evidencia de los esquemas de quimioterapia en segunda línea es débil. El esquema a utilizar dependerá del tratamiento realizado en primera línea, de su toxicidad potencial y del estado general del paciente.

Existen dos ensayos fase 3 que han demostrado beneficio en supervivencia global, el CONKO 003 (oxaliplatino, fluorouracilo bolo y leucovorina) ${ }^{118}$ y el NAPOLI 1 (irinotecan nanoliposomal, fluorouracilo y leucovorina). ${ }^{119}$ Esta última opción no está disponible en nuestro medio.

La combinación de oxaliplatino con fluorouracilo infusional (FOLFOX) no fue superior a fluorouracilo en el protocolo PANCREOX. ${ }^{120}$

La poliquimioterapia continúa siendo de elección en los pacientes con buen PS en esta línea de quimioterapia.

Por evidencia de estudio fase II y recomendación de expertos, el tratamiento con nab paclitaxel-gemcitabina en los pacientes progresados a FOLFIRINOX es una opción tolerable y con mayor tasa de respuesta comparado con terapia con monodroga. ${ }^{121,122}$

Aquellos pacientes que progresaron luego de una primera línea de quimioterapia y que presentan inestabilidad microsatelital (MSI) o deficiencia en las proteínas de reparación del ADN por apareamiento (dMMR) se benefician con el tratamiento con inhibidores de PD-L1 (pembrolizumab). ${ }^{123}$

\section{- ¿Cúal es el rol de la radioterapia en los pacientes con ACDP M/R?}

Consideramos que la radioterapia paliativa de lesiones metastásicas o del tumor primario sintomático es útil.

\section{- ¿Qué técnica de radioterapia debemos utilizar en pacientes con ACDP M/R?}

En pacientes con oligometástasis y PS 0-1 podría utilizarse radiocirugía estereotáxica (SRS)/SBRT.

En pacientes con múltiples metástasis se sugiere radioterapia 3D de curso corto.

En pacientes con recaída local sin antecedentes de radioterapia previa se sugiere técnica de radioterapia 3D, IMRT o SBRT, según disponibilidad del centro.

\footnotetext{
- ¿Cuál es la utilidad de la colocación de marcadores fiduciarios por USE para radioterapia dirigida?

En la radioterapia neoadyuvante o paliativa del cáncer de páncreas, el tratamiento radiante estereotáxico permite evitar la radiación de órganos vecinos y disminuir la toxicidad. Para lograr enfocar con alta precisión
} 
el objetivo se colocan marcadores radiopacos dentro del tumor. La USE provee una excelente visualización del tumor y permite la inserción de marcadores fiduciarios de oro o platino dentro de la lesión, siendo una técnica muy segura. ${ }^{124}$

\section{- ¿Cuál sería el rol de la radiofrecuencia guiada por USE en el cáncer de páncreas?}

Es una técnica introducida hace pocos años y la experiencia es limitada. Los dos principales escenarios en los que eventualmente podría cumplir un rol son: alternativa en pacientes con tumor resecable pero con alto riesgo quirúrgico o que rechaza la cirugía, y tratamiento multimodal adyuvante de tumor localmente avanzado.

El objetivo es reducir la masa tumoral y, además, presenta un efecto estimulante del sistema inmune que actúa contra el tumor luego de la aplicación incrementando la respuesta a la quimioterapia. ${ }^{125,126}$

\section{Rol de la cirugía y estándares quirúrgicos}

Como fue mencionado previamente, la resecabilidad del cáncer de páncreas se define teniendo en cuenta la combinación de tres factores:

- Las características locales del tumor con respecto al contacto con las estructuras vasculares.

- Factores biológicos evaluados por biomarcadores como el CA 19-9.

- El performance status del paciente.

El concepto de resecabilidad "biológica" está relacionado con aquellas situaciones en las cuales se sospecha una enfermedad más avanzada que la que muestran las imágenes. Un dosaje de marcador de CA 19-9 > 500 UI/ $\mathrm{ml}$ o la presencia de adenopatías loco-regionales sugieren la posibilidad de enfermedad sistémica.

Desde el punto de vista del paciente, la resecabilidad se refiere a la capacidad funcional esperada para afrontar una cirugía de riesgo.

La edad por sí misma no es una limitación para recomendar una resección pancreática. Debe evaluarse de forma individual la fragilidad de cada paciente. Existen diversos scores que intentan objetivar esa fragilidad.

El performance status del paciente, sus comorbilidades y su estado nutricional serán los principales condicionantes de las decisiones terapéuticas. ${ }^{53}$

- En un tumor resecable, ¿Debe confirmarse el diagnóstico histológico previo a la cirugía en todos los casos?

Ante la firme sospecha de ACDP evaluado por un comité multidisciplinario puede procederse a la resección sin biopsia previa. ${ }^{127}$

En caso de que exista duda diagnóstica -considerada cuando la clínica, las imágenes y los resultados del laboratorio recomendados por este consenso no sean concluyentes- está indicada la biopsia si el resultado de la misma pudiera revertir la indicación quirúrgica.

- ¿Cuál es la cirugía oncológica que debe realizarse en los tumores cefálicos?

La duodenopancreatectomía cefálica (DPC) con linfadenectomía estándar de los grupos ganglionares 5, 6, 8A, 12B, 12C, 13A, 13B, 14A, 14B, 17A y 17B.

No se han demostrado diferencias en cuanto a complicaciones o supervivencia alejada entre la técnica clásica y la cirugía con conservación de píloro.

El tipo de reconstrucción debe estar sujeto a la experiencia del grupo tratante, ya que no se han reportado beneficios concluyentes de algún tipo de técnica de reconstrucción sobre otra.

La resección de venas del eje venoso mesentérico-portal con posibilidad de reconstrucción debe ser considerada una opción terapéutica válida.

La resección de arteria mesentérica superior y la resección de tronco celíaco no están recomendadas. Pueden indicarse resecciones de arteria hepática común y arteria hepática derecha proveniente de mesentérica superior.

Se recomienda que el cirujano actuante o su grupo estén entrenados en cirugía vascular. ${ }^{128}$

- ¿Cuál es la cirugía oncológica adecuada en los tumores de córporo-caudales?

La cirugía recomendada en estos tumores es la esplenopancreatectomía con linfadenectomía de los grupos ganglionares 9, 10, 11 y 18 .

La resección de venas del eje venoso mesentérico-portal con posibilidad de reconstrucción debe ser considerada una opción terapéutica válida.

La resección de arteria mesentérica superior no está recomendada.

Puede indicarse resección del tronco celíaco si se garantiza la preservación del flujo hepático. ${ }^{128}$

\footnotetext{
- ¿Cuál es el rol del abordaje laparoscópico en la resección del ACDP?

El abordaje videolaparoscópico o robótico se considera una alternativa en desarrollo. Debe ser realizado por cirujanos entrenados en esta técnica y en centros con alto número de cirugías pancreáticas.

La resección laparoscópica en casos de lesiones cefá-
} 
licas requiere una larga curva de aprendizaje con importante morbimortalidad reportada en dicho proceso. $\mathrm{Su}$ uso rutinario está desaconsejado fuera de un programa de desarrollo supervisado y auditado en grupos de alto volumen. ${ }^{129}$

La resección laparoscópica en casos de lesiones córporo-caudales es una práctica aceptada en la actualidad. Los resultados oncológicos publicados no mostraron diferencias con el abordaje convencional. La decisión entre ambos abordajes depende de la experiencia de cada grupo. ${ }^{130}$

\section{- ¿Debe realizarse una estadificación laparoscópica sistemática?}

La laparoscopía diagnóstica es una herramienta más en la estadificación de tumores de páncreas. Sin embargo, la utilidad de su realización sistemática es aún motivo de controversia.

No consideramos recomendable la indicación sistemática en tumores de la cabeza pancreática.

Se sugiere la utilización de laparoscopía estadificadora ante la sospecha de enfermedad avanzada, como primer gesto quirúrgico, previo a la intención de resección. Consideramos que los pacientes con sospecha de enfermedad avanzada son aquellos que presentan tumores primarios mayores a $4 \mathrm{~cm}$, adenomegalias regionales y dosaje de CA 19-9 > $500 \mathrm{UI} / \mathrm{ml}$.

Dado que la mayoría de los tumores córporo-caudales no necesita un procedimiento quirúrgico paliativo, la laparoscopía estadificadora tiene mayor utilidad en estos casos.

\section{- ¿Qué rol tiene la cirugía en pacientes con tumores resecables?}

La cirugía con márgenes negativos y quimioterapia adyuvante es en la actualidad el estándar de tratamiento de los tumores resecables. ${ }^{127}$

\section{- ¿Cuál es el rol de la cirugía en pacientes con tu- mores borderline?}

Estos casos deben ser evaluados por un comité multidisciplinario. Las alternativas son neoadyuvancia con posterior cirugía si no hay progresión de la enfermedad o la resección quirúrgica $\mathrm{R} 0$ seguida de adyuvancia.

$\mathrm{Al}$ no lograrse con relativa frecuencia el $\mathrm{R} 0$, la tendencia actual se orienta cada vez más a realizar tratamiento neoadyuvante en tumores borderline. ${ }^{106,127}$

- ¿Cuál es el rol de la cirugía en pacientes con tumores irresecables localmente?

La cirugía no está indicada como abordaje inicial en pacientes con evidencia de enfermedad irresecable diagnosticada en los estudios por imágenes.

En estos pacientes la paliación debe ser realizada de preferencia por procedimientos endoscópicos y/o percutáneos.

En pacientes con enfermedad irresecable localmente, sin progresión por imágenes y con signos biológicos de respuesta (CA 19-9 en descenso) luego de un tratamiento oncológico completo, puede evaluarse multidisciplinariamente y plantearse realizar un intento de rescate quirúrgico. ${ }^{131}$

Cuando la irresecabilidad es determinada intraoperatoriamente, deberán tenerse en cuenta distintas situaciones:

- Pacientes sintomáticos (ictericia, obstrucción duodenal, dolor): la mejor indicación sería realizar la paliación en el mismo acto quirúrgico.

- Pacientes asintomáticos con vía biliar no dilatada: no se recomienda la derivación biliodigestiva profiláctica.

\section{- ¡Cuáles son los límites de la resección oncológica} (cirugía extendida)?

Cuando mencionamos la cirugía extendida nos referimos a la realización de una linfadenectomía más allá de la realizada clásicamente, así como también a la práctica de resecciones de órganos fuera de los criterios de resecabilidad convencionales.

Este tipo de cirugía aumenta la morbimortalidad perioperatoria de los pacientes y debería indicarse neoadyuvancia como tratamiento inicial.

La cirugía extendida solo deber ser considerada en casos seleccionados, en centros de alto volumen de pacientes con patologías pancreáticas y luego de ser evaluados por comité multidisciplinario. ${ }^{132}$

\section{- ¿Dónde deberían ser operados los pacientes con cáncer de páncreas?}

Ante el diagnóstico de un ACDP la recomendación es realizar un análisis multidisciplinario del caso por especialistas en diagnóstico por imágenes, gastroenterología, endoscopía intervencionista, oncología médica, radioterapia, cirugía y cirugía percutánea, cuidados intensivos, anatomía patológica, genética clínica, endocrinología, medicina geriátrica, nutrición, salud mental y cuidados paliativos.

La cirugía pancreática presenta un elevado porcentaje de complicaciones, el cual debe ser inferior al 55\%. Sin embargo, la mortalidad está directamente relacionada con la experiencia del grupo quirúrgico y de la institución en el manejo de este tipo de cirugías. 
Un centro de referencia debería tener menos de $5 \%$ de mortalidad en pancreatectomías para realizar estos procedimientos.

Se aconseja que el grupo tratante tenga un volumen de al menos 16 pancreatectomías por año para ser considerado como un centro de alto volumen. ${ }^{133}$

\section{Estudio de la pieza quirúrgica e informe histopatológico}

De un detallado estudio macroscópico depende una correcta estadificación patológica para cualquier tipo de pieza quirúrgica. Las resecciones pancreáticas, en particular las duodenopancreatectomías (DPC), son piezas desafiantes para los patólogos, debido a la complejidad de su anatomía. Por otra parte, estas cirugías se realizan en pocos centros, por lo que es limitado el número de patólogos con acceso a estas piezas quirúrgicas.

El estudio macroscópico de las piezas de pancreatectomía corporocaudal (distal) no suele presentar mayores dificultades, pero en las piezas de DPC existen muchas diferencias en las formas de disección, en el estudio de los márgenes e, incluso, en la definición de compromiso de márgenes. El estudio de las piezas que han recibido tratamiento neoadyuvante es especialmente particular debido a que se generan importantes cambios anatómicos e histológicos.

El problema radica en que no existe una recomendación universalmente aceptada para el estudio macroscópico de estas piezas, motivo por el cual deben extremarse los esfuerzos para lograr una estandarización de los estudios patológicos, lo cual es esencial para comparar mejor el pronóstico, la supervivencia y la respuesta al tratamiento.

El College of American Pathologists (CAP) ${ }^{134}$ y el American Joint Committee on Cancer (AJCC) ${ }^{135}$ tienen protocolos estándar para orientar el análisis histopatológico de las muestras, pero las recomendaciones no son muy detalladas; el Royal College of Pathologists (RCPath) ${ }^{136}$ hace mención y reseña brevemente la técnica de disección, y varios grupos han estudiado y reportado diferentes enfoques en el manejo de las piezas quirúrgicas, cada uno con sus ventajas y desventajas. ${ }^{137-139}$

\section{- ¿Quién debe orientar la pieza quirúrgica?}

La correcta orientación de la pieza, el reparo de los márgenes quirúrgicos y el entintado de los márgenes y/o superficies requiere el trabajo conjunto entre cirujanos y patólogos. Las piezas deben llegar al laboratorio de patología abiertas por el borde antimesentérico del duodeno para conservar la morfología de la ampolla de
Vater, fijadas en formol en 24 a 48 horas posteriores a la cirugía, con los correspondientes reparos en los márgenes y debidamente especificados en la solicitud de estudio.

\section{- ¿Qué técnica de disección se utiliza?}

Las piezas quirúrgicas deben ser preferiblemente abiertas y seccionadas por el patólogo. La elección de la técnica de disección a ser utilizada depende de las preferencias de los diferentes laboratorios o de la experiencia de los patólogos. Cualquier método es válido en un contexto estandarizado, para lo cual la integridad de la pieza quirúrgica es primordial, con el fin de obtener resultados fiables y reproducibles.

Un método simple y fácil de realizar son los cortes en el plano axial, el cual se basa en cortes seriados de la cabeza pancreática en un solo plano perpendicular al eje longitudinal del duodeno, sin la apertura de los conductos pancreático y biliar, por lo cual el margen circunferencial queda intacto. Se obtiene un gran número de rebanadas, usualmente entre 10 y 13, y permite una vista extensa de la lesión y su relación con el margen circunferencial completo y con las estructuras anatómicas claves. ${ }^{136,137}$

\section{- ¿Cuáles son los márgenes y/o superficies que de- ben ser evaluados?}

Según lo publicado en la literatura, la terminología de los márgenes de resección es confusa y carece de consenso. Los márgenes de transección no suelen plantear problemas con la nomenclatura y se reconocen sin mayor dificultad en la pieza quirúrgica, contrario a lo que sucede con el resto de la superficie de la cabeza pancreática, donde existen diferentes opiniones sobre lo que constituye un margen y/o superficie de resección, colectivamente denominado margen circunferencial (MC). ${ }^{135}$, 137, 139, 140 Esto sigue siendo un tema de mucho debate y controversia, fundamentalmente en cuanto a qué debe considerarse margen y el impacto pronóstico que tiene el o los márgenes que están comprometidos. ${ }^{141}$ Sin embargo, la definición de los márgenes y la uniformidad de la nomenclatura son críticas para la presentación de informes estandarizados.

En las piezas de DPC deben evaluarse los siguientes márgenes quirúrgicos:

Margen proximal gástrico / duodenal (transección).

Margen distal duodenal / yeyunal (transección).

Margen del conducto biliar distal (transección).

Margen pancreático distal (transección). 
La evaluación del margen circunferencial (MC) pancreático, generalmente aceptado y adoptado por diferentes guías, ${ }^{142}$ incluye:

Superficie anterior (superficie).

Margen posterior (margen de disección).

Las superficies anterior y posterior están separadas por una superficie medial enfrentada a los vasos mesentéricos que se encuentra por debajo del margen de transección pancreático e incluye:

a) Margen de la arteria mesentérica superior (margen de transección).

b) Surco de la vena mesentérica superior (VMS) (margen de disección).

Consultar tabla con definiciones y sinonimia en el Anexo D.

Si la pieza quirúrgica incluye resección venosa deben informarse adicionalmente el margen venoso proximal y el distal.

Para que el MC pueda ser reconocido en el examen microscópico debe ser pintado con tintas de diferentes colores.

En las piezas de pancreatectomía distal, los márgenes quirúrgicos a estudiar son:

Margen pancreático proximal (de transección).

Superficie peripancreática anterior (superficie).

Margen peripancreático posterior (margen de disección).

\section{- ¿Cuándo se considera que una resección es R0?}

A los problemas de la nomenclatura de los márgenes circunferenciales se suma la falta de consenso en la definición del compromiso microscópico (R1). La Union for International Cancer Control (UICC) ${ }^{142}$ considera un margen infiltrado (R1) cuando se detectan células tumorales en el borde quirúrgico ( $0 \mathrm{~mm}$ o contacto directo), mientras que el College of American Pathologists (CAP), el Royal College of Pathologists (RCPath) y el International Study Group of Pancreatic Surgery (ISGPS) ${ }^{143}$ definen como R1 a la presencia de tumor en o dentro de 1 mm del margen de resección.

Actualmente se desconoce qué constituye un margen adecuado en la muestra de resección de carcinoma pancreático. Varios estudios han evaluado la distancia entre el tumor y el margen y el impacto en el pronóstico, la recurrencia y la supervivencia, con resultados disímiles. ${ }^{106,144,145}$
Permanece sin determinar cuál sería el margen apropiado después del tratamiento neoadyuvante; Liu y colaboradores $^{146}$ sugieren una distancia $>1 \mathrm{~mm}$ para lograr una resección R0 en piezas de DPC postratamiento. Está recomendado informar en milímetros la distancia del tumor a los márgenes quirúrgicos.

La definición de resección R1 debe aplicarse cuando el tumor se encuentra a $1 \mathrm{~mm}$ o menos de los márgenes de resección previamente descritos.

\section{- ¿Cuántos ganglios linfáticos se requieren para una adecuada estadificación?}

De una DPC debe estudiarse un mínimo de 15 ganglios linfáticos para una correcta estadificación. ${ }^{136}$

- ¿Cómo debe estudiarse e informarse la respuesta histológica a la terapia neoadyuvante?

El informe patológico de las resecciones de cáncer de páncreas después del tratamiento neoadyuvante presenta controversias y dificultades con respecto a la evaluación de la extensión del tejido tumoral residual, la clasificación de la regresión tumoral y la evaluación de los márgenes. ${ }^{147}$

No existe un consenso sobre los criterios histológicos que definan la respuesta histológica. Diferentes esquemas se han propuesto para evaluar el grado de regresión tumoral, ${ }^{147,148}$ los cuales básicamente reflejan la cantidad de tejido tumoral residual en relación con el tamaño original del tumor o la extensión de los cambios regresivos, fundamentalmente la fibrosis.

Debido a que no hay un criterio estándar, se recomienda un detallado examen macroscópico y un extenso muestreo de la pieza, que debe ser total, particularmente cuando se establezca un diagnóstico de respuesta completa.

Con respecto al grado de regresión tumoral sugerimos utilizar el sistema del College of American Pathologists (CAP) que propone una clasificación de cuatro niveles para la extensión del carcinoma residual: 0 (respuesta completa), 1 (respuesta casi completa), 2 (respuesta parcial) 3 (respuesta pobre o no respuesta).

Consultar tabla en el Anexo E.

\section{- ¿Cuáles datos no deben faltar en el informe pa- tológico? \\ EL College of American Pathologists (CAP) y el Royal} College of Pathologists definen los elementos considerados como componentes esenciales del informe histopatológico para carcinoma de páncreas. Estos componentes incluyen ubicación anatómica, tamaño tumoral, tipo histológico y grado tumoral, compromiso linfovascular, 
invasión perineural, estado de los márgenes quirúrgicos, efectos del tratamiento neoadyuvante y estadio patológico (TNM UICC/AJCC $8^{\circ}$ edición). ${ }^{149}$

\section{Manejo endoscópico de las complicaciones}

\subsection{Tratamiento del dolor}

\section{- ¿Cuál es el rol de la USE en el tratamiento del dolor?}

El manejo del dolor involucra herramientas farmacológicas y otras más invasivas y exige un manejo multidisciplinario.

La USE-NPC (neurolisis del plexo celíaco) tiene un éxito técnico $>90 \%$ con un éxito clínico de 60 a $70 \%$ en la mayoría de las series publicadas. El efecto analgésico duraría aproximadamente tres meses y pueden realizarse nuevas neurólisis. Los efectos adversos más frecuentes son leves (< 20\%: hipotensión ortostática, diarrea, aumento de dolor transitorio postintervención). ${ }^{97,98}$ La USE-NPC demostró en un trabajo randomizado ser superior en el mantenimiento del efecto analgésico en comparación con el abordaje guiado por tomografía. ${ }^{150}$

La técnica consiste en la inyección inicial de $10 \mathrm{ml}$ de bupivacaína $0,25 \%$ seguidos de 12 a $20 \mathrm{ml}$ de alcohol $96 \%$ mediante una aguja de 22 o 19 G guiados por USE en tiempo real y evitando interposición vascular mediante la utilización de Doppler.

Existen trabajos recientes que muestran mejoría en la calidad de vida y reducción en el uso de morfina en pacientes que se presentan con dolor pancreático, a los cuales se les realiza neurólisis temprana (en etapas más tempranas que las usualmente contempladas). ${ }^{151}$

\subsection{Manejo endoscópico de la obstrucción gastroduo- denal}

- ¿Cuál es el rol de la USE en el manejo de la obstrucción gastroduodenal por el cáncer de páncreas?

Las opciones tradicionales en el tratamiento de la obstrucción del tracto de salida del estómago por un tumor de páncreas avanzado irresecable son: gastroyeyunostomía quirúrgica (desventajas: recuperación prolongada que puede retrasar el inicio de la quimioterapia, gastroparesia postoperatoria, etc.) y la colocación de stent metálico duodenal sea por vía radiológica, endoscópica o combinada (desventajas: obstrucción frecuente por alimentos y crecimiento tumoral, migración). ${ }^{152-154}$ Este último método se indica cuando la expectativa de vida es $<2$ meses. En los últimos años se ha desarrollado una tercera opción que consiste en la gastroenteroanastomosis guiada por USE mediante la colocación de un stent me- tálico cubierto de aposición de lumen con un diámetro de 15 a $20 \mathrm{~mm}$; se ha publicado una alta tasa de éxito técnico en la colocación y en la respuesta clínica $(90 \%)$ y una tasa de complicaciones de $11,5 \% .{ }^{155-157}$

- ¿Cuáles son las indicaciones de realizar paliación endoscópica de la obstrucción gastroduodenal?

Los pacientes con cáncer irresecable o recurrencia en el sitio de anastomosis que presentan síntomas (intolerancia a la vía oral) por obstrucción gastroduodenal por la lesión y que tienen baja expectativa de vida ( $<2$ meses) son candidatos al tratamiento radiológico, endoscópico o combinado mediante la colocación de prótesis autoexpandibles, con el objetivo de lograr restablecer la permeabilidad aliviando los síntomas de obstrucción, reiniciando la alimentación supervisada por la vía oral y mejorando la calidad de vida. ${ }^{154,158-161}$

Es fundamental tener en cuenta si coexiste obstrucción biliar (situación que es muy frecuente si el paciente ya presenta obstrucción duodenal), dado que luego de colocar una prótesis duodenal metálica el acceso al árbol biliar por la papila no es sencillo. Por lo tanto, debería intentarse tratar primero la obstrucción biliar con una prótesis biliar metálica autoexpandible y luego realizar el tratamiento de la obstrucción duodenal.

- ¿En quiénes no está recomendado realizar paliación endoscópica de la obstrucción gastroduodenal?

Aquellos pacientes que persisten asintomáticos y que toleran una dieta normal no son candidatos para realizar la paliación endoscópica. Tampoco está recomendada si la obstrucción intestinal está presente en múltiples sitios (ya que la colocación de una prótesis proximal no mejoraría los síntomas) ni si hay signos de perforación. ${ }^{154}$

La presencia de carcinomatosis peritoneal no es una contraindicación para la paliación endoscópica; sin embargo, estos pacientes podrían tener una tasa de respuesta sintomática menor. ${ }^{162}$

\footnotetext{
- ¿Cuáles son las prótesis recomendadas para la paliación de la obstrucción gastroduodenal?

Se recomienda utilizar prótesis metálicas duodenales no recubiertas ya que presentan menor riesgo de migración, mayor flexibilidad y permiten el pasaje de la bilis por la malla del stent. El diámetro de las prótesis es, en general, de 20-22 mm y la longitud de la prótesis a elegir dependerá de la longitud de la estenosis (hay disponibles de $6 \mathrm{~cm}, 9 \mathrm{~cm}$ y $12 \mathrm{~cm}$ ).
} 
- ¿Cuáles son los beneficios de la paliación endoscópica con prótesis metálicas de la obstrucción gastroduodenal?

Las prótesis gastroduodenales y duodenales logran colocarse en $>90 \%$ de los casos (éxito técnico) con resolución de los síntomas (éxito clínico) en $>80 \%$ de los casos. En comparación con otras alternativas de tratamiento no endoscópicas, la paliación endoscópica está asociada a una resolución más rápida de los síntomas de obstrucción (alivio temprano) y una estadía hospitalaria más corta.

\section{- ¿Cuál es la tasa de complicaciones de la paliación} endoscópica con prótesis metálicas de la obstrucción gastroduodenal?

Los efectos adversos durante el procedimiento pueden estar relacionados con la anestesia, broncoaspiración, mal posicionamiento de la prótesis, sangrado y perforación. ${ }^{154,158-162}$

Los efectos adversos tardíos son la migración distal de la prótesis, la oclusión de la prótesis, sangrado, perforación y disfunción de prótesis biliares.

\subsection{Manejo endoscópico de la obstrucción biliar}

- ¿Cuál es el rol de la USE en el manejo de la obstrucción biliar por el cáncer de páncreas?

La obstrucción biliar es una complicación frecuente en el cáncer de páncreas. El primer tratamiento de elección para el drenaje biliar es la colangiopancreatografía retrógrada endoscópica (CPRE). Cuando la CPRE fracasa existen dos opciones: drenaje guiado por USE y drenaje percutáneo. En estudios comparativos se ha mostrado cierta ventaja del drenaje por USE debido a una menor frecuencia de eventos adversos, menor estadía hospitalaria y mejor calidad de vida. ${ }^{163,164}$

Las opciones de la vía de drenaje guiado por USE son: técnica de rendez-vous por USE seguido por CPRE, coledocoduodenostomía y hepaticogastrostomía. La elección de la técnica depende de la anatomía biliopancreática, la disponibilidad de insumos y la experiencia del endoscopista.

- ¿Está indicado el drenaje biliar endoscópico en pacientes con colestasis extrahepática por tumor de páncreas resecable?

$\mathrm{Su}$ rol en pacientes con colestasis es controvertido, siendo sugerido en los siguientes escenarios: niveles de bilirrubina total superiores de $15 \mathrm{mg} / \mathrm{dL}$ y tiempo estimado al tratamiento quirúrgico (más de 2 a 4 semanas). La conducta dependerá de la disponibilidad del método y materiales adecuados (las prótesis metálicas cortas demostraron ser superiores a las prótesis plásticas en términos de eficacia y costo).

- ¿Está indicado el drenaje biliar endoscópico en pacientes con colestasis extrahepática por tumor de páncreas borderline o no resecable?

Todo paciente con signos de colestasis debe ser evaluado por el equipo multidisciplinario para definir la estrategia de manejo de la vía biliar previo al inicio del tratamiento. ${ }^{52,90}$

Consideramos que todo paciente elegible para un tratamiento neoadyuvante debe tener bilirrubina $<1,5$ veces el valor de referencia. ${ }^{52,90}$

El drenaje biliar endoscópico es la herramienta más adecuada en pacientes con cáncer de páncreas borderline o no resecable que presentan colestasis o síntomas relacionados (colangitis, prurito) asociados a la obstrucción de la vía biliar extrahepática.

El éxito técnico y clínico de la intervención endoscópica por CPRE debería ser $>90 \%$, con tasas de complicaciones $<10 \%$ en centros terciarios.

En casos en los que el drenaje es requerido recomendamos la realización de toma de muestra mediante el cepillado de la estenosis, aunque el rédito diagnóstico descrito es bajo (30 a 40\%), dado que si resultara concluyente para malignidad evitaría la realización del USE, el cual no se encuentra disponible con facilidad en nuestro medio.

La elección del tipo de stent biliar a utilizar dependerá de la disponibilidad y el escenario clínico. Se recomienda la colocación de stent metálico autoexpandible, ya que ha demostrado menor tasa de obstrucción y mejor relación costo/beneficio. ${ }^{165}$

\section{Rol del drenaje biliar percutáneo}

\section{- ¿Cuándo está indicado el drenaje biliar percu-} táneo?

El drenaje percutáneo de la vía biliar está indicado cuando no se dispone de CPRE.

Si se dispone de ecoendoscopía y CPRE en simultáneo, el drenaje percutáneo está indicado ante el fracaso de la CPRE y el rendez-vous ecoendoscópico-CPRE.

Si no se dispone de ecoendoscopía y CPRE en simultáneo, el drenaje percutáneo está indicado después del fracaso de la CPRE.

Tradicionalmente, el drenaje percutáneo de la vía biliar fue la segunda línea de tratamiento luego del fracaso del tratamiento endoscópico por CPRE, el cual es de aproximadamente 5 a $10 \%$. ${ }^{166}$ Este algoritmo se basó en el trabajo de Speer AG et al. ${ }^{167}$ en el cual se comparaba la 
colocación de stent por vía endoscópica y por vía percutánea, habiéndose observado mejores resultados en la rama endoscópica. Sin embargo, cabe destacar que este trabajo data de 1987 y, por lo tanto, contiene conceptos antiguos como la colocación de stents plásticos cuyos diámetros eran mucho mayores a los de los dispositivos de delivery de los stents metálicos actuales, lo que pudo haber generado mayores complicaciones en el grupo percutáneo.

En la actualidad, algunos estudios han demostrado que es seguro y efectivo colocar stents metálicos por vía percutánea en comparación con la vía endoscópica, ${ }^{168}$ por lo cual en centros donde no se realiza CPRE es una alternativa válida como primera línea de tratamiento.

Si bien hacen falta estudios prospectivos y randomizados de calidad que comparen la colocación de stents biliares metálicos de primera intención por vía percutánea y por vía endoscópica, el consenso actual es que la primera opción de tratamiento es la vía endoscópica, considerando el drenaje percutáneo como segunda línea ante el fracaso endoscópico o la falta de disponibilidad.

Como se mencionó previamente, en la actualidad existe una alternativa más: la ecoendoscopía. Por este método es posible realizar una técnica combinada de rendezvous ecoendoscópico más CPRE y, de ese modo, aumentar el éxito terapéutico de la CPRE. Ante el fracaso de este rendez-vous, existen dos técnicas ecoendoscópicas: la coledocoduodenostomía y la hepaticogastrostomía.

En un trabajo muy interesante, Jason G et al. ${ }^{169} \mathrm{com}$ pararon a un grupo de rendez-vous ecoendoscópico versus drenaje percutáneo en pacientes con CPRE fallida, y concluyeron que el éxito técnico fue mayor en el grupo percutáneo, aunque se observó que en aquellos pacientes en los cuales el rendez-vous fue exitoso, la cantidad de reintervenciones y la estadía hospitalaria fueron menores. Por tal motivo, si se dispone de ecoendoscopía y CPRE en simultáneo debe intentarse el rendez-vous, y si este fracasa debe indicarse el drenaje percutáneo. Si no se dispone de ecoendoscopía y CPRE en simultáneo, debe indicarse el drenaje percutáneo de la vía biliar ya que presenta tasa más alta de éxito técnico.

Las otras opciones ecoendoscópicas (coledocoduodenostomía y la hepaticogastrostomía) no demostraron hasta el momento superioridad con respecto al drenaje percutáneo de la vía biliar y no deberían utilizarse fuera de protocolos de investigación hasta que su efectividad sea probada. ${ }^{170}$

Hay pocos estudios prospectivos randomizados que comparen el drenaje ecoendoscópico versus el percutáneo después de CPRE fallida, y muestran resultados disímiles. ${ }^{171,172}$
Una vez que se ha indicado el drenaje percutáneo de la vía biliar, en pacientes con poco tiempo de ictericia, sin colangitis y con niveles de bilirrubina no muy elevados, o en pacientes con ascitis, puede realizarse la colocación del stent metálico no recubierto de primera intención, embolizando el trayecto de ingreso y sin dejar drenaje biliar. En los casos donde no se cumplan dichos requisitos, deberá realizarse primero un drenaje percutáneo de la vía biliar y en un segundo tiempo colocar el stent. ${ }^{173-175}$

- ¿Está indicado el drenaje biliar percutáneo en pacientes con síndrome coledociano por tumor de páncreas resecable?

El drenaje biliar endoscópico o percutáneo no está indicado de rutina en forma preoperatoria.

En el año 2010, en un estudio prospectivo randomizado multicéntrico, Van der Gaag NA et al. ${ }^{176}$ demostraron que el drenaje preoperatorio endoscópico estaba asociado a un incremento de las complicaciones. Sin embargo, algunos problemas de diseño fueron señalados: el tiempo entre el drenaje y la cirugía era demasiado prolongado ( 4 a 6 semanas) así como el uso de stents plásticos en lugar de metálicos.

Un reciente metaanálisis ${ }^{177}$ y otros estudios ${ }^{178}$ concluyeron que el drenaje preoperatorio está indicado solo en casos particulares y no en forma sistemática.

Su rol está sugerido en los siguientes escenarios: niveles de bilirrubina total superiores de $15 \mathrm{mg} / \mathrm{dL}$, tiempo estimado al tratamiento quirúrgico (más de 2 a 4 semanas). ${ }^{179,} 180$

En los casos en los cuales está indicado el drenaje preoperatorio, en un reciente metaanálisis que incluyó a 2334 pacientes, Dorcaratto D. ${ }^{181}$ sugirió que el drenaje percutáneo estaba asociado a menores complicaciones relacionadas al procedimiento y menores complicaciones postoperatorias en comparación con el drenaje endoscópico, pero no se observaron diferencias en las complicaciones mayores, fístula pancreática, infecciones de sitio quirúrgico y mortalidad. El riesgo de sesgo por la falta de estudio prospectivo fue alto así como la selección de pacientes para el grupo percutáneo posterior a tratamientos fallidos del grupo endoscópico sin análisis por intención de tratamiento.

\section{- ¿Está indicado el drenaje biliar percutáneo en pa- cientes con síndrome coledociano por tumor de pán- creas borderline o no resecable?}

Reiteramos la recomendación de que todo paciente con colestasis sea evaluado por el equipo multidisciplinario para definir la estrategia de manejo de la vía biliar previo al inicio del tratamiento. 
Como se mencionó, consideramos que todo paciente elegible para un tratamiento neoadyuvante debe tener bilirrubina $<1,5$ veces el valor de referencia.

Cuando el drenaje biliar está indicado por colestasis o síntomas relacionados (colangitis, prurito), la primera opción de tratamiento es la colocación de stents metálicos autoexpandibles cortos por CPRE. Ante su fracaso o falta de disponibilidad, está indicada su colocación por vía percutánea. ${ }^{180}$

\section{Seguimiento}

\section{- ¿Cuál es el seguimiento recomendado?}

El seguimiento del paciente con cáncer ACDP incluye evaluación clínica, imagenológica y laboratorio de rutina asociado a dosaje de CA 19-9.

En pacientes con enfermedad resecada se sugiere control cada 3-6 meses. ${ }^{52,} 90$

En pacientes con enfermedad metastásica se sugiere control cada 3 meses. ${ }^{52,90}$

- ¿Con qué método por imágenes se realiza el seguimiento del paciente operado de ACDP?

Mediante TC de tórax, abdomen y pelvis con contraste oral y EV en fase portal. En caso de alergia u otra contraindicación para TC se recomienda TC de tórax sin contraste y RM de abdomen y pelvis con contraste EV.

\section{Aspectos nutricionales}

La nutrición juega un papel importante en la prevención y el tratamiento del cáncer.

En los pacientes con cáncer, la presencia de malnutrición $(\mathrm{MN})$ afecta negativamente la evolución y la calidad de vida, aumentando la incidencia de infecciones, estadía hospitalaria y mortalidad. ${ }^{182,183}$

La sarcopenia y la caquexia en los pacientes con cáncer de páncreas se presentan con una prevalencia de 30-65\% y 80\%, respectivamente. ${ }^{210-213}$ Estos síndromes impactan negativamente en el performance status, la morbilidad postoperatoria, la respuesta al tratamiento y la expectativa de vida. ${ }^{182,}$ 184-189

Para promover un adecuado estado nutricional en pacientes con ACDP, es necesario un abordaje nutricional basado en la evidencia científica y en recomendaciones prácticas. Por ello, la intervención nutricional debe formar parte de la atención integral de los pacientes con esta patología.

\subsection{Evaluación y requerimientos nutricionales}

- ¿Cuándo realizar la evaluación nutricional en el paciente con ACDP?

Deberá realizarse una evaluación nutricional completa desde la primera consulta y durante todo el seguimiento con la finalidad de determinar el diagnóstico nutricional, definir los objetivos, planificar una intervención oportuna, monitorear el tratamiento y realizar los ajustes pertinentes. ${ }^{190}$

\section{Figura 1.}

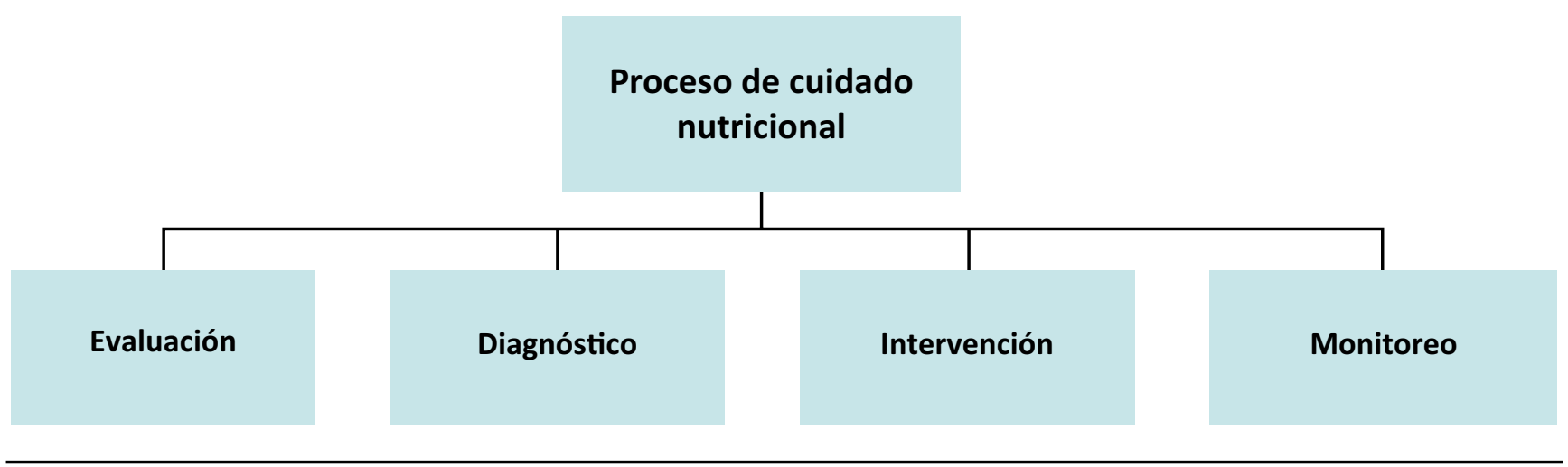

\footnotetext{
- ¡Cómo realizar la evaluación nutricional en el paciente con ACDP?

La evaluación nutricional comprende dos instancias:

- Tamizaje nutricional.

- Evaluación nutricional completa.

El tamizaje se realiza para identificar a los sujetos con riesgo nutricional, quienes deberán recibir posteriormente una evaluación completa para determinar el diagnóstico nutricional. ${ }^{190}$
}

Las herramientas de tamizaje validadas son: $\mathrm{Nu}$ tritional Risk Screening 2002 (NRS-2002), Malnutrición Universal Screening Tool (MUST), Mini-Nutritional Assessment (MNA) en su forma completa o corta (MNA-SF), Malnutrición Screening Tool (MST) y Short Nutritional Assessment Questionnaire (SNAQ). ${ }^{183}, 191-193$

La herramienta más adecuada es aquella que sea fácil de realizar, sensible a los cambios agudos y crónicos del 
estado nutricional, no invasiva y específica. La elección de la herramienta dependerá de cada institución.

La evaluación nutricional puede realizarse a través de la Valoración Global Subjetiva (VGS), la cual constituye un método clínico sistematizado e integrado que permite establecer el diagnóstico nutricional. ${ }^{194,195}$

La herramienta gold standard para pacientes oncológicos es la VGS-GP (Valoración Global Subjetiva Generada por el Paciente). ${ }^{192,195}$

Ambas herramientas permiten determinar el diagnóstico subjetivo del estado nutricional clasificando a los pacientes en: normonutridos o con MN moderada o severa.

Para completar la evaluación nutricional deben contemplarse:

a) Parámetros antropométricos: peso (actual y habitual), talla, índice de masa corporal (IMC), pliegues cutáneos, perímetros y circunferencias.

El porcentaje de pérdida de peso (\% PP) valora la severidad y significación de la variación del peso producida en relación con el tiempo y no se correlaciona necesariamente con un IMC bajo, por lo cual esta herramienta tradicional de la evaluación nutricional no debe ser considerada como un indicador de MN de manera aislada.

b) Parámetros bioquímicos: la albúmina es una proteína de fase aguda; este parámetro no debe ser contemplado como indicador nutricional, sino que cobra importancia como factor clínico-quirúrgico, como predictor de morbimortalidad. La proteína $\mathrm{C}$ reactiva (PCR) es una proteína de fase aguda que evidencia inflamación; cuando se encuentre dentro de parámetros normales, las proteínas viscerales podrán ser evaluadas como marcador nutricional.

c) Pruebas funcionales: la fuerza de agarre es una medida simple de la fuerza muscular y puede correlacionarse con el diagnóstico o pronóstico nutricional.

d) Evaluación de la ingesta alimentaria: incluye la anamnesis completa, el cálculo de la ingesta por vía oral (VO) y permite conocer en qué porcentaje se cubren los requerimientos nutricionales.

El resultado de la evaluación nutricional debe documentarse en la historia clínica para que todo el equipo de salud conozca el diagnóstico nutricional del paciente y el plan de intervención que se implementará.

La evaluación nutricional completa será aplicada por un licenciado en Nutrición debidamente especializado que disponga del equipamiento necesario para tal fin. ${ }^{196}$

\section{- ¿Cuáles son los requerimientos nutricionales?}

El gasto energético total de los pacientes con cáncer es similar al de los sujetos sanos.
Se recomienda que las necesidades energéticas se determinen mediante calorimetría indirecta y si no se dispone de este recurso utilizar un método práctico.

Los requerimientos nutricionales para pacientes con ACDP que este grupo recomienda se detallan en la Tabla 5 a continuación. ${ }^{197-199}$

\section{Tabla 5.}

\begin{tabular}{|c|c|}
\hline \multirow[t]{2}{*}{ Calorías } & 25-30 kcal/kg/día. \\
\hline & $\begin{array}{l}30-40 \mathrm{kcal} / \mathrm{kg} / \mathrm{dí} a \text { en paciente con malnutri- } \\
\text { ción. }\end{array}$ \\
\hline
\end{tabular}

Proteínas

$$
\text { 1,2-1,5 g/kg/día. }
$$

\section{$2 \mathrm{~g} / \mathrm{kg} / \mathrm{día}$ en paciente con hipercatabolismo.}

1-1,2 $\mathrm{g} / \mathrm{kg} / \mathrm{dí}$ en paciente con insuficiencia renal.

$\begin{array}{ll}\begin{array}{l}\text { Hidratos de } \\ \text { carbono y grasas }\end{array} & \text { Sin restricción. } \\ \text { Con selección individualizada. }\end{array}$

Micronutrientes Cubrir RDA (Recommended Dietary Allowance).

Suplementar en caso de deficiencia.

Zinc y vitamina $\mathrm{C}$ aumentados en paciente quirúrgico.

Selenio aumentado en estado crítico.

Para calcular los requerimientos nutricionales deberá utilizarse el peso actual. En caso de obesidad, se utilizará el peso ideal corregido.

\subsection{Terapia nutricional}

La terapia nutricional consiste en la provisión de nutrientes en pacientes que no logran cubrir sus requerimientos nutricionales exclusivamente con alimentos por VO. Su principal objetivo es prevenir o tratar la MN.

La terapia nutricional puede realizarse a través de suplementos nutricionales orales (SNO), nutrición enteral (NE) o nutrición parenteral (NP), exclusiva o complementaria.

Es requisito esencial para la utilización de terapia nutricional con SNO o NE la conservación de la capacidad funcional digesto-absortiva con el fin de asimilar los nutrientes aportados.

El beneficio de esta terapia se obtiene cuando se indica al paciente correcto y en el momento adecuado. ${ }^{200}$ 


\section{- ¿Cuándo está indicada la terapia nutricional?}

Está indicada en los siguientes casos: ${ }^{199,} 201$

- Pacientes con MN o en riesgo en el perioperatorio.

- Pacientes normonutridos que no podrán consumir alimentos por 7 días o más.

- Pacientes con baja ingesta alimentaria que no alcancen a cubrir el 50 a $75 \%$ de los requerimientos nutricionales por más de 7 días.

La European Society for Clinical Nutrition and Metabolism (ESPEN) definió "riesgo nutricional severo" a la presencia de, al menos, uno de los siguientes criterios:

- Pérdida de peso $>10-15 \%$ en 6 meses.

- IMC $<18,5 \mathrm{~kg} / \mathrm{m}^{2}$.

- VGS grado C.

- Albúmina sérica $<30 \mathrm{~g} / \mathrm{L}$ (sin evidencia de disfunción renal o hepática).

En pacientes con riesgo nutricional severo y que requieran cirugía, deberá implementarse la terapia nutricional para recuperar su estado antes del procedimiento quirúrgico.

A pesar de que el período de tiempo óptimo para la recuperación preoperatoria aún no está definido, un período de 7-14 días puede ser razonable para mejorar la morbilidad postoperatoria. ${ }^{202}$

\section{- ¿Cuáles son las vías de administración de la tera- pia nutricional?}

1. SNO: Es la primera intervención y la más comúnmente utilizada para optimizar la VO cuando esta es insuficiente (menor al 75\%). ${ }^{203}$

2. NE: Se indica en aquellos pacientes que presenten una ingesta alimentaria menor del $50 \%$ de sus requerimientos diarios y con abordaje previo de todas las medidas posibles para mejorar su ingesta (VO enriquecida y SNO) ${ }^{203,204}$

3. NP: Se utiliza cuando la NE resulta insuficiente o está contraindicada. Puede administrarse por vía periférica cuando se estime una duración a corto plazo (7-10 días) o por vía central si el período de administración es más prolongado. ${ }^{204}$

Cuando con la vía de elección no se cubran los requerimientos nutricionales, puede utilizarse la combinación de las distintas vías de administración mencionadas.

\footnotetext{
- ¿Qué tipo de fórmula enteral se recomienda en ACDP?

La elección de la fórmula dependerá de la capacidad digesto-absortiva de los individuos.

En pacientes con ACDP podrá evaluarse la tolerancia de fórmulas poliméricas. En caso de presentar síntomas
}

de insuficiencia pancreática exocrina (IPE), se recomienda utilizar fórmulas hidrolizadas (oligoméricas-semielementales) ya que son bajas en grasas, contienen ácidos grasos de cadena media y no requieren una actividad enzimática significativa para su absorción. ${ }^{205}$

Las fórmulas enriquecidas con inmunonutrientes tienen la función de atenuar la respuesta inflamatoria. El uso de estas fórmulas en pacientes con cáncer y sometidos a cirugía gastrointestinales se asocia con reducción de las infecciones postoperatorias y de la estadía hospitalaria. ${ }^{204} \mathrm{El}$ beneficio de la inmunonutrición en el perioperatorio deriva del efecto sinérgico de los tres principales inmunonutrientes (arginina, aceite de pescado y nucleótidos). ${ }^{206,207}$

Sin embargo, actualmente no hay evidencia clara para el uso exclusivo de estas fórmulas enriquecidas con inmunonutrientes versus el uso de una fórmula estándarpolimérica.

- ¿Qué implicancias nutricionales deben considerarse según el tipo de intervención quirúrgica?

La intervención quirúrgica representa una injuria que provoca un estrés inflamatorio, generando un estado de hipercatabolismo e hipermetabolismo. Si previo a la cirugía hay compromiso del estado nutricional, esta situación es aún más grave.

En la duodenopancreatectomía total o pancreatectomía total se requiere en forma inmediata la instauración de tratamiento de reemplazo con enzimas pancreáticas (TREP) y de insulina exógena. Por ello el plan de alimentación deberá ser adecuado a estas dos situaciones metabólicas.

En la DPC ocurren modificaciones anatómicas y funcionales que están relacionadas con el volumen de parénquima pancreático resecado, el estado del parénquima remanente y la reconstrucción del tracto gastrointestinal. Estas modificaciones producen alteraciones que pueden impactar en la evolución nutricional de los pacientes, pudiendo ocurrir el desarrollo de insuficiencia pancreática exocrina y/o endocrina.

En esplenopancreatectomía corporocaudal o pancreatectomía izquierda, los pacientes presentan generalmente adecuada tolerancia oral y por ello es posible progresar a una alimentación completa, variada y saludable. Es necesario el seguimiento para detectar insuficiencia pancreática endocrina y/o exocrina.

\section{- ¿Cuál es la intervención nutricional recomendada en el postoperatorio de ACDP?}

La intervención nutricional debe ser precoz. Siempre que sea factible, deberá priorizarse el uso de la vía digestiva: oral o NE frente a la NP. ${ }^{196}$ 
- VO: Según las recomendaciones del grupo de estudio internacional de cirugía pancreática (ISGPS), ${ }^{208}$ la reanudación temprana de la ingesta oral es segura. Esta vía de alimentación puede considerarse como primera opción únicamente en pacientes que llegan a la cirugía normonutridos y la progresión dependerá de la tolerancia individual. En esta etapa el objetivo proteico es más importante que la ingesta calórica, debido a que el inadecuado aporte proteico se asocia con pérdida de masa corporal, con un impacto negativo en la recuperación funcional y en la calidad de vida. ${ }^{202}$

En la práctica clínica, el inicio de la VO suele indicarse entre el $3^{\circ}$ a $5^{\circ}$ día postoperatorio, comenzando con dieta líquida y progresando según la tolerancia a una dieta completa, variada, fraccionada en 5 a 6 comidas, con volumen disminuido.

- NE: El inicio precoz, dentro de las primeras 24 a 48 h, estará indicado como primera opción en pacientes que no pueden iniciar $\mathrm{VO}$ temprana y en quienes presenten $\mathrm{MN}$ evidente al momento de la intervención quirúrgica.
La NE precoz ayuda a disminuir el íleo postoperatorio, atenuar la dismotilidad y prevenir el edema de la pared intestinal. ${ }^{206}$

La vía de acceso para la NE puede ser sonda nasoyeyunal o yeyunostomía de alimentación. La elección dependerá del equipo tratante.

La NE yeyunal debe realizarse con bomba de infusión continua. Se iniciará a baja velocidad de infusión y se sugiere progresar paulatinamente según evolución y tolerancia de cada paciente.

- NP: Estará indicada cuando las otras vías de alimentación no sean factibles o cuando sea necesario implementarla de manera complementaria en pacientes con complicaciones postoperatorias que no logren cubrir requerimientos nutricionales por otras vías. ${ }^{202,} 206$

En caso de requerir terapia nutricional mixta $(\mathrm{VO}+$ $\mathrm{NE}$ o $\mathrm{VO}+\mathrm{NE} / \mathrm{NP})$, continuar con NE y/o NP hasta cubrir más allá del $50 \%$ de los requerimientos nutricionales con $\mathrm{VO}$.

Figura 2. Algoritmo de intervención nutricional en el postoperatorio

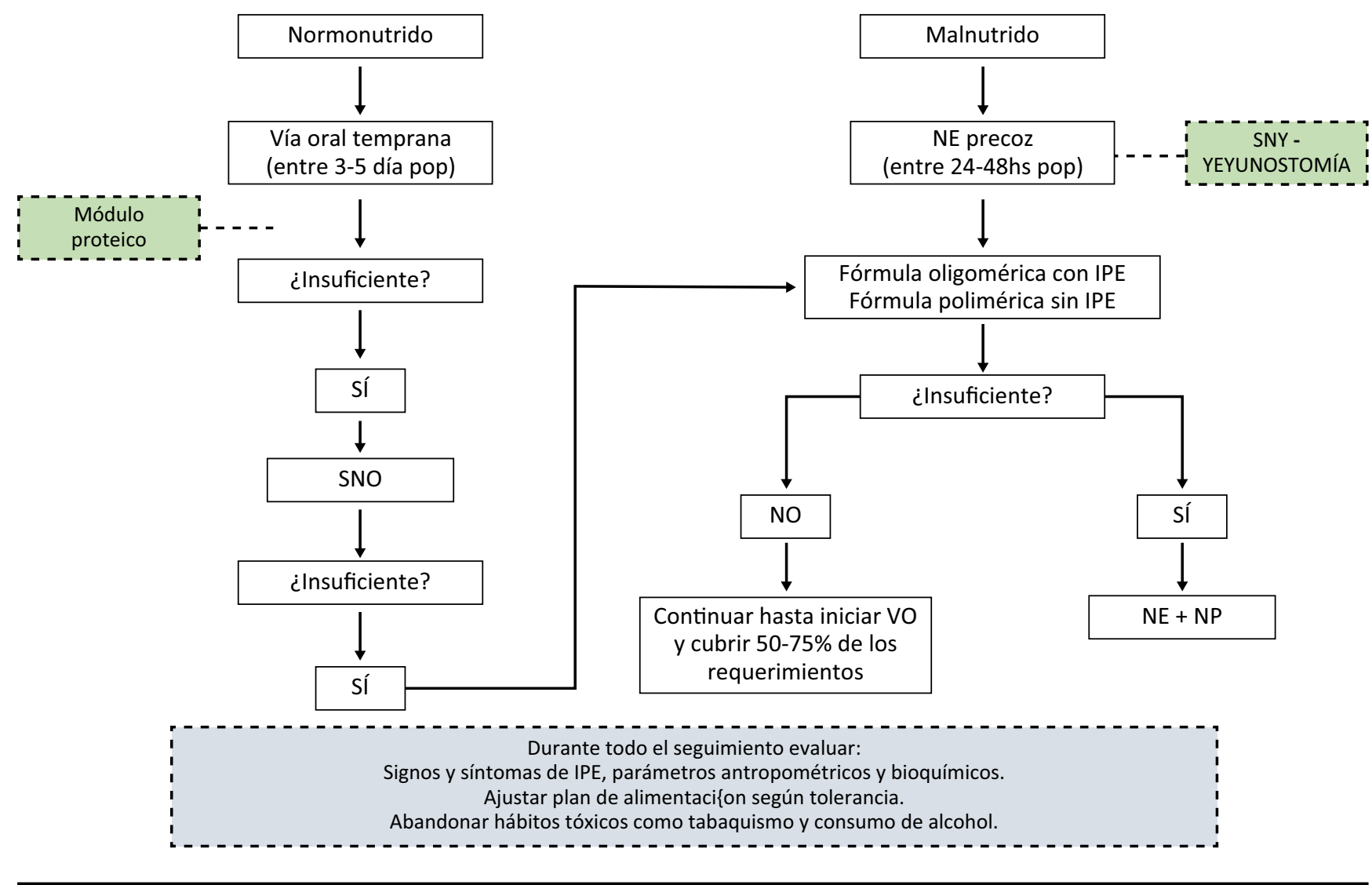

SNO: suplemento nutricional oral; NE: nutrición enteral; VO: vía oral; NP: nutrición parenteral; SNY: sonda nasoyeyunal; IPE: insuficiencia pancreática exocrina. 
- ¿Cuáles son las complicaciones postoperatorias que pueden obstaculizar la terapia nutricional?

Fístula pancreática: la elección de la vía de alimentación sigue siendo controversial. No hay evidencia que demuestre el beneficio de evitar la ingesta oral en pacientes clínicamente estables complicados por fístula pancreática. Según el ISGPS, ${ }^{208}$ los pacientes estables con una fístula de tipo A o B pueden tolerar alimentación oral. Sin embargo, cada caso debe ser abordado de manera particular de acuerdo con sus necesidades.

- ¿Cuál es la terapia nutricional sugerida en pacientes con tumores borderline?

En pacientes candidatos a recibir quimioterapia neoadyuvante es fundamental el seguimiento nutricional con el objetivo de prevenir o tratar la MN y lograr una adecuada recuperación nutricional previa al tratamiento quirúrgico.

\subsection{Insuficiencia pancreática exocrina (IPE)}

- ¿Cuándo se recomienda el testeo y/o tratamiento de IPE en pacientes con tumores de cabeza de páncreas?

En pacientes con tumores cefálicos que presentan signos de obstrucción ductal en las imágenes, la alta frecuencia de IPE justifica el TREP empírico temprano con supervisión de Gastroenterología y Nutrición con el objetivo de mejorar y/o mantener los parámetros nutricionales y la calidad de vida. ${ }^{209}$

Si no hay evidencias de obstrucción ductal y el paciente no presenta síntomas o signos de malnutrición (clínica y/o bioquímica) se recomienda utilizar el Test de Elastasa en materia fecal para decidir la indicación de TREP.

- ¿Cuándo se recomienda el testeo y/o tratamiento de IPE en pacientes con tumores de cuerpo y/o cola de páncreas?

En estos pacientes la frecuencia de IPE es menor que en los de localización cefálica y se recomienda utilizar el Test de Elastasa en materia fecal para decidir la indicación de TREP. ${ }^{209}$

\section{- ¿Cuál debería ser la dosis de enzimas pancreáticas para pacientes con ACDP?}

La dosis inicial de reemplazo se define teniendo en cuenta múltiples factores, entre los cuales está la localización del tumor, el estado del resto del parénquima pancreático y del conducto principal.

Se recomienda indicar cápsulas con 20.000-25.000 UI de lipasa durante las ingestas y a dosis iniciales de:
- Tumor cefálico. ${ }^{209}$

Comidas principales: 2-3 cápsulas.

Comidas menores: 1-2 cápsulas.

- Tumor de cuerpo-cola. ${ }^{209}$

Comidas principales: 2 cápsulas.

Comidas menores: 1 cápsula.

Como en otras situaciones, deben ser consideradas las características de las ingestas (volumen, valor calórico, contenido de grasa, duración).

El objetivo de la terapia de reemplazo con enzimas pancreáticas es normalizar la digestión, por lo cual es necesario individualizar el aporte de enzimas titulándolo según clínica y bioquímica.

- ¿Cuándo se recomienda el testeo y/o tratamiento de IPE luego de una DPC?

La probabilidad de IPE luego de una DPC por ACDP es especialmente alta. Si el paciente tiene síntomas de maldigestión, compromiso nutricional clínico o bioquímico o presentó obstrucción ductal preoperatoria, se acepta indicar TREP sin realizar ningún test previo.

Es importante resaltar que en los pacientes a los que se les realizó una DPC, el Test de Elastasa en materia fecal no es de utilidad ya que solo evalúa la secreción enzimática pancreática y no el proceso digestivo global, el cual se ve significativamente afectado por la asincronía entre el vaciado gástrico de los nutrientes y la secreción biliopancreática resultante de los cambios anatómicos producidos por este tipo de cirugía.

- ¿Cuándo se recomienda el testeo y/o tratamiento de IPE luego de una pancreatectomía izquierda?

En los pacientes con pancreatectomías izquierdas la variabilidad de la frecuencia de IPE hace necesaria la realización de pruebas diagnósticas. En estos casos, el Test de Elastasa en materia fecal es un estudio útil. El test de Van de Kamer y los parámetros nutricionales también son útiles como herramientas para tomar una decisión de tratamiento. ${ }^{209}$

- ¿Cuál debería ser la dosis de enzimas pancreáticas para pacientes sometidos a cirugías por ACDP?

La dosis inicial de reemplazo se define teniendo en cuenta múltiples factores, entre los cuales está el tipo de procedimiento quirúrgico realizado, el estado del conducto pancreático y del parénquima pancreático remanente.

Se recomienda indicar cápsulas con 20.000-25.000 UI de lipasa durante las ingestas, a dosis iniciales de: 
- Posduodenopancreatectomía total. ${ }^{209}$

Comidas principales: 3 cápsulas.

Comidas menores: 2 cápsulas.

- Post DPC. ${ }^{209}$

Comidas principales: 2-3 cápsulas.

Comidas menores: 1-2 cápsulas.

- Pospancreatectomía izquierda. ${ }^{209}$

Comidas principales: 2 cápsulas.

Comidas menores: 1 cápsula.

Como en otras situaciones, deben ser consideradas las características de las ingestas (volumen, valor calórico, contenido de grasa, duración). ${ }^{210,211}$

El objetivo de la terapia de reemplazo con enzimas pancreáticas es normalizar la digestión, por lo cual es necesario individualizar el aporte de enzimas titulándolo según clínica y bioquímica.

- ¿̨e recomienda indicar un inhibidor de la bomba de protones a pacientes con cáncer de páncreas (operados y no operados)?

Sí. La falta de bicarbonato en la luz ocasiona disminución del ph inactivando las enzimas pancreáticas.

- ¿Cuál es el manejo clínico-nutricional recomendado en pacientes que reciben TREP por vía oral?

Los pacientes deben recibir asesoramiento respecto del adecuado consumo de las enzimas pancreáticas. ${ }^{210-212}$

- Las cápsulas deben tragarse intactas, sin triturar ni masticar, con suficiente líquido durante cada comida y colación.

- Las enzimas deben administrarse durante las comidas (no antes ni después de comer). Para comidas de larga duración, distribuir las cápsulas.

- La eficacia del TREP se monitorea mediante la evolución clínica y de los parámetros nutricionales. ${ }^{213}$

El plan de alimentación debe ser completo, variado y saludable, fraccionado, con volumen disminuido. ${ }^{210,211}$

No restringir el aporte de grasa en la alimentación. Deberá ajustarse la dosis de enzimas en función del volumen y la cantidad de grasa de la comida. ${ }^{210,211}$

No exceder el consumo de 30 gramos de fibra diaria. ${ }^{210,211}$

En caso de una respuesta no satisfactoria al TREP y luego de verificar el adecuado cumplimiento del tratamiento podrá ser necesario ajustar la dosis enzimática, reevaluar la cantidad de grasa consumida y considerar el aporte de triglicéridos de cadena media. Otras consideraciones en el paciente no respondedor incluyen evaluar la indicación de un inhibidor de la bomba de protones, según el caso, y considerar la posibilidad de diagnósticos alternativos (sobrecrecimiento bacteriano intestinal, etcétera). ${ }^{211}$

\section{- ¿Cuál es el manejo recomendado del TREP en pacientes que reciben $\mathrm{NE}$ ?}

En esta situación, este consenso recomienda:

- Pacientes con NE exclusiva: utilizar fórmulas oligoméricas o semielementales que no requieren lipasa pancreática para su absorción. ${ }^{205,214}$

La administración de enzimas mediante la mezcla en la fórmula de alimentación no está respaldada por directrices y ningún estudio prospectivo demuestra la eficacia o seguridad de esta práctica. ${ }^{205,214}$

En caso de no contar con fórmulas oligoméricas o semielementales, no se recomienda la mezcla de fórmula polimérica con las enzimas debido a:

- Mayor manipulación del producto farmacéutico y mayor riesgo de contaminación.

- Posible riesgo de obstrucción de la sonda de alimentación.

- Menor actividad enzimática del preparado.

- La preparación y administración de estas mezclas puede suponer una carga para los enfermeros o cuidadores en términos de tiempo requerido.

- Pacientes con VO + NE complementaria: utilizar fórmula oligomérica para NE, y el TREP deberá calcularse en función de la ingesta oral (alimentos y/o SNO).

Si el paciente puede ingerir las cápsulas, una alternativa puede ser su administración distribuida: una dosis al comienzo de la NE, a la mitad y otra al final de la infusión intermitente de una fórmula enteral polimérica.

\section{Conflictos de Interés}

Para el desarrollo de estas recomendaciones consensuadas para el diagnóstico y tratamiento del cáncer de Páncreas, el aporte del laboratorio Abbott posibilitó la reunión física de los profesionales intervinientes, en Sierra de la Ventana, comarca Serrana a $120 \mathrm{~km}$ de la ciudad de Babia Blanca, con fecha 5 al 7 de abril de 2019. El grupo de trabajo fue conformado con colegas especialistas en patología pancreática de distintas especialidades, tanto de CABA. Ciudades del interior de provincia de Buenos Aires, como asi también de otras Provincias Argentinas. El conjunto de items seleccionados para su tratamiento, asi como las recomendaciones vertidas en el presente documento, surgen del análisis multidisciplinario de los profesionales participantes y de manera independiente. 


\section{Sin Conflictos de Interés}

Marisa Canicova; Jose Mella; Marcela Carballido; Mirta Kujaruk; Mariano Volpacchio; Tomas Lancelotti; Pablo Capitanich; Mariano Moro; Gustavo Kohan; Juan Carlos Spina; Hui Jer; Silvia Gutierrez; Eduardo Mullen; Javier Crisci; Graciela Uranga; Nicolas Munoz; Jorge Nefa; Sebastian Piaggio; Elisa Paneli; Diego Fernandez; Eduardo Javier Houghton; Lisandro Alle; María Laura Vergara; Anabel Villagra; Zohar Jastreblansky; Natalia Zavaroni; Luciana Olivero.

\section{Con Conflictos de Interés}

Sandra Basso es Speaker de Abbott y recibe grants RossmoreRoemmers. Lucio Uranga es Speaker de Abbott. Federico Cayol es Speaker de Merck Serono y Pfizer-Roche, y recibe grants de Merck Serono. Analia Pasqua es Speaker de Abbott. Lucas Granero es Speaker de Abbott. Oscar Mazza es Speaker de Abbott Johnson-Johnson. Federico Marcaccio es Speaker de Boston Scientific.

\section{Referencias}

1. Siegel RL, Miller KD, Jemal A. Cancer statistics, 2018 [Internet]. CA: A Cancer Journal for Clinicians 2018; 68: 7-30. Disponible en: http://dx.doi.org/10.3322/caac.21442

2. Bray F, Ferlay J, Soerjomataram I, Siegel RL, Torre LA, Jemal A. Global cancer statistics 2018: GLOBOCAN estimates of incidence and mortality worldwide for 36 cancers in 185 countries. CA Cancer J Clin 2018; 68 (6): 394-424.

3. Rahib L, Smith BD, Aizenberg R, Rosenzweig AB, Fleshman JM, Matrisian LM. Projecting cancer incidence and deaths to 2030: the unexpected burden of thyroid, liver, and pancreas cancers in the United States. Cancer Res 2014; 74 (11): 2913-2921.

4. Yeo TP. Demographics, epidemiology, and inheritance of pancreatic ductal adenocarcinoma. Semin Oncol 2015; 42 (1): 8-18.

5. Olson SH, Xu Y, Herzog K, Saldia A, DeFilippis EM, Li P, et al. Weight Loss, Diabetes, Fatigue, and Depression Preceding Pancreatic Cancer. Pancreas 2016; 45 (7): 986-991.

6. Porta M, Fabregat X, Malats N, Guarner L, Carrato A, de Miguel A, et al. Exocrine pancreatic cancer: symptoms at presentation and their relation to tumour site and stage. Clin Transl Oncol 2005; 7 (5): 189-197.

7. Li J, Li Y, Cao G, Guo K, Zhang L, Ma Q. Early manifestations of pancreatic cancer: the effect of cancer-nerve interaction. Med Hypotheses 2013; 81 (2): 180-182.

8. Munigala S, Kanwal F, Xian H, Scherrer JF, Agarwal B. Increased Risk of Pancreatic Adenocarcinoma After Acute Pancreatitis [Internet]. Clinical Gastroenterology and Hepatology 2014; 12: 1143-1150.e1. Disponible en: http://dx.doi.org/10.1016/j. cgh.2013.12.033
9. Phillips AE, Shah N, Borhani AA, Yadav D, Brand RE. Prior History of Pancreatitis Accelerates the Development of Pancreatic Adenocarcinoma. Pancreas 2018; 47 (10): 1262-1266.

10. Epstein AS, Soff GA, Capanu M, Crosbie C, Shah MA, Kelsen $\mathrm{DP}$, et al. Analysis of incidence and clinical outcomes in patients with thromboembolic events and invasive exocrine pancreatic cancer. Cancer 2012; 118 (12): 3053-3061.

11. Hicks AM, DeRosa A, Raj M, Do R, Yu KH, Lowery MA, et al. Visceral Thromboses in Pancreas Adenocarcinoma: Systematic Review. Clin Colorectal Cancer 2018; 17 (2): e207-e216.

12. Barnes AF, Yeo TP, Leiby B, Kay A, Winter JM. Pancreatic Cancer-Associated Depression [Internet]. Pancreas 2018; 47: 1065-1077. Disponible en: http://dx.doi.org/10.1097/ mpa.0000000000001148

13. Cosci F, Fava GA, Sonino N. Mood and Anxiety Disorders as Early Manifestations of Medical Illness: A Systematic Review [Internet]. Psychotherapy and Psychosomatics 2015; 84: 22-29. Disponible en: http://dx.doi.org/10.1159/000367913

14. Korc M, Jeon CY, Edderkaoui M, Pandol SJ, Petrov MS. Tobacco and alcohol as risk factors for pancreatic cancer [Internet]. Vol. 31, Best Practice \& Research Clinical Gastroenterology 2017; 31: 529-536. Disponible en: http://dx.doi.org/10.1016/j. bpg.2017.09.001

15. Lugo A, Peveri G, Bosetti C, Bagnardi V, Crippa A, Orsini N, et al. Strong excess risk of pancreatic cancer for low frequency and duration of cigarette smoking: A comprehensive review and metaanalysis. Eur J Cancer 2018; 104: 117-126.

16. Bosetti C, Lucenteforte E, Silverman DT, Petersen G, Bracci PM, Ji BT, et al. Cigarette smoking and pancreatic cancer: an analysis from the International Pancreatic Cancer Case-Control Consortium (Panc4) [Internet]. Annals of Oncology 2012; 23: 1880-1888. Disponible en: http://dx.doi.org/10.1093/annond $\operatorname{mdr} 541$

17. Rawla P, Sunkara T, Gaduputi V. Epidemiology of Pancreatic Cancer: Global Trends, Etiology and Risk Factors. World J Oncol 2019; 10 (1): 10-27.

18. Carreras-Torres R, Johansson M, Gaborieau V, Haycock PC, Wade KH, Relton CL, et al. The Role of Obesity, Type 2 Diabetes, and Metabolic Factors in Pancreatic Cancer: A Mendelian Randomization Study [Internet]. JNCI: Journal of the National Cancer Institute. 2017; 109. Disponible en: http://dx.doi. org/10.1093/jnci/djx012

19. Ben Q, Xu M, Ning X, Liu J, Hong S, Huang W, et al. Diabetes mellitus and risk of pancreatic cancer: A meta-analysis of cohort studies [Internet]. European Journal of Cancer 2011; 47: 1928-1937. Disponible en: http://dx.doi.org/10.1016/j. ejca.2011.03.003

20. Andersen DK, Korc M, Petersen GM, Eibl G, Li D, Rickels MR, et al. Diabetes, Pancreatogenic Diabetes, and Pancreatic Cancer [Internet]. Diabetes 2017; 66: 1103-1110. Disponible en: http:// dx.doi.org/10.2337/db16-1477

21. Chari ST, Leibson CL, Rabe KG, Ransom J, de Andrade M, Petersen GM. Probability of Pancreatic Cancer Following Diabetes: A Population-Based Study [Internet]. Gastroenterology 2005; 129: 504-511. Disponible en: http://dx.doi.org/10.1053/j.gastro.2005.05.007 
22. Maitra A, Sharma A, Brand RE, Van Den Eeden SK, Fisher WE, Hart PA, et al. A Prospective Study to Establish a New-Onset Diabetes Cohort [Internet]. Pancreas 2018; 47: 1244-1248. Disponible en: http://dx.doi.org/10.1097/ mpa.0000000000001169

23. Abbruzzese JL, Andersen DK, Borrebaeck CAK, Chari ST, Costello E, Cruz-Monserrate Z, et al. The Interface of Pancreatic Cancer With Diabetes, Obesity, and Inflammation [Internet]. Pancreas 2018; 47: 516-525. Disponible en: http://dx.doi.org/10.1097/ mpa.0000000000001037

24. Pothuraju R, Rachagani S, Junker WM, Chaudhary S, Saraswathi V, Kaur S, et al. Pancreatic cancer associated with obesity and diabetes: an alternative approach for its targeting [Internet]. Journal of Experimental \& Clinical Cancer Research 2018; 37. Disponible en: http://dx.doi.org/10.1186/s13046-018-0963-4

25. Talamini G, Falconi M, Bassi C, Sartori N, Salvia R, Caldiron E, et al. Incidence of Cancer in The Course of Chronic Pancreatitis [Internet]. American Journal of Gastroenterology 1999; 94: 1253-1260. Disponible en: http://dx.doi.org/10.1111/j.15720241.1999.01075.x

26. Raimondi S, Lowenfels AB, Morselli-Labate AM, Maisonneuve P, Pezzilli R. Pancreatic cancer in chronic pancreatitis; aetiology, incidence, and early detection [Internet]. Best Practice \& Research Clinical Gastroenterology 2010; 24: 349-358. Disponible en: http://dx.doi.org/10.1016/j.bpg.2010.02.007

27. Kamisawa T, Wood LD, Itoi T, Takaori K. Pancreatic cancer [Internet]. The Lancet 2016; 388: 73-85. Disponible en: http:// dx.doi.org/10.1016/s0140-6736(16)00141-0

28. Yabar CS, Winter JM. Pancreatic Cancer [Internet]. Gastroenterology Clinics of North America 2016; 45: 429-445. Disponible en: http://dx.doi.org/10.1016/j.gtc.2016.04.003

29. US Preventive Services Task Force, Owens DK, Davidson KW, Krist AH, Barry MJ, Cabana M, et al. Screening for Pancreatic Cancer: US Preventive Services Task Force Reaffirmation Recommendation Statement. JAMA 2019; 322 (5): 438-444.

30. Grover S, Syngal S. Hereditary Pancreatic Cancer [Internet]. Gastroenterology 2010; 139: 1076-1080.e2. Disponible en: http:// dx.doi.org/10.1053/j.gastro.2010.08.012

31. Van Lier MGF, Wagner A, Mathus-Vliegen EMH, Kuipers EJ, Steyerberg EW, Van Leerdam ME. High Cancer Risk in Peutz-Jeghers Syndrome: A Systematic Review and Surveillance Recommendations [Internet]. American Journal of Gastroenterology 2010; 105: 1258-1264. Disponible en: http://dx.doi. org/10.1038/ajg.2009.725

32. Van Asperen CJ. Cancer risks in BRCA2 families: estimates for sites other than breast and ovary [Internet]. Journal of Medical Genetics 2005; 42: 711-719. Disponible en: http://dx.doi. org/10.1136/jmg.2004.028829

33. De Snoo FA, Bishop DT, Bergman W, van Leeuwen I, Van der Drift C, Van Nieuwpoort FA, et al. Increased risk of cancer other than melanoma in CDKN2A founder mutation ( 16 Leiden)-positive melanoma families. Clin Cancer Res 2008; 14 (21): 7151-7157.

34. Kastrinos F, Mukherjee B, Tayob N, Wang F, Sparr J, Raymond $\mathrm{VM}$, et al. Risk of pancreatic cancer in families with Lynch syndrome. JAMA 2009; 302 (16): 1790-1795.
35. Giardiello FM, Offerhaus GJ, Lee DH, Krush AJ, Tersmette AC, Booker SV, et al. Increased risk of thyroid and pancreatic carcinoma in familial adenomatous polyposis. Gut 1993; 34 (10): 1394-1396.

36. Galiatsatos P, Foulkes WD. Familial Adenomatous Polyposis [Internet]. The American Journal of Gastroenterology 2006; 101: 385-398. Disponible en: http://dx.doi.org/10.1111/j.15720241.2006.00375.x

37. Bartsch DK, Gress TM, Langer P. Familial pancreatic cancercurrent knowledge. Nat Rev Gastroenterol Hepatol 2012; 9 (8): 445-453.

38. Rebours V, Boutron-Ruault M-C, Jooste V, Bouvier A-M, Hammel P, Ruszniewski P, et al. Mortality Rate and Risk Factors in Patients With Hereditary Pancreatitis: Uni- and Multidimensional Analyses [Internet]. The American Journal of Gastroenterology 2009; 104: 2312-2317. Disponible en: http://dx.doi. org/10.1038/ajg.2009.363

39. McGuigan A, Kelly P, Turkington RC, Jones C, Coleman HG, Stephen McCain R. Pancreatic cancer: A review of clinical diagnosis, epidemiology, treatment and outcomes [Internet]. Vol. 24, World Journal of Gastroenterology 2018; 24: 4846-4861. Disponible en: http://dx.doi.org/10.3748/wjg. v24.i43.4846

40. Canto MI, Harinck F, Hruban RH, Offerhaus GJ, Poley J-W, Kamel I, et al. International Cancer of the Pancreas Screening (CAPS) Consortium summit on the management of patients with increased risk for familial pancreatic cancer [Internet]. Gut 2013; 62: 339-347. Disponible en: http://dx.doi.org/10.1136/ gutjnl-2012-303108

41. Miura F, Takada T, Amano H, Yoshida M, Furui S, Takeshita K. Diagnosis of pancreatic cancer [Internet]. HPB 2006; 8: 337-342. Disponible en: http://dx.doi. org/10.1080/13651820500540949

42. Brennan DDD, Zamboni GA, Raptopoulos VD, Kruskal JB. Comprehensive Preoperative Assessment of Pancreatic Adenocarcinoma with 64-Section Volumetric CT [Internet]. RadioGraphics 2007; 27: 1653-1666. Disponible en: http://dx.doi. org/10.1148/rg.276075034

43. Sandrasegaran K, Lin C, Akisik FM, Tann M. State-of-the-Art Pancreatic MRI [Internet]. American Journal of Roentgenology 2010; 195: 42-53. Disponible en: http://dx.doi.org/10.2214/ ajr.10.4421

44. Tamm EP. Imaging of pancreatic ductal adenocarcinoma: State of the art [Internet]. World Journal of Radiology 2013; 5: 98. Disponible en: http://dx.doi.org/10.4329/wjr.v5.i3.98

45. Prokesch RW, Chow LC, Beaulieu CF, Bammer R, Jeffrey $\mathrm{RB}$ Jr. Isoattenuating pancreatic adenocarcinoma at multidetector row CT: secondary signs. Radiology 2002; 224 (3): 764-768.

46. Lee ES. Imaging diagnosis of pancreatic cancer: A state-of-the-art review [Internet]. World Journal of Gastroenterology 2014; 20: 7864. Disponible en: http://dx.doi.org/10.3748/wjg.v20.i24.7864

47. Sahani DV, Bonaffini PA, Catalano OA, Guimaraes AR, Blake MA. State-of-the-Art PET/CT of the Pancreas: Current Role and Emerging Indications [Internet]. RadioGraphics 2012; 32: 11331158. Disponible en: http://dx.doi.org/10.1148/rg.324115143 
48. Kauhanen SP, Komar G, Seppänen MP, Dean KI, Minn HR, Kajander SA, et al. A Prospective Diagnostic Accuracy Study of 18F-Fluorodeoxyglucose Positron Emission Tomography/Computed Tomography, Multidetector Row Computed Tomography, and Magnetic Resonance Imaging in Primary Diagnosis and Staging of Pancreatic Cancer [Internet]. Annals of Surgery 2009; 250: 957-963. Disponible en: http://dx.doi.org/10.1097/ sla.0b013e3181b2fafa

49. Pery C, Meurette G, Ansquer C, Frampas E, Regenet N. Role and limitations of $18 \mathrm{~F}-\mathrm{FDG}$ positron emission tomography (PET) in the management of patients with pancreatic lesions [Internet]. Gastroentérologie Clinique et Biologique 2010; 34: 465-474. Disponible en: http://dx.doi.org/10.1016/j.gcb.2009.04.014

50. Brook OR, Brook A, Vollmer CM, Kent TS, Sánchez N, Pedrosa I. Structured reporting of multiphasic CT for pancreatic cancer: potential effect on staging and surgical planning. Radiology 2015; 274 (2): 464-472.

51. Al-Hawary MM, Francis IR, Chari ST, Fishman EK, Hough DM, Lu DS, et al. Pancreatic Ductal Adenocarcinoma Radiology Reporting Template: Consensus Statement of the Society of Abdominal Radiology and the American Pancreatic Association [Internet]. Gastroenterology 2014; 146: 291-304.e1. Disponible en: http://dx.doi.org/10.1053/j.gastro.2013.11.004

52. Ducreux M, Sa. Cuhna A, Caramella C, Hollebecque A, Burtin $\mathrm{P}$, Goéré D, et al. Cancer of the pancreas: ESMO Clinical Practice Guidelines for diagnosis, treatment and follow-up [Internet]. Annals of Oncology 2015; 26: v56-v68. Disponible en: http:// dx.doi.org/10.1093/annonc/mdv295

53. Isaji S, Mizuno S, Windsor JA, Bassi C, Castillo CF, Hackert T, et al. International consensus on definition and criteria of borderline resectable pancreatic ductal adenocarcinoma 2017 [Internet]. Pancreatology 2018; 18: 2-11. Disponible en: http://dx.doi. org/10.1016/j.pan.2017.11.011

54. Holzapfel K, Reiser-Erkan C, Fingerle AA, Erkan M, Eiber MJ, Rummeny EJ, et al. Comparison of diffusion-weighted MR imaging and multidetector-row CT in the detection of liver metastases in patients operated for pancreatic cancer [Internet]. Abdominal Imaging 2011; 36: 179-184. Disponible en: http://dx.doi. org/10.1007/s00261-010-9633-5

55. Kitano M, Yoshida T, Itonaga M, Tamura T, Hatamaru K, Yamashita Y. Impact of endoscopic ultrasonography on diagnosis of pancreatic cancer [Internet]. Journal of Gastroenterology 2019; 54: 1932. Disponible en: http://dx.doi.org/10.1007/s00535-018-1519-2

56. Wang K-X, Ben Q-W, Jin Z-D, Du Y-Q, Zou D-W, Liao Z, et al. Assessment of morbidity and mortality associated with EUS-guided FNA: a systematic review [Internet]. Gastrointestinal Endoscopy 2011; 73: 283-290. Disponible en: http://dx.doi. org/10.1016/j.gie.2010.10.045

57. Sakamoto H, Kitano M, Suetomi Y, Maekawa K, Takeyama Y, Kudo M. Utility of Contrast-Enhanced Endoscopic Ultrasonography for Diagnosis of Small Pancreatic Carcinomas [Internet]. Ultrasound in Medicine \& Biology 2008; 34: 525-532. Disponible en: http://dx.doi.org/10.1016/j.ultrasmedbio.2007.09.018

58. Bodea R, Seicean A, Vasile T, Calinici T, Ciuca I, Al Hajjar N, et al. Role of computer tomography and endoscopic ultrasonography in assessing portal and superior mesenteric vessels invasion in cephalopancreatic adenocarcinoma. Ann Ital Chir 2017; 88: 336-341.
59. DeWitt J, Yu M, Al-Haddad MA, Sherman S, McHenry L, LeBlanc JK. Survival in patients with pancreatic cancer after the diagnosis of malignant ascites or liver metastases by EUS-FNA [Internet]. Gastrointestinal Endoscopy 2010; 71: 260-265. Disponible en: http://dx.doi.org/10.1016/j.gie.2009.08.025

60. Iglesias-García J, Lariño-Noia J, Domínguez-Muñoz J. When to puncture, when not to puncture: Pancreatic masses [Internet]. Endoscopic Ultrasound 2014; 3: 91. Disponible en: http:// dx.doi.org/10.4103/2303-9027.123007

61. Van Gulik TM, Reeders JW, Bosma A, Moojen TM, Smits NJ, Allema JH, et al. Incidence and clinical findings of benign, inflammatory disease in patients resected for presumed pancreatic head cancer. Gastrointest Endosc 1997; 46 (5): 417-423.

62. Abraham SC, Wilentz RE, Yeo CJ, Sohn TA, Cameron JL, Boitnott JK, et al. Pancreaticoduodenectomy (Whipple resections) in patients without malignancy: are they all "chronic pancreatitis"? Am J Surg Pathol 2003; 27 (1): 110-120.

63. Van Heerde MJ, Biermann K, Zondervan PE, Kazemier G, Van Eijck CHJ, Pek C, et al. Prevalence of autoimmune pancreatitis and other benign disorders in pancreatoduodenectomy for presumed malignancy of the pancreatic head. Dig Dis Sci 2012; 57 (9): 2458-2465.

64. Chen G, Liu S, Zhao Y, Dai M, Zhang T. Diagnostic accuracy of endoscopic ultrasound-guided fine-needle aspiration for pancreatic cancer: A meta-analysis [Internet]. Pancreatology 2013; 13: 298-304. Disponible en: http://dx.doi.org/10.1016/j. pan.2013.01.013

65. Banafea O, Mghanga FP, Zhao J, Zhao R, Zhu L. Endoscopic ultrasonography with fine-needle aspiration for histological diagnosis of solid pancreatic masses: a meta-analysis of diagnostic accuracy studies [Internet]. BMC Gastroenterology 2016; 16. Disponible en: http://dx.doi.org/10.1186/s12876-016-0519-z

66. Dumonceau J-M, Deprez PH, Jenssen C, Iglesias-García J, Larghi A, Vanbiervliet G, et al. Indications, results, and clinical impact of endoscopic ultrasound (EUS)-guided sampling in gastroenterology: European Society of Gastrointestinal Endoscopy (ESGE) Clinical Guideline - Updated January 2017. Endoscopy 2017; 49 (7): 695-714.

67. Song Z, Trujillo CN, Song H, Tongson-Ignacio JE, Chan MY. Endoscopic Ultrasound-Guided Tissue Acquisition Using ForkTip Needle Improves Histological Yield, Reduces Needle Passes, Without On-Site Cytopathological Evaluation [Internet]. Journal of Pancreatic Cancer 2018; 4: 75-80. Disponible en: http:// dx.doi.org/10.1089/pancan.2018.0018

68. James TW, Baron TH. A comprehensive review of endoscopic ultrasound core biopsy needles. Expert Rev Med Devices 2018; 15 (2): 127-135.

69. Khan M, Grimm I, Ali B, Nollan R, Tombazzi C, Ismail M, et al. A meta-analysis of endoscopic ultrasound-fine-needle aspiration compared to endoscopic ultrasound-fine-needle biopsy: diagnostic yield and the value of onsite cytopathological assessment [Internet]. Endoscopy International Open 2017; 5: E363-E375. Disponible en: http://dx.doi.org/10.1055/s-0043-101693

70. Bhatti I, Ojo D, Dennison AR, Rees Y, Elabassy M, Garcea G. Percutaneous Pancreatic Biopsies-Still an Effective Method for Histologic Confirmation of Malignancy. Surg Laparosc Endosc Percutan Tech 2016; 26 (4): 334-337. 
71. Tyng CJ. Computed tomography-guided percutaneous core needle biopsy in pancreatic tumor diagnosis [Internet]. World Journal of Gastroenterology 2015: 21: 3579. Disponible en: http://dx.doi.org/10.3748/wjg.v21.i12.3579

72. Eloubeidi MA, Tamhane A, Varadarajulu S, Wilcox CM. Frequency of major complications after EUS-guided FNA of solid pancreatic masses: a prospective evaluation. Gastrointest Endosc 2006; 63 (4): 622-629.

73. O’Toole D, Palazzo L, Arotçarena R, Dancour A, Aubert A, Hammel P, et al. Assessment of complications of EUSguided fine-needle aspiration. Gastrointest Endosc 2001; 53 (4): 470-474.

74. Chong A, Venugopal K, Segarajasingam D, Lisewski D. Tumor seeding after EUS-guided FNA of pancreatic tail neoplasia. Gastrointest Endosc 2011; 74 (4): 933-935.

75. Micames C, Jowell PS, White R, Paulson E, Nelson R, Morse $\mathrm{M}$, et al. Lower frequency of peritoneal carcinomatosis in patients with pancreatic cancer diagnosed by EUS-guided FNA vs. percutaneous FNA. Gastrointest Endosc 2003; 58 (5): 690-695.

76. Yoon WJ, Daglilar ES, Fernández-del Castillo C, Mino-Kenudson M, Pitman MB, Brugge WR. Peritoneal seeding in intraductal papillary mucinous neoplasm of the pancreas patients who underwent endoscopic ultrasound-guided fine-needle aspiration: the PIPE Study. Endoscopy 2014; 46 (5): 382-387.

77. Beane JD, House MG, Coté GA, DeWitt JM, Al-Haddad M, LeBlanc JK, et al. Outcomes after preoperative endoscopic ultrasonography and biopsy in patients undergoing distal pancreatectomy. Surgery 2011; 150 (4): 844-853.

78. Klapman JB, Logrono R, Dye CE, Waxman I. Clinical impact of on-site cytopathology interpretation on endoscopic ultrasound-guided fine needle aspiration. Am J Gastroenterol 2003; 98 (6):1289-1294.

79. Iglesias-García J, Domínguez-Muñoz JE, Abdulkader I, LarinoNoia J, Eugenyeva E, Lozano-Leon A, et al. Influence of on-site cytopathology evaluation on the diagnostic accuracy of endoscopic ultrasound-guided fine needle aspiration (EUS-FNA) of solid pancreatic masses. Am J Gastroenterol 2011; 106 (9): 1705-1710.

80. Schmidt RL, Witt BL, Matynia AP, Barraza G, Layfield LJ, Adler DG. Rapid on-site evaluation increases endoscopic ultrasoundguided fine-needle aspiration adequacy for pancreatic lesions. Dig Dis Sci 2013; 58 (3): 872-882.

81. Matynia AP, Schmidt RL, Barraza G, Layfield LJ, Siddiqui AA, Adler DG. Impact of rapid on-site evaluation on the adequacy of endoscopic-ultrasound guided fine-needle aspiration of solid pancreatic lesions: a systematic review and meta-analysis. J Gastroenterol Hepatol 2014; 29 (4): 697-705.

82. Jhala NC, Eltoum IA, Eloubeidi MA, Meara R, Chhieng DC, Crowe DR, et al. Providing on-site diagnosis of malignancy on endoscopic-ultrasound-guided fine-needle aspirates: should it be done? Ann Diagn Pathol. 2007; 11 (3): 176-181.

83. Iglesias-García J, Lariño-Noia J, Abdulkader I, Enrique Domínguez-Muñoz J. Rapid on-site evaluation of endoscopic-ultrasoundguided fine-needle aspiration diagnosis of pancreatic masses [Internet]. World Journal of Gastroenterology 2014; 20: 9451-9457. Disponible en: http://dx.doi.org/10.3748/wjg.v20.i28.9451
84. Abdelgawwad MS, Alston E, Eltoum IA. The frequency and cancer risk associated with the atypical cytologic diagnostic category in endoscopic ultrasound-guided fine-needle aspiration specimens of solid pancreatic lesions: a meta-analysis and argument for a Bethesda System for Reporting Cytopathology of the Pancreas. Cancer Cytopathol 2013; 121 (11): 620-628.

85. Pitman MB, Centeno BA, Ali SZ, Genevay M, Stelow E, MinoKenudson M, et al. Standardized terminology and nomenclature for pancreatobiliary cytology: the Papanicolaou Society of Cytopathology guidelines. Diagn Cytopathol 2014; 42 (4): 338-350.

86. Saieg MA, Munson V, Colletti S, Nassar A. The impact of the new proposed Papanicolaou Society of Cytopathology terminology for pancreaticobiliary cytology in endoscopic US-FNA: A single-institutional experience. Cancer Cytopathol 2015; 123 (8): 488-494.

87. Wright PK, Shelton DA, Holbrook MR, Thiryayi SA, Narine $\mathrm{N}$, Slater D, et al. Outcomes of endoscopic ultrasound-guided pancreatic FNAC diagnosis for solid and cystic lesions at Manchester Royal Infirmary based upon the Papanicolaou Society of Cytopathology pancreaticobiliary terminology classification scheme [Internet]. Cytopathology 2018; 29: 71-79. Disponible en: http://dx.doi.org/10.1111/cyt.12502

88. Hoda RS, Finer EB, Arpin RN 3rd, Rosenbaum M, Pitman MB. Risk of malignancy in the categories of the Papanicolaou Society of Cytopathology system for reporting pancreaticobiliary cytology. J Am Soc Cytopathol 2019; 8 (3): 120-127.

89. Kumar R, Herman JM, Wolfgang CL, Zheng L. Multidisciplinary Management of Pancreatic Cancer [Internet]. Surgical Oncology Clinics of North America 2013; 22: 265-287. Disponible en: http://dx.doi.org/10.1016/j.soc.2012.12.003

90. Disponible en: 153. Sitio web [acceso el 5 de abril de 2019 ]. Disponible en: National Comprehensive Cancer Network. Pancreatic Cancer (Version 1.2019). http://www.nccn.org/professionals/ physician_gls/pdf/pancreas [acceso en 2019]

91. Birkmeyer JD, Siewers AE, Finlayson EVA, Stukel TA, Lee Lucas F, Batista I, et al. Hospital Volume and Surgical Mortality in the United States [Internet]. New England Journal of Medicine 2002; 346: 11281137. Disponible en: http://dx.doi.org/10.1056/nejmsa012337

92. Meguid RA, Ahuja N, Chang DC. What Constitutes a "HighVolume" Hospital for Pancreatic Resection? [Internet]. Journal of the American College of Surgeons 2008; 206: 622.e1-622.e9. Disponible en: http://dx.doi.org/10.1016/j.jamcollsurg.2007.11.011

93. Sohn T, Yeo C, Cameron J, Koniaris L, Kaushal S, Abrams R, et al. Resected adenocarcinoma of the pancreas? 616 patients: results, outcomes, and prognostic indicators [Internet]. Vol. 4, Journal of Gastrointestinal Surgery 2000; 4: 567-579. Disponible en: http://dx.doi.org/10.1016/s1091-255x(00)80105-5

94. Khorana AA, Mangu PB, Berlin J, Engebretson A, Hong TS, Maitra A, et al. Potentially Curable Pancreatic Cancer: American Society of Clinical Oncology Clinical Practice Guideline Update [Internet]. Journal of Clinical Oncology 2017; 35: 2324-2328. Disponible en: http://dx.doi.org/10.1200/jco.2017.72.4948

95. Khorana AA, Mangu PB, Berlin J, Engebretson A, Hong TS, Maitra A, et al. Potentially Curable Pancreatic Cancer: American Society of Clinical Oncology Clinical Practice Guideline [Internet]. Journal of Clinical Oncology 2016; 34: 2541-2556. Disponible en: http://dx.doi.org/10.1200/jco.2016.67.5553 
96. Valle JW, Palmer D, Jackson R, Cox T, Neoptolemos JP, Ghaneh P, et al. Optimal Duration and Timing of Adjuvant Chemotherapy After Definitive Surgery for Ductal Adenocarcinoma of the Pancreas: Ongoing Lessons From the ESPAC-3 Study [Internet]. Journal of Clinical Oncology 2014; 32: 504-512. Disponible en: http://dx.doi.org/10.1200/ jco.2013.50.7657

97. Mirkin KA, Greenleaf EK, Hollenbeak CS, Wong J. Time to the initiation of adjuvant chemotherapy does not impact survival in patients with resected pancreatic cancer [Internet]. Cancer 2016; 122: 2979-2987. Disponible en: http://dx.doi. org/10.1002/cncr.30163

98. Conroy T, Desseigne F, Ychou M, Bouché O, Guimbaud R, Bécouarn $\mathrm{Y}$, et al. FOLFIRINOX versus Gemcitabine for Metastatic Pancreatic Cancer [Internet]. New England Journal of Medicine 2011; 364: 1817-1825. Disponible en: http://dx.doi. org/10.1056/nejmoa1011923

99. Conroy T, Hammel P, Hebbar M, Ben Abdelghani M, Wei AC, Raoul J-L, et al. FOLFIRINOX or Gemcitabine as Adjuvant Therapy for Pancreatic Cancer [Internet]. New England Journal of Medicine. 2018; 379: 2395-2406. Disponible en: http:// dx.doi.org/10.1056/nejmoa1809775

100. Neoptolemos JP, Palmer DH, Ghaneh P, Psarelli EE, Valle JW, Halloran CM, et al. Comparison of adjuvant gemcitabine and capecitabine with gemcitabine monotherapy in patients with resected pancreatic cancer (ESPAC-4): a multicentre, open-label, randomised, phase 3 trial. Lancet 2017; 389 (10073): 1011-1024.

101. Oettle H, Neuhaus P, Hochhaus A, Hartmann JT, Gellert K, Ridwelski K, et al. Adjuvant chemotherapy with gemcitabine and long-term outcomes among patients with resected pancreatic cancer: the CONKO-001 randomized trial. JAMA 2013; 310 (14): 1473-1481.

102. Oettle H, Post S, Neuhaus P, Gellert K, Langrehr J, Ridwelski $\mathrm{K}$, et al. Adjuvant chemotherapy with gemcitabine vs. observation in patients undergoing curative-intent resection of pancreatic cancer: a randomized controlled trial. JAMA 2007; 297 (3): 267-277.

103. Neoptolemos JP, Stocken DD, Friess H, Bassi C, Dunn JA, Hickey $\mathrm{H}$, et al. A Randomized Trial of Chemoradiotherapy and Chemotherapy after Resection of Pancreatic Cancer [Internet]. New England Journal of Medicine 2004; 350: 1200-1210. Disponible en: http://dx.doi.org/10.1056/nejmoa032295

104. Kalser MH, Ellenberg SS. Pancreatic cancer. Adjuvant combined radiation and chemotherapy following curative resection. Arch Surg 1985; 120 (8): 899-903.

105. Klinkenbijl JH, Jeekel J, Sahmoud T, Van Pel R, Couvreur ML, Veenhof $\mathrm{CH}$, et al. Adjuvant radiotherapy and 5-fluorouracil after curative resection of cancer of the pancreas and periampullary region: phase III trial of the EORTC gastrointestinal tract cancer cooperative group. Ann Surg 1999; 230 (6): 776-782. Discussion 782-784.

106. Butturini G. Influence of Resection Margins and Treatment on Survival in Patients With Pancreatic Cancer [Internet]. Archives of Surgery 2008; 143: 75. Disponible en: http://dx.doi. org/10.1001/archsurg.2007.17
107. Tzeng C-WD, Fleming JB, Lee JE, Wang X, Pisters PWT, Vauthey J-N, et al. Yield of clinical and radiographic surveillance in patients with resected pancreatic adenocarcinoma following multimodal therapy [Internet]. HPB 2012; 14: 365-372. Disponible en: http://dx.doi.org/10.1111/j.14772574.2012.00445.x

108. Chatterjee D, Katz MH, Rashid A, Varadhachary GR, Wolff $\mathrm{RA}$, Wang $\mathrm{H}$, et al. Histologic grading of the extent of residual carcinoma following neoadjuvant chemoradiation in pancreatic ductal adenocarcinoma [Internet]. Cancer 2012; 118: 3182-3190. Disponible en: http://dx.doi.org/10.1002/ cncr. 26651

109. Zhu X, Shi D, Li F, Ju X, Cao Y, Shen Y, et al. Prospective analysis of different combined regimens of stereotactic body radiation therapy and chemotherapy for locally advanced pancreatic cancer [Internet]. Cancer Medicine 2018; 7: 2913-2924. Disponible en: http://dx.doi.org/10.1002/cam4.1553

110. Park JJ, Hajj C, Reyngold M, Shi W, Zhang Z, Cuaron JJ, et al. Stereotactic body radiation vs. intensity-modulated radiation for unresectable pancreatic cancer. Acta Oncol 2017; 56 (12): 17461753.

111. Katz MHG, Fleming JB, Bhosale P, Varadhachary G, Lee JE, Wolff $\mathrm{R}$, et al. Response of borderline resectable pancreatic cancer to neoadjuvant therapy is not reflected by radiographic indicators [Internet]. Cancer 2012; 118: 5749-5756. Disponible en: http://dx.doi.org/10.1002/cncr.27636

112. Zins M, Matos C, Cassinotto C. Pancreatic Adenocarcinoma Staging in the Era of Preoperative Chemotherapy and Radiation Therapy [Internet]. Radiology 2018; 287: 374-390. Disponible en: http://dx.doi.org/10.1148/radiol.2018171670

113. Gassner E-M, Poskaite P. Imaging response evaluation after novel neoadjuvant treatments of pancreatic cancer [Internet]. European Surgery 2019; 51: 146-152. Disponible en: http:// dx.doi.org/10.1007/s10353-019-0598-5

114. Burris HA, Moore MJ, Andersen J, Green MR, Rothenberg ML, Modiano MR, et al. Improvements in survival and clinical benefit with gemcitabine as first-line therapy for patients with advanced pancreas cancer: a randomized trial [Internet]. Journal of Clinical Oncology 1997; 15: 2403-2413. Disponible en: http://dx.doi.org/10.1200/jco.1997.15.6.2403

115. Hoff DDV, Von Hoff DD, Ervin T, Arena FP, Gabriela Chiorean E, Infante J, et al. Increased Survival in Pancreatic Cancer with nab-Paclitaxel plus Gemcitabine [Internet]. New England Journal of Medicine 2013; 369: 1691-1703. Disponible en: http://dx.doi.org/10.1056/nejmoa1304369

116. Hann A, Bohle W, Egger J, Zoller W. Feasibility of alternating induction and maintenance chemotherapy in pancreatic cancer. Sci Rep 2017; 7: 41549.

117. Golan T, Hammel P, Reni M, Van Cutsem E, Macarulla T, Hall MJ, et al. Maintenance Olaparib for Germline -Mutated Metastatic Pancreatic Cancer. N Engl J Med 2019; 381 (4): 317-327.

118. Oettle H, Riess H, Stieler JM, Heil G, Schwaner I, Seraphin J, et al. Second-line oxaliplatin, folinic acid, and fluorouracil versus folinic acid and fluorouracil alone for gemcitabine-refractory pancreatic cancer: outcomes from the CONKO-003 trial. J Clin Oncol 2014; 32 (23): 2423-2429. 
119. Wang-Gillam A, Li C-P, Bodoky G, Dean A, Shan Y-S, Jameson $G$, et al. Nanoliposomal irinotecan with fluorouracil and folinic acid in metastatic pancreatic cancer after previous gemcitabinebased therapy (NAPOLI-1): a global, randomised, open-label, phase 3 trial. Lancet 2016; 387 (10018): 545-557.

120. Gill S, Ko Y-J, Cripps C, Beaudoin A, Dhesy-Thind S, Zulfiqar M, et al. PANCREOX: A Randomized Phase III Study of Fluorouracil/Leucovorin With or Without Oxaliplatin for SecondLine Advanced Pancreatic Cancer in Patients Who Have Received Gemcitabine-Based Chemotherapy. J Clin Oncol 2016; 34 (32): 3914-3920.

121. Mita N, Iwashita T, Uemura S, Yoshida K, Iwasa Y, Ando N, et al. Second-Line Gemcitabine Plus Nab-Paclitaxel for Patients with Unresectable Advanced Pancreatic Cancer after First-Line FOLFIRINOX Failure [Internet]. Journal of Clinical Medicine 2019; 8: 761. Disponible en: http://dx.doi.org/10.3390/ jcm8060761

122. Sohal DPS, Kennedy EB, Khorana A, Copur MS, Crane CH, Garrido-Laguna I, et al. Metastatic Pancreatic Cancer: ASCO Clinical Practice Guideline Update [Internet]. Journal of Clinical Oncology 2018; 36: 2545-2556. Disponible en: http:// dx.doi.org/10.1200/jco.2018.78.9636

123. Díaz LA Jr, Le DT. PD-1 Blockade in Tumors with MismatchRepair Deficiency [Internet]. New England Journal of Medicine 2015; 373: 1979. Disponible en: http://dx.doi.org/10.1056/ nejmc1510353

124. Fuccio L, Guido A, Larghi A, Antonini F, Lami G, Fabbri C. The role of endoscopic ultrasound in the radiation treatment of pancreatic tumor [Internet]. Expert Review of Gastroenterology \& Hepatology 2014; 8: 793-802. Disponible en: http://dx.doi. org/10.1586/17474124.2014.913479

125. Crinò SF, D’Onofrio M, Bernardoni L, Frulloni L, Iannelli M, Malleo G, et al. EUS-guided Radiofrequency Ablation (EUSRFA) of Solid Pancreatic Neoplasm Using an 18-gauge Needle Electrode: Feasibility, Safety, and Technical Success. J Gastrointestin Liver Dis 2018; 27 (1): 67-72.

126. Rustagi T, Chhoda A. Endoscopic Radiofrequency Ablation of the Pancreas [Internet]. Digestive Diseases and Sciences 2017; 62: 843-850. Disponible en: http://dx.doi.org/10.1007/ s10620-017-4452-y

127. Erratum to: NCCN Guidelines Insights: Small Cell Lung Cancer, Version 2.2018: J Natl Compr Canc Netw 2018; 16 (10): 1171-1182 [Internet]. Journal of the National Comprehensive Cancer Network 2019; 17: lvib. Disponible en: http://dx.doi. org/10.6004/jnccn.2019.0102

128. Tol JAMG, Johanna AM, Gouma DJ, Bassi C, Dervenis C, Montorsi $\mathrm{M}$, et al. Definition of a standard lymphadenectomy in surgery for pancreatic ductal adenocarcinoma: A consensus statement by the International Study Group on Pancreatic Surgery (ISGPS) [Internet]. Surgery 2014; 156: 591-600. Disponible en: http://dx.doi.org/10.1016/j.surg.2014.06.016

129. De Rooij T, Lu MZ, Steen MW, Gerhards MF, Dijkgraaf MG, Busch OR, et al. Minimally Invasive Versus Open Pancreatoduodenectomy: Systematic Review and Meta-analysis of Comparative Cohort and Registry Studies. Ann Surg 2016; 264 (2): 257-267.
130. Riviere D, Gurusamy KS, Kooby DA, Vollmer CM, Besselink MGH, Davidson BR, et al. Laparoscopic versus open distal pancreatectomy for pancreatic cancer [Internet]. Cochrane Database of Systematic Reviews 2016. Disponible en: http://dx.doi. org/10.1002/14651858.cd011391.pub2

131. Michelakos T, Pergolini I, Castillo CF, Honselmann KC, Cai L, Deshpande V, et al. Predictors of Resectability and Survival in Patients With Borderline and Locally Advanced Pancreatic Cancer who Underwent Neoadjuvant Treatment With FOLFIRINOX [Internet]. Annals of Surgery 2019; 269: 733-740. Disponible en: http://dx.doi.org/10.1097/ sla.0000000000002600

132. Hartwig W, Vollmer CM, Fingerhut A, Yeo CJ, Neoptolemos JP, Adham M, et al. Extended pancreatectomy in pancreatic ductal adenocarcinoma: Definition and consensus of the International Study Group for Pancreatic Surgery (ISGPS) [Internet]. Surgery 2014; 156: 1-14. Disponible en: http://dx.doi. org/10.1016/j.surg.2014.02.009

133. Ziegler KM, Nakeeb A, Pitt HA, Max Schmidt C, Bishop SN, Moreno J, et al. Pancreatic surgery: Evolution at a high-volume center [Internet]. Surgery 2010; 148: 702-710. Disponible en: http://dx.doi.org/10.1016/j.surg.2010.07.029

134. Nash G, Hutter RVP, Henson DE, for the Members of the Cancer Committee, College of American Pathologists, and the Task Force on the Examination of Specimens From Patients With Lung Cancer. Practice protocol for the examination of specimens from patients with lung cancer [Internet]. Cancer 1996; 77: 2167-2174. Disponible en: 3.0.co;2-r">http://dx.doi. org/10.1002/(sici)1097-0142(19960515)77:10<2167::aidcncr31>3.0.co;2-r

135. Cancer AJC on, American Joint Committee on Cancer. Exocrine and Endocrine Pancreas [Internet]. AJCC Cancer Staging Manual 2010: 241-249. Disponible en: http://dx.doi. org/10.1007/978-0-387-88441-7_24

136. Royal College of Pathologists. The Cell and Cancer: Symposium Organized by the Royal College of Pathologists, Entregado en Londres en febrero de 1973. Editado por A.R Currie 1974: 135.

137. Verbeke CS. Resection margins and R1 rates in pancreatic cancer - are we there yet? [Internet]. Histopathology 2008; 52: 787-796. Disponible en: http://dx.doi.org/10.1111/j.13652559.2007.02935.x

138. Elebro J, Jirström K. Use of a standardized diagnostic approach improves the prognostic information of histopathologic factors in pancreatic and periampullary adenocarcinoma. Diagn Pathol 2014; 9: 80 .

139. Adsay NV, Basturk O, Saka B, Bagci P, Ozdemir D, Balci S, et al. Whipple made simple for surgical pathologists: orientation, dissection, and sampling of pancreaticoduodenectomy specimens for a more practical and accurate evaluation of pancreatic, distal common bile duct, and ampullary tumors. Am J Surg Pathol 2014; 38 (4): 480-493.

140. Esposito I, Kleeff J, Bergmann F, Reiser C, Herpel E, Friess $\mathrm{H}$, et al. Most Pancreatic Cancer Resections are R1 Resections [Internet]. Annals of Surgical Oncology 2008; 15: 1651-1660. Disponible en: http://dx.doi.org/10.1245/s10434-008-9839-8. 
141. Jamieson NB, Foulis AK, Oien KA, Going JJ, Glen P, Dickson EJ, et al. Positive Mobilization Margins Alone Do Not Influence Survival Following Pancreatico-Duodenectomy for Pancreatic Ductal Adenocarcinoma [Internet]. Annals of Surgery 2010; 251: 1003-1010. Disponible en: http://dx.doi.org/10.1097/ sla.0b013e3181d77369

142. Sobin LH, Gospodarowicz MK, Wittekind C. TNM Classification of Malignant Tumours. John Wiley \& Sons 2011: 336.

143. Bockhorn M, Uzunoglu FG, Adham M, Imrie C, Milicevic M, Sandberg AA, et al. Borderline resectable pancreatic cancer: A consensus statement by the International Study Group of Pancreatic Surgery (ISGPS) [Internet]. Surgery 2014; 155: 977-988. Disponible en: http://dx.doi.org/10.1016/j. surg.2014.02.001

144. Campbell F, Smith RA, Whelan P, Sutton R, Raraty M, Neoptolemos JP, et al. Classification of R1 resections for pancreatic cancer: the prognostic relevance of tumour involvement within $1 \mathrm{~mm}$ of a resection margin. Histopathology 2009; 55 (3): 277-283.

145. Jamieson NB, Chan NIJ, Foulis AK, Dickson EJ, McKay CJ, Carter CR. The prognostic influence of resection margin clearance following pancreaticoduodenectomy for pancreatic ductal adenocarcinoma. J Gastrointest Surg 2013; 17 (3): 511-521.

146. Liu L, Katz MH, Lee SM, Fischer LK, Prakash L, Parker N, et al. Superior Mesenteric Artery Margin of Posttherapy Pancreaticoduodenectomy and Prognosis in Patients With Pancreatic Ductal Adenocarcinoma [Internet]. The American Journal of Surgical Pathology 2015; 39: 1395-1403. Disponible en: http:// dx.doi.org/10.1097/pas.0000000000000491

147. Evans DB, Rich TA, Byrd DR, Cleary KR, Connelly JH, Levin $\mathrm{B}$, et al. Preoperative chemoradiation and pancreaticoduodenectomy for adenocarcinoma of the pancreas. Arch Surg 1992; 127 (11): 1335-1339.

148. College of American Pathologists. College of American Pathologists Conference XXXIV 1999.

149. Gospodarowicz MK, Brierley JD, Wittekind C. TNM Classification of Malignant Tumours. John Wiley \& Sons 2017: 272.

150. Gress F, Schmitt C, Sherman S, Ikenberry S, Lehman G. A prospective randomized comparison of endoscopic ultrasound-and computed tomography-guided celiac plexus block for managing chronic pancreatitis pain [Internet]. The American Journal of Gastroenterology 1999; 94: 900-905. Disponible en: http:// dx.doi.org/10.1111/j.1572-0241.1999.01042.x

151. Wyse JM, Carone M, Paquin SC, Usatii M, Sahai AV. Randomized, double-blind, controlled trial of early endoscopic ultrasound-guided celiac plexus neurolysis to prevent pain progression in patients with newly diagnosed, painful, inoperable pancreatic cancer. J Clin Oncol 2011; 29 (26): 3541-3546.

152. Jeurnink SM, Steyerberg EW, Van Hooft JE, Van Eijck CHJ, Schwartz MP, Vleggaar FP, et al. Surgical gastrojejunostomy or endoscopic stent placement for the palliation of malignant gastric outlet obstruction (SUSTENT study): a multicenter randomized trial. Gastrointest Endosc 2010; 71 (3): 490-499.
153. Nagaraja V, Eslick GD, Cox MR. Endoscopic stenting versus operative gastrojejunostomy for malignant gastric outlet obstruction-a systematic review and meta-analysis of randomized and non-randomized trials. J Gastrointest Oncol 2014; 5 (2): 92-98.

154. Baron TH. Minimizing Endoscopic Complications: Endoluminal Stents [Internet]. Gastrointestinal Endoscopy Clinics of North America 2007; 17: 83-104. Disponible en: http://dx.doi. org/10.1016/j.giec.2007.01.004

155. Amin S, Sethi A. Endoscopic Ultrasound-Guided Gastrojejunostomy [Internet]. Gastrointestinal Endoscopy Clinics of North America 2017; 27: 707-713. Disponible en: http://dx.doi. org/10.1016/j.giec.2017.06.009

156. Irani S, Baron TH, Itoi T, Khashab MA. Endoscopic gastroenterostomy: techniques and review. Curr Opin Gastroenterol 2017; 33 (5): 320-329.

157. Yoshida Y, Fukutomi A, Tanaka M, Sugiura T, Kawata N, Kawai S, et al. Gastrojejunostomy versus duodenal stent placement for gastric outlet obstruction in patients with unresectable pancreatic cancer. Pancreatology 2017; 17 (6): 983-989.

158. Van Heek NT, Van Geenen RCI, Busch ORC, Gouma DJ. Palliative treatment in "peri"-pancreatic carcinoma: stenting or surgical therapy? Acta Gastroenterol Belg 2002; 65 (3): 171175.

159. Woo SM, Kim DH, Lee WJ, Park KW, Park S-J, Han S-S, et al. Comparison of uncovered and covered stents for the treatment of malignant duodenal obstruction caused by pancreaticobiliary cancer. Surg Endosc 2013; 27 (6): 2031-2039.

160. Baron TH, Schöfl R, Puespoek A, Sakai Y. Expandable metal stent placement for gastric outlet obstruction. Endoscopy 2001; 33 (7): 623-628.

161. Van Halsema EE, Rauws EAJ, Fockens P, van Hooft JE. Selfexpandable metal stents for malignant gastric outlet obstruction: A pooled analysis of prospective literature. World J Gastroenterol 2015; 21 (43): 12468-12481.

162. Mendelsohn RB, Gerdes H, Markowitz AJ, DiMaio CJ, Schattner MA. Carcinomatosis is not a contraindication to enteral stenting in selected patients with malignant gastric outlet obstruction [Internet]. Gastrointestinal Endoscopy 2011; 73: 1135-1140. Disponible en: http://dx.doi.org/10.1016/j. gie.2011.01.042

163. Sharaiha RZ, Khan MA, Kamal F, Tyberg A, Tombazzi CR, Ali B, et al. Efficacy and safety of EUS-guided biliary drainage in comparison with percutaneous biliary drainage when ERCP fails: a systematic review and meta-analysis [Internet]. Gastrointestinal Endoscopy 2017; 85: 904-914. Disponible en: http:// dx.doi.org/10.1016/j.gie.2016.12.023

164. Saxena P, Baars J, Kaffes A. EUS-guided biliary drainage: A comprehensive review of the literature [Internet]. Endoscopic Ultrasound 2018; 7: 4. Disponible en: http://dx.doi.org/10.4103/eus. eus_105_17

165. Almadi MA, Barkun A, Martel M. Plastic vs. Self-Expandable Metal Stents for Palliation in Malignant Biliary Obstruction: A Series of Meta-Analyses [Internet]. American Journal of Gastroenterology 2017; 112: 260-273. Disponible en: http:// dx.doi.org/10.1038/ajg.2016.512 
166. Prachayakul V, Aswakul P. Endoscopic ultrasound-guided biliary drainage as an alternative to percutaneous drainage and surgical bypass. World J Gastrointest Endosc 2015; 7 (1): 37-44.

167. Speer A, Christopher R, Russell G, Hatfield AW, Macrae K, Cotton P, et al. Randomised Trial of Endoscopic Versus Percutaneous Stent Insertion in Malignant Obstructive Jaundice [Internet]. The Lancet 1987; 330: 57-62. Disponible en: http:// dx.doi.org/10.1016/s0140-6736(87)92733-4

168. Briggs CD, Irving GRB, Cresswell A, Peck R, Lee F, Peterson $\mathrm{M}$, et al. Percutaneous transhepatic insertion of self-expanding short metal stents for biliary obstruction before resection of pancreatic or duodenal malignancy proves to be safe and effective. Surg Endosc 2010; 24 (3): 567-571.

169. Bill JG, Darcy M, Fujii-Lau LL, Mullady DK, Gaddam S, Murad FM, et al. A comparison between endoscopic ultrasoundguided rendezvous and percutaneous biliary drainage after failed ERCP for malignant distal biliary obstruction. Endosc Int Open 2016; 4 (9): E980-E985.

170. Nakai Y, Isayama H, Yamamoto N, Matsubara S, Kogure H, Mizuno S, et al. Su1275 EUS-Guided Biliary Intervention: Does EUS Always Come After Failed ERCP? [Internet]. Gastrointestinal Endoscopy 2016; 83: AB332. Disponible en: http://dx.doi.org/10.1016/j. gie.2016.03.849

171. Artifon ELA, Aparicio D, Paione JB, Lo SK, Bordini A, Rabello C, et al. Biliary drainage in patients with unresectable, malignant obstruction where ERCP fails: endoscopic ultrasonography-guided choledochoduodenostomy versus percutaneous drainage. J Clin Gastroenterol 2012; 46 (9): 768-774.

172. Khashab MA, Valeshabad AK, Afghani E, Singh VK, Kumbhari $\mathrm{V}$, Messallam A, et al. A comparative evaluation of EUS-guided biliary drainage and percutaneous drainage in patients with distal malignant biliary obstruction and failed ERCP. Dig Dis Sci 2015; 60 (2): 557-565.

173. Sofue K, Arai Y, Takeuchi Y, Fujiwara H, Tokue H, Sugimura K. Safety and efficacy of primary metallic biliary stent placement with tract embolization in patients with massive ascites: a retrospective analysis of 16 patients. J Vasc Interv Radiol 2012; 23 (4): 521-527.

174. Yoshida H, Mamada Y, Taniai N, Mizuguchi Y, Shimizu T, Yokomuro $S$, et al. One-step palliative treatment method for obstructive jaundice caused by unresectable malignancies by percutaneous transhepatic insertion of an expandable metallic stent. World J Gastroenterol 2006; 12 (15): 2423-2426.

175. Thornton RH, Frank BS, Covey AM, Maybody M, Solomon SB, Getrajdman GI, et al. Catheter-free survival after primary percutaneous stenting of malignant bile duct obstruction. AJR Am J Roentgenol 2011; 197 (3): W514-W518.

176. Kumar A. Faculty Opinions recommendation of Preoperative biliary drainage for cancer of the head of the pancreas [Internet]. Faculty Opinions - Post-Publication Peer Review of the Biomedical Literature 2010. Disponible en: http://dx.doi. org/10.3410/f.1598956.1091054
177. Fang Y, Gurusamy KS, Wang Q, Davidson BR, Lin H, Xie X, et al. Pre-operative biliary drainage for obstructive jaundice. Cochrane Database Syst Rev 2012; 9: CD005444.

178. Iacono C, Ruzzenente A, Campagnaro T, Bortolasi L, Valdegamberi A, Guglielmi A. Role of preoperative biliary drainage in jaundiced patients who are candidates for pancreatoduodenectomy or hepatic resection: highlights and drawbacks. Ann Surg 2013; 257 (2): 191-204.

179. Sauvanet A, Boher J-M, Paye F, Bachellier P, Sa Cuhna A, Le Treut Y-P, et al. Severe Jaundice Increases Early Severe Morbidity and Decreases Long-Term Survival after Pancreaticoduodenectomy for Pancreatic Adenocarcinoma. J Am Coll Surg 2015; 221 (2): 380-389.

180. Tol JAMG, Johanna AM, Busch ORC, Van der Gaag NA, van Gulik TM, Gouma DJ. The Quandary of Preresection Biliary Drainage for Pancreatic Cancer [Internet]. The Cancer Journal 2012; 18: 550-554. Disponible en: http://dx.doi.org/10.1097/ ppo.0b013e31827568b6

181. Dorcaratto D, Hogan NM, Muñoz E, Garcés M, Limongelli P, Sabater L, et al. Is Percutaneous Transhepatic Biliary Drainage Better than Endoscopic Drainage in the Management of Jaundiced Patients Awaiting Pancreaticoduodenectomy? A Systematic Review and Meta-analysis [Internet]. Journal of Vascular and Interventional Radiology 2018; 29: 676-687. Disponible en: http://dx.doi.org/10.1016/j.jvir.2017.12.027

182. Mattox TW. Cancer Cachexia: Cause, Diagnosis, and Treatment. Nutr Clin Pract 2017; 32 (5): 599-606.

183. Gilliland T, Villafane-Ferriol N, Shah K, Shah R, Cao HT, Massarweh N, et al. Nutritional and Metabolic Derangements in Pancreatic Cancer and Pancreatic Resection [Internet]. Nutrients 2017; 9: 243. Disponible en: http://dx.doi.org/10.3390/ nu9030243

184. Chan MY, Chok KSH. Sarcopenia in pancreatic cancer - effects on surgical outcomes and chemotherapy [Internet]. World Journal of Gastrointestinal Oncology 2019; 11: 527-537. Disponible en: http://dx.doi.org/10.4251/wjgo.v11.i7.527

185. Lee SH, Chung MJ, Kim B, Lee HS, Lee HJ, Heo JY, et al. The Significance of the Prognostic Nutritional Index for All Stages of Pancreatic Cancer. Nutr Cancer 2017; 69 (3): 512-519.

186. Tan CR, Yaffee PM, Jamil LH, Lo SK, Nissen N, Pandol SJ, et al. Pancreatic cancer cachexia: a review of mechanisms and therapeutics. Front Physiol 2014; 5: 88.

187. Pausch T, Hartwig W, Hinz U, Swolana T, Bundy BD, Hackert $\mathrm{T}$, et al. Cachexia but not obesity worsens the postoperative outcome after pancreatoduodenectomy in pancreatic cancer [Internet]. Surgery 2012; 152: S81-S88. Disponible en: http:// dx.doi.org/10.1016/j.surg.2012.05.028

188. Gärtner S, Krüger J, Aghdassi AA, Steveling A, Simon P, Lerch MM, et al. Nutrition in Pancreatic Cancer: A Review [Internet]. Gastrointestinal Tumors 2016; 2: 195-202. Disponible en: http://dx.doi.org/10.1159/000442873

189. Bicakli DH, Uslu R, Güney SC, Coker A. The Relationship Between Nutritional Status, Performance Status, and Survival Among Pancreatic Cancer Patients. Nutr Cancer 2020; 72 (2): 202-208.

190. Canicoba ME, Alza SM. Valoración del estado nutricional en diversas situaciones clínicas. Fondo editorial UPN 2018: 581. 
191. Camblor-Álvarez M, Ocón-Bretón MJ, Luengo-Pérez LM, Viruzuela JA, Sendrós-Maroño MJ, Cervera-Peris M, et al. Soporte nutricional y nutrición parenteral en el paciente oncológico: informe de consenso de un grupo de expertos [Internet]. Nutrición Hospitalaria 2018. Disponible en: http://dx.doi. org/10.20960/nh.1361

192. Thompson KL, Elliott L, Fuchs-Tarlovsky V, Levin RM, Voss AC, Piemonte T. Oncology Evidence-Based Nutrition Practice Guideline for Adults [Internet]. Journal of the Academy of Nutrition and Dietetics 2017; 117: 297-310.e47. Disponible en: http://dx.doi.org/10.1016/j.jand.2016.05.010

193. Kirsch R, Matthews K, Williams V. Using Global Criteria to Detect Malnutrition: Application in Disease States [Internet]. Nutrition in Clinical Practice 2020; 35: 85-97. Disponible en: http://dx.doi.org/10.1002/ncp.10444

194. Detsky AS, Baker JP, O’Rourke K, Johnston N, Whitwell J, Mendelson RA, et al. Predicting nutrition-associated complications for patients undergoing gastrointestinal surgery. JPEN J Parenter Enteral Nutr 1987; 11 (5): 440-446.

195. August DA, Huhmann MB, the American Society for Parenteral and Enteral Nutrition (A. S. P. E. N.) Board of Directors. A.S.P.E.N. Clinical Guidelines: Nutrition Support Therapy During Adult Anticancer Treatment and in Hematopoietic Cell Transplantation [Internet]. Journal of Parenteral and Enteral Nutrition 2009; 33: 472-500. Disponible en: http://dx.doi. org/10.1177/0148607109341804

196. O’Reilly D, Fou L, Hasler E, Hawkins J, O’Connell S, Pelone F, et al. Diagnosis and management of pancreatic cancer in adults: A summary of guidelines from the UK National Institute for Health and Care Excellence. Pancreatology 2018; 18 (8): 962-970.

197. Arends J, Baracos V, Bertz H, Bozzetti F, Calder PC, Deutz NEP, et al. ESPEN expert group recommendations for action against cancer-related malnutrition. Clin Nutr 2017; 36 (5): 1187-1196.

198. Afaneh C, Gerszberg D, Slattery E, Seres DS, Chabot JA, Kluger MD. Pancreatic cancer surgery and nutrition management: a review of the current literature. Hepatobiliary Surg Nutr 2015; 4 (1): 59-71.

199. de las Peñas R, Majem M, Pérez-Altozano J, Virizuela JA, Cancer E, et al. SEOM clinical guidelines on nutrition in cancer patients (2018) [Internet]. Clinical and Translational Oncology 2019; 21: 87-93. Disponible en: http://dx.doi.org/10.1007/ s12094-018-02009-3

200. Laviano A, Di Lazzaro L, Koverech A. Nutrition support and clinical outcome in advanced cancer patients. Proc Nutr Soc 2018; 77 (4): 388-393.

201. Neumann I, Cifuentes L. Hacia guías de práctica clínica más confiables: La Guía para el manejo de la Influenza del Ministerio de Salud [Internet]. Revista Médica de Chile 2012; 140 : 1615-1616. Disponible en: http://dx.doi.org/10.4067/s003498872012001200015

202. Wischmeyer PE, Carli F, Evans DC, Guilbert S, Kozar R, Pryor A, et al. American Society for Enhanced Recovery and Perioperative Quality Initiative Joint Consensus Statement on Nutrition Screening and Therapy Within a Surgical Enhanced Recovery Pathway. Anesth Analg 2018; 126 (6): 1883-1895.
203. West MA, Wischmeyer PE, Grocott MPW. Prehabilitation and Nutritional Support to Improve Perioperative Outcomes. Curr Anesthesiol Rep 2017; 7 (4): 340-349.

204. Weimann A, Braga M, Carli F, Higashiguchi T, Hübner M, Klek $S$, et al. ESPEN guideline: Clinical nutrition in surgery [Internet]. Clinical Nutrition 2017; 36: 623-650. Disponible en: http://dx.doi.org/10.1016/j.clnu.2017.02.013

205. Berry AJ. Pancreatic Enzyme Replacement Therapy During Pancreatic Insufficiency [Internet]. Nutrition in Clinical Practice 2014; 29: 312-321. Disponible en: http://dx.doi. org/10.1177/0884533614527773

206. McClave SA, Taylor BE, Martindale RG, Warren MM, Johnson DR, Braunschweig C, et al. Guidelines for the Provision and Assessment of Nutrition Support Therapy in the Adult Critically Ill Patient [Internet]. Journal of Parenteral and Enteral Nutrition 2016; 40: 159-211. Disponible en: http://dx.doi. org/10.1177/0148607115621863

207. Bermúdez C, Sanabria Á, Ayala J, Becerra A, Chona M, Colpas $\mathrm{L}$, et al. Inmunonutrición perioperatoria. Consenso de la Asociación Colombiana de Nutrición Clínica [Internet]. Revista de Nutrición Clínica y Metabolismo 2019; 2: 15-28. Disponible en: http://dx.doi.org/10.35454/rncm.v2n1.055

208. Gianotti L, Sandini M. Reply to: Re: Nutritional support and therapy in pancreatic surgery: A position paper of the International Study Group on Pancreatic Surgery (ISGPS) [Internet]. Surgery 2019; 165: 1249. Disponible en: http://dx.doi. org/10.1016/j.surg.2019.01.022

209. Basso S, Canicoba M, Capitanich P, Carballido M, Crisci J, Giustina D, Granero L, Gutiérrez SC, Hwang HJ, Jerez I, Kohan G, Linares ME, Marchi L, Martini G, Mazza O, Moro M, Palavecino M, Pasqua A, Uranga G. I Consenso argentino de diagnóstico y tratamiento de la insuficiencia pancreática exocrina. Acta Gastroenterol Latinoam 2018; 48 (3): 213-225.

210. Domínguez-Muñoz JE. Management of pancreatic exocrine insufficiency [Internet]. Current Opinion in Gastroenterology 2019; 35: 455-459. Disponible en: http://dx.doi.org/10.1097/ mog.0000000000000562

211. Pezzilli R, Caccialanza R, Capurso G, Brunetti O, Milella M, Falconi M. Pancreatic Enzyme Replacement Therapy in Pancreatic Cancer. Cancers [Internet] 2020; 12 (2). Disponible en: http://dx.doi.org/10.3390/cancers12020275

212. Sikkens ECM, Cahen DL, de Wit J, Looman CWN, van Eijck C, Bruno MJ. A Prospective Assessment of the Natural Course of the Exocrine Pancreatic Function in Patients With a Pancreatic Head Tumor [Internet]. Journal of Clinical Gastroenterology 2014; 48: e43-e46. Disponible en: http://dx.doi.org/10.1097/ mcg.0b013e31829f56e7

213. Barkin JA, Westermann A, Hoos W, Moravek C, Matrisian L, Wang H, et al. Frequency of Appropriate Use of Pancreatic Enzyme Replacement Therapy and Symptomatic Response in Pancreatic Cancer Patients [Internet]. Pancreas 2019; 48: 780-786. Disponible en: http://dx.doi.org/10.1097/ mpa.0000000000001330

214. Freedman SD. Options for addressing exocrine pancreatic insufficiency in patients receiving enteral nutrition supplementation. Am J Manag Care 2017; 23 (12 Suppl): S220-S228. 


\section{Anexo A.}

\section{¿Cómo se calcula el consumo de alcohol?}

La graduación alcohólica se expresa en grados y mide el contenido de alcohol absoluto en $100 \mathrm{cc}$, o sea el porcentaje de alcohol que contiene una bebida. Es decir, que un vino tenga 13 grados significa que $13 \mathrm{cc}$ de cada $100 \mathrm{cc}$ son de alcohol absoluto, o sea el 13\%. El grado alcohólico viene expresado en los envases como $\left(^{\circ}\right)$ o bien como vol\%.

Desde la perspectiva sanitaria tiene mayor relevancia determinar los gramos de etanol absoluto ingerido, no el volumen de bebida alcohólica.

Para calcular el contenido en gramos de una bebida alcohólica basta con multiplicar los grados de la misma por la densidad del alcohol $(0,8)$.

\section{La fórmula sería:}

gramos alcohol= volumen (expresado en c.c.) $x$ graduación $\times$ 0,8

100

Es decir, si una persona consume 100 c.c. de un vino de 13 grados, la cantidad de alcohol absoluto ingerida es:

$$
100 \text { c.c. } \times 13 \times 0,8=10,4 \text { gr alcohol puro }
$$

Otro ejemplo, en una cerveza de cuarto (250 c.c.) y de graduación 4,8 grados, la cantidad de alcohol absoluto es:

$$
\frac{250 \times 4,8 \times 0,8}{100}=9 \text { gr alcohol puro }
$$

www.mscbs.gob.es

\section{Anexo B.}

\begin{tabular}{|c|c|c|}
\hline & Resumen de la categoría & Definición / Ejemplos \\
\hline Categoría I & No diagnóstico & $\begin{array}{l}\text { Una muestra de citología no diagnóstica es aquella que no proporciona información diagnós- } \\
\text { tica o útil sobre la lesión muestreada. Cualquier atipia celular impide un informe no diagnóstico. }\end{array}$ \\
\hline Categoría II & Negativo para malignidad & $\begin{array}{l}\text { Celularidad adecuada para evaluar una lesión. La categoría negativa debe calificarse mediante } \\
\text { un diagnóstico de una condición benigna específica. Ejemplos: pancreatitis crónica, pancreatitis } \\
\text { autoinmune, seudoquiste, etcétera. }\end{array}$ \\
\hline Categoría III & Atípico & Atipia citológica insuficiente para justificar la clasificación como Categoría IV o V. \\
\hline Categoría IV A & Neoplásico, benigno & $\begin{array}{l}\text { Material citológico suficientemente celular y representativo de neoplasia benigna. } \\
\text { Ejemplos: cistoadenoma seroso, linfangioma, teratoma, shwannoma. }\end{array}$ \\
\hline Categoría IV B & Neoplásico, otros & $\begin{array}{l}\text { Neoplasias premalignas: neoplasia mucinosa papilar intraductal y neoplasia quística mucinosa; } 0 \\
\text { neoplasias con potencial maligno: tumores neuroendócrinos bien diferenciados, neoplasia sólida } \\
\text { pseudopapilar y tumor del estroma gastrointestinal. }\end{array}$ \\
\hline Categoría V & Sospechoso para malignidad & $\begin{array}{l}\text { La citomorfología plantea una fuerte sospecha de malignidad pero las características o el material } \\
\text { resultan insuficientes para un diagnóstico definitivo de una neoplasia maligna específica. }\end{array}$ \\
\hline Categoría VI & Positivo o maligno & $\begin{array}{l}\text { Neoplasia con características citológicas malignas inequívocas. Una neoplasia de alto grado y/o } \\
\text { agresiva incluye adenocarcinoma ductal pancreático y variantes, colangiocarcinoma, carcinoma } \\
\text { de células acinares, carcinoma neuroendocrino de células pequeñas y de células grandes, pan- } \\
\text { creatoblastoma, linfoma, sarcomas y metástasis. }\end{array}$ \\
\hline
\end{tabular}

\section{Clasificación de la Papanicolaou Society of Cytopathology para informar muestras citológicas pancreatobiliares}




\section{Anexo C.}

Performance status. Eastern Cooperative Oncology Group (ECOG)

ECOG 0

ECOG 1

ECOG 2

ECOG 3

ECOG 4

ECOG 5
Completamente asintomático.

Restricción para realizar actividades físicas intensas. Puede realizar trabajos ligeros.

Puede realizar todas las actividades de autocuidado. Permanece menos del $50 \%$ del tiempo en la cama.

Limitación en las actividades de autocuidados. Permanece más del 50\% del tiempo en la cama.

Completamente imposibilitado. Requiere cuidado. Permanece todo el tiempo en la cama.

Muerte.

\section{Anexo D.}

\section{Márgenes quirúrgicos: descripción y sinonimia}

$\begin{array}{lll}\text { Término } & \text { Sinónimos } & \text { Margen/S } \\ & \text { Parte del margen uncinado. } & \\ \text { Margen } & \text { Parte del margen retroperitoneal. } & \text { Superficie }^{2} \\ \text { posterior } & \begin{array}{l}\text { Superficie posterior retroperitoneal profunda. } \\ \text { Margen de la vena cava inferior. }\end{array} & \text { Margen }^{1,3} \\ & & \end{array}$

Superficie anterior

Margen de
la arteria
mesentérica
superior

superior

$\begin{array}{lll}\text { Surco de } & \text { Surco vascular. } & \text { Superficie }^{2} \\ \text { la VMS } & \text { Lecho vascular. } & \text { Margen }^{3}\end{array}$

Margen uncinado.

Margen retroperitoneal.

Margen posterior medial.

Margen retroperitoneal inferior-posterior. Margen ${ }^{1,2,3}$

Margen mesopancreático.

Margen radial.

Margen medial.

Superficieie, 3
Se trata de una superficie anatómica, no de un verdadero margen quirúrgico, la presencia de células tumorales en dicha superficie es probable que aumente el riesgo de recurrencia local, por lo tanto su informe está recomendado.

Aspecto postero-inferior del proceso uncinado - tejido blando adyacente a la pared lateral derecha de la AMS. Textura rugosa (área de disección).

Surco poco profundo con superficie lisa, se extiende desde el borde inferior al superior de la cabeza pancreática, pasando por debajo y por detrás del margen de transección del cuello pancreático.

Pancreático Margen del cuello pancreático.

distal Margen del conducto pancreático.

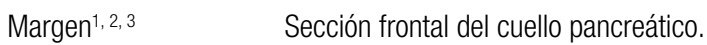

${ }^{1}$ AJCC (American Joint Committee on Cancer). ${ }^{2} \mathrm{CAP}$ (College of American Pathologist). ${ }^{3} \mathrm{RCPath}$ (Royal College of Pathologists). 


\section{Anexo E.}

Sistema de clasificación de Regresión Tumoral - CAP

\section{Grado de regresión tumoral}

0

1

2

3

\section{Descripción}

Respuesta completa (no hay células neoplásicas viables).

Respuesta casi completa (hay células neoplásicas aisladas o en pequeños grupos).

Respuesta parcial (neoplasia residual con regresión tumoral evidente, pero más que células individuales o pequeños grupos de células neoplásicas).

Sin respuesta (extenso tumor residual, sin regresión evidente). 


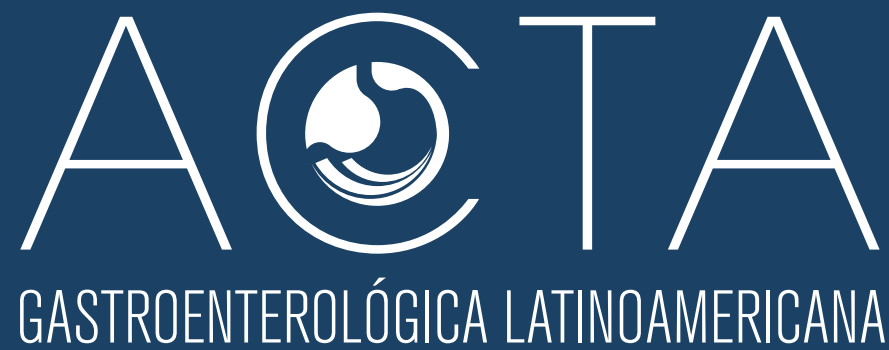

Vol 50 Supl. №2 año 2020 